\title{
Avaliação de aterosclerose carotídea através de ultra-sonografia e ressonância magnética
}

Tese apresentada à Faculdade de Medicina da Universidade de São Paulo, para a obtenção do título de Doutor em Ciências.

Área de concentração: Cardiologia

Orientador: Prof. Dr. Cláudio Campi de Castro

SÃO PAULO

2004 
"A ciência avança através de respostas provisórias, conjeturais, em direção a uma série sempre mais sutil de perguntas que penetram cada vez mais fundo na essência dos fenômenos naturais".

Louis Pasteur 
DEDICATÓRIA 
Aos meus pais, Aparecida e Lázaro.

Ao meu esposo, Fernando.

À Ana Amélia, irmã de coração. 


\section{AGRADECIMENTOS}

Ao Prof. Dr. Cláudio Campi de Castro, por quem tenho grande respeito e admiração, pelo incentivo, orientação segura e precisa. Sem sua confiança em mim depositada, este trabalho não teria sido iniciado.

Ao Prof. Dr. Protásio Lemos da Luz e Prof. Dr. Giovanni Guido Cerri, pelo suporte neste empreendimento.

Ao Eduardo Figueiredo, pelo apoio na aplicação dos protocolos de Ressonância Magnética.

Agradeço, especialmente, às biomédicas Ana Paula Shimizu Chagas e Luciana Peri Sandoval, pela dedicação, amizade e competência.

Às enfermeiras Rosa Maria Catapirra, Neusa Satie Misumi e à auxiliar de enfermagem Maria de Jesus Costa.

Ao pessoal administrativo: Sebastiana F. M. Araújo, Elma Regina Batista Alves, Valquíria Spina, Elaine Clotilde Correa Antônio, Marines Lopes Brito e Maria Aparecida Ambrósio.

Aos colegas de convivência e trocas de experiência, durante minha formação na área de Ressonância Magnética: Dr. José R. Parga Filho, Dr. Luiz Francisco Rodrigues Ávila, Dr. Carlos Eduardo Rochitte, Dra. Rosa Piva, Dr.Cláudio L. Lucarelli e Dra. Kiyomi Kato Uezumi.

À Creuza Dal Bó, pela análise dos dados.

A Josetti de Parada, pelas sugestões na elaboração do banco de dados.

Instituições

Instituto do Coração - InCor - HC FMUSP e Fundação Euríclides de Jesus Zerbini, pela oportunidade desta realização científica.

Projeto financiado pela FAPESP - Fundação de Amparo à Pesquisa do Estado de São Paulo, processo número 00/01038-1. 


\title{
SUMÁRIO
}

\author{
Lista de siglas e abreviaturas \\ Lista de símbolos \\ Lista de tabelas \\ Lista de gráficos \\ Resumo \\ Summary
}

1. INTRODUÇÃO

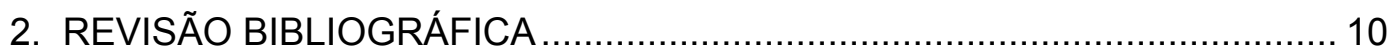

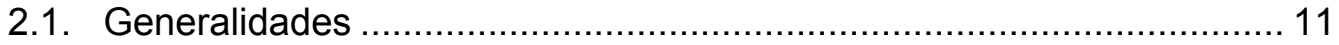

2.2. Fatores de risco de doença coronariana ........................................... 13

2.3. Considerações fisiopatológicas ....................................................... 14

2.4. Diagnóstico por imagem ............................................................... 19

2.5. Inspeção visual das artérias carótidas internas extracranianas por imagens de ultra-sonografia, em escala de cinza ........................ 20

2.6. Análise espectral Doppler ............................................................. 21

2.7. Estimativa do grau de estenose das artérias carótidas internas, através da ultra-sonografia com fluxo Doppler colorido ....................... 23

2.8. Análise ultra-sonográfica da ecogenicidade das placas ..................... 25

2.9. Avaliação da superfície das placas, através de ultra-sonografia .......... 28

2.10. Avaliação das artérias carótidas internas, através de ressonância

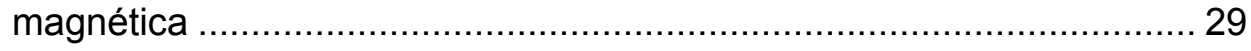

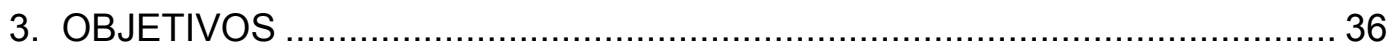

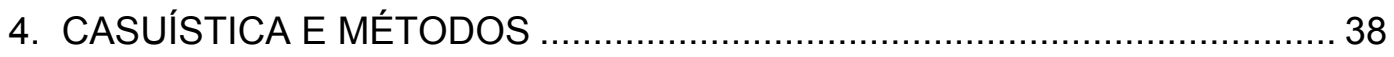

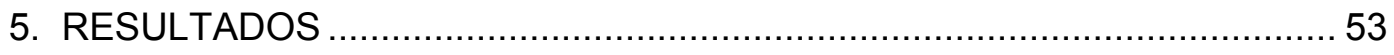

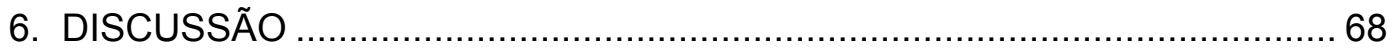

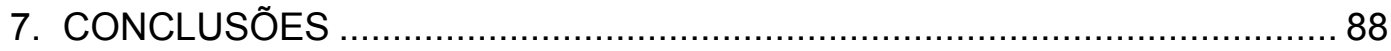

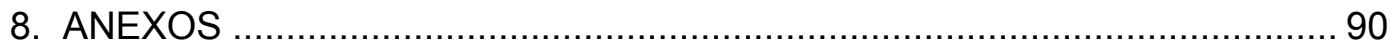

9. REFERÊNCIAS BIBLIOGRÁFICAS ............................................... 112 


\section{LISTA DE SIGLAS E ABREVIATURAS}

$\begin{array}{ll}\text { 3D } & \text { tridimensional } \\ \text { AIT } & \text { ataque isquêmico transitório } \\ \text { AS } & \text { aterosclerose } \\ \text { ARM } & \text { angiografia por ressonância magnética } \\ \text { AVC } & \text { acidente vascular cerebral } \\ \text { ACAS } & \text { Asymptomatic Carotid Atherosclerosis Study } \\ \text { ACC } & \text { artéria carótida comum } \\ \text { ACE } & \text { arteria carótida externa } \\ \text { ACI } & \text { arteria carótida interna } \\ \text { AHA } & \text { American Heart Association } \\ \text { BB } & \text { sangue escuro ("black-blood") } \\ \text { CID } & \text { código internacional de doenças } \\ \text { CPI } & \text { cardiopatia isquêmica } \\ \text { DM } & \text { diabetes mellitus } \\ \text { ECG } & \text { eletrocardiograma } \\ \text { ECOM } & \text { músculo esternocleiomastóideo } \\ \text { ECST } & \text { European Carotid Surgery Trial } \\ \text { et al. } & \text { e outros } \\ \text { FS } & \text { saturação de gordura ("fat sat”) } \\ \text { GD-DTPA } & \text { gadopentetato dimeglumínico } \\ \text { GRE } & \text { gradiente-eco } \\ \text { HAS } & \text { hipertensão arterial sistêmica } \\ \text { HCFMUSP } & \text { Hospital das Clínicas da Faculdade de Medicina da } \\ & \text { Universidade de São Paulo } \\ \text { IAM } & \text { infarto agudo do miocárdio } \\ \text { InCor } & \text { Instituto do Coração } \\ \text { I-M } & \text { íntima-média } \\ \text { NASCET } & \text { North American Symtomatic Carotid Endarterectomy Trial } \\ \text { OMS } & \text { Organização Mundial de Saúde } \\ \text { RF } & \text { radiofreqüência } \\ \text { RM } & \text { ressonância magnética } \\ \text { RSR } & \text { relação sinal-ruído } \\ \text { T1 } & \text { relaxação longitudinal } \\ \text { T2 } & \text { relaxação transversal } \\ \text { TOF } & \text { tempo de vôo ("time-of-flight") } \\ \text { TR } & \text { tempo de repetição } \\ \text { USG } & \text { ultra-sonografia } \\ \text { UDC } & \text { Ultra-som com fluxo Doppler colorido } \\ \text { VDF } & \text { velocidade telediastólica final } \\ \text { VSM } & \text { velocidade sistólica máxima } \\ & \\ \end{array}$




\section{LISTA DE SÍMBOLOS}

$\begin{array}{ll}\% & \text { percentagem } \\ > & \text { maior que } \\ \mathrm{cm} / \mathrm{s} & \text { centímetro por segundo } \\ \mathrm{mg} & \text { miligrama } \\ \mathrm{dL} & \text { decilitro } \\ \mathrm{MHz} & \text { megahertz } \\ \mathrm{T} & \text { tesla }=10000 \text { Gauss } \\ \mathrm{ml} & \text { mililitro } \\ \mathrm{kg} & \text { quilograma }\end{array}$




\section{LISTA DE TABELAS}

pg.

TABELA 1. Fatores de risco avaliados nos pacientes estudados.

TABELA 2. Distribuição segundo as características de intensidade de sinal, visualizadas através da RM, nas diferentes seqüências de pulso.

TABELA 3. Associação entre os tipos de placas encontradas nos exames de USG e a intensidade de sinal nos exames de RM, na seqüência 3D TOF.

TABELA 4. Associação entre os tipos de placas encontradas nos exames de USG e a intensidade de sinal nos exames de RM, na seqüência T1-BB.

TABELA 5. Associação entre os tipos de placas encontradas nos exames de USG e a intensidade de sinal nos exames de RM, na seqüência T1-FSBB.

TABELA 6. Associação entre os tipos de placas encontradas nos exames de USG e a intensidade de sinal nos exames de RM, na seqüência T2-BB.

TABELA 7. Associação entre os tipos de placas encontradas nos exames de USG e a intensidade de sinal nos exames de RM, na seqüência T2-FSBB.

TABELA 8. Associação entre o grau de estenose visualizado através de USG modo B com fluxo Doppler colorido e angiografia por RM, com contraste.

TABELA 9. Associação entre o grau de estenose visualizado através de USG modo B com fluxo Doppler colorido e angiografia por RM, sem contraste.

TABELA 10 Confiabilidade inter-observadores na avaliação dos exames de ressonância magnética. 


\section{LISTA DE GRÁFICOS}

Gráfico 1. Distribuição dos casos, segundo o tipo de ecogenicidade das paredes das artérias carótidas internas, examinadas pela ultrasonografia.

Gráfico 2. Distribuição de freqüência em relação à regularidade da superfície interna das artérias carótidas internas, examinadas pela USG.

Gráfico 3. Distribuição de freqüência de estimativa do grau de estenose das artérias carótidas internas, segundo avaliação feita pela USG modo B com fluxo Doppler colorido.

Gráfico 4. Distribuição de freqüência da presença de placas visualizadas nas artérias carótidas internas, quando examinadas pela ressonância magnética.

Gráfico 5. Distribuição dos casos segundo o grau de estenose visualizado pela angiografia por ressonância magnética, com contraste.

Gráfico 6. Distribuição dos casos segundo o grau de estenose visualizado pela angiografia por ressonância magnética, sem contraste.

Gráfico 7. Distribuição dos casos segundo a qualidade de imagem dos exames de angiografia por ressonância magnética, de acordo com a utilização de contraste.

Gráfico 8. Distribuição dos casos segundo a qualidade de imagem dos exames de ressonância magnética, nas diversas seqüências de pulso realizadas. 


\section{RESUMO}

SOUZA, L. V. Avaliação da aterosclerose carotídea, através de ultrasonografia e ressonância magnética. São Paulo, 2004. 126p. Tese (Doutorado) - Faculdade de Medicina, Universidade de São Paulo.

A aterosclerose é uma doença progressiva crônica. Embora segmentar, é generalizada e acomete as artérias carótidas, propiciando maior risco de acidente vascular cerebral. Utilizamos dois métodos diagnósticos, nesta avaliação, que foram a ultra-sonografia modo $B$ em escala de cinza associada também a fluxo Doppler colorido, e a ressonância magnética (RM) com seqüências ponderadas em T1 e T2, ambas pelas técnicas "black-blood" (BB) e "fat sat black-blood" (FSBB), e angiografia por ressonância magnética "time-of-flight" tridimensional (3D TOF), com e sem a administração do contraste paramagnético. Objetivou-se a identificação de ateromas carotídeos em pacientes coronariopatas, comprovados por cateterismo cardíaco com indicação de terapia cirúrgica. Realizou-se a estimativa do grau de estenose das artérias carótidas internas, através de ultra-sonografia com fluxo Doppler colorido (UDC) e angiografia por ressonância magnética (ARM), comparando-se os métodos. Também foram feitas comparações entre a ecogenicidade das placas visualizadas através de ultra-sonografia (USG), com a intensidade de sinal adquirida pelos exames de ressonância magnética (RM). Foi realizada avaliação de qualidade de imagens e confiabilidade inter-observadores, nos exames de ressonância magnética. Houve alta incidência de aterosclerose carotídea, nos pacientes em estudo. Do total de 100 segmentos carotídeos analisados por ultra-sonografia, com fluxo Doppler colorido para estimativa do grau de estenose, $81 \%$ apresentaram algum tipo de estenose, sendo o grau leve (grau II) predominante, evidenciado em $59 \%$ dos casos. Avaliamos a associação entre o grau de estenose visualizado através de UDC e ARM, com e sem contraste, e houve reprodutibilidade marginal entre os métodos. Observaram-se alterações de intensidade de sinal das paredes vasculares nos exames de RM, nas seqüências ponderadas em T1-BB, T1-FSBB, T2-BB e T2-FSBB, entre $71 \%$ e $72 \%$. O aumento da intensidade de sinal foi predominante. Nas 72 placas com ecogenicidade tipo 4, houve aumento da intensidade de sinal em 13,9\% em 3D TOF, 59,7\% em T1-BB, $65,3 \%$ em T1-FSBB, $62,5 \%$ em T2-BB e $66,7 \%$ em T2-FSBB. Nas placas com ecogenicidade tipo 2, houve aumento da intensidade de sinal em $42,9 \%$ em 3D TOF, $71,4 \%$ em T1-BB e T1-FSBB, $85,7 \%$ em T2-BB e $71,4 \%$ em T2-FSBB. Nas placas com ecogenicidade tipo 1 , houve aumento da intensidade de sinal em $50,0 \%$, nas seqüências ponderadas em 3D TOF, T1 e T2. Em 19 segmentos carotídeos, a USG foi considerada normal. Quando os mesmos segmentos foram avaliados através de RM, observou-se aumento da intensidade de sinal em 21,1\% em 3D TOF, 47,4\% em T1-BB, 57,9\% em T1-FSBB, 52,6\% em T2-BB e T2-FSBB. Não houve correlação entre os tipos de ecogenicidade das placas visualizadas através de USG, com as alterações de intensidade de sinal pela RM. A avaliação da qualidade de imagens dos exames de RM, com cortes no plano axial nas seqüências ponderadas em T1 e T2 (BB e FSBB), foi considerada ótima e, em 3D TOF, muito boa. A qualidade de imagem dos exames de ARM, com e sem contraste, foi considerada excelente. Notou-se ótima reprodutibilidade interobservadores, com valores de índice Kappa acima de 0,71. 


\section{Summary}

\section{SOUZA, L. V. Assessment of carotid artery atherosclerosis through ultrasound and magnetic resonance imaging. São Paulo, 2004. 126p. Tese (Doutorado) - Faculdade de Medicina , Universidade de São Paulo.}

Atherosclerosis is a chronic progressive disease. Although being segmental, atherosclerosis is systemic and attacks carotid arteries, propitiating a greater risk of cerebral vascular accident. In this assessment, we have applied two diagnostic imaging methods such as gray-scale B-mode ultrasound (US) in association with color flow Doppler (CFD-US) and T1 and T2-weighted magnetic resonance imaging (MRI) sequences, using black-blood (T1-BB and T2-BB) and black-blood with fat saturation (T1-FSBB and T2-FSBB) techniques, and magnetic resonance angiography (MRA) with and without paramagnetic contrast agent (threedimensional time-of-flight, 3D TOF). Our objective was the identification of carotid atheromas in patients with coronary artery disease - as confirmed by cardiac catheterism, and referred to cardiac surgery. The degree of stenosis of the internal carotid arteries was estimated by CFD-US and by MRA, and the results from both methods were compared. The echogenicity of carotid plaques as seen by US and the signal intensity of MR images were also compared. Evaluation of image quality and inter-rater reliability of evaluation of MR images were also performed. There was a high incidence of carotid atherosclerosis in the patient population under study. From a total of one hundred (100) carotid artery segments analyzed by CFD-US for stenosis degree estimation, $81 \%$ showed some degree of stenosis, with a predominance of mild grade (grade II), which was detected in $59.0 \%$ of the cases. We have evaluated the association between the degree of stenosis visualized by CFD-US and by MRA with and without contrast agent and there was a marginal reproducibility between these methods. It was observed changes in artery wall signal intensity of $71 \%$ to $72 \%$, in the T1-BB, T1-FSB, T2-BB and T2-FSBB sequences of the MRI examinations. Increases in signal intensity were predominant. Among 72 plaques with echogenicity type 4, the signal intensity has increased $13.9 \%$ in 3D TOF, $59.7 \%$ inT1-BB, $65.3 \%$ in T1-FSBB, $62.5 \%$ in T2-BB and $66.7 \%$ in T2-FSBB. Among plaques with echogenicity type 2, the signal intensity has increased $42.9 \%$ in 3D TOF, $71.4 \%$ in T1-BB and T1-FSBB, $85.7 \%$ in T2-BB and $71.4 \%$ in T2-FSBB. Plaques with echogenicity type 1, showed signal intensity increase of $50.0 \%$ in the 3D TOF, T1 and T2 weighted MRI sequences. In 19 carotid artery segments, CFD-US was considered normal. When the same segments were evaluated by $\mathrm{MRI}$, it was noted an increase of the image signal intensity in $21.1 \%$ in 3D TOF, $47.4 \%$ in T1-BB, $57.9 \%$ in T1-FSBB, $52.6 \%$ in T2-BB and T2-FSBB. There was no correlation between the types of plaque echogenicities seen by the CFD-US with the changes of signal intensity seen by MRI. The image quality and interobserver reliability of MR examinations were evaluated. The image quality of the T1 and T2-weighted axial MR images was considered excellent and for 3D TOF images, the quality was considered very good. The quality of the MRA images with and without paramagnetic contrast agent was considered excellent. It was noted an excellent interobserver reproducibility with values of Kappa index greater than 0.71 . 
As doenças cardiovasculares são responsáveis por altas taxas de morbimortalidade no mundo, em países desenvolvidos ou em desenvolvimento. A Europa apresenta índices aproximados de 50\% de mortalidade por doenças cardiovasculares (LAURENTI et al., 2001). Dados do Ministério da Saúde mostram que, no Brasil, a mortalidade foi de 160 mortes em cada 100.000 habitantes, superando os índices por causas externas (74/100.000), por neoplasias (58/100.000) ou decorrentes de moléstias respiratórias (48/100.000). Em 1996, as doenças do aparelho circulatório responderam por 248.983 das 906.033 mortes $(27,5 \%)$ e foram registrados cerca de um milhão de internações anuais por doenças cardiovasculares, com profundas repercussões na força de trabalho, óbvio prejuízo e alto custo social. As projeções feitas pela Organização Mundial de Saúde mostram a tendência de elevação desses índices e as desastrosas conseqüências em termos de saúde pública (DATASUS, 1999).

Durante o ano 2000, as doenças cardiovasculares foram responsáveis pela principal alocação de recursos públicos em hospitalizações no Brasil (aproximadamente 821 milhões de dólares), e 
foram a terceira causa de permanência hospitalar prolongada. Registrou-se um aumento de $176 \%$ naqueles gastos, entre os anos 1991 e 2000 (DATASUS, 2000).

Mesmo os países desenvolvidos estão se preocupando com a redução de tais custos, otimizando os recursos disponíveis, para ampliar a cobertura dos serviços a toda população. É imperiosa a racionalização dos gastos, atentando-se para a relação entre custo e efetividade nas ações que buscam promover a saúde ou prolongar a vida (LAURENTI et al., 2001).

O cômputo dos custos diretos nesta avaliação inclui gastos nos serviços de saúde (exames diagnósticos, laboratoriais, medicações, pessoal da área médica e utilização do espaço físico), tempo consumido pelo paciente para o tratamento, cuidados prestados ao doente por profissionais ou parentes, faltas ao trabalho, aposentadorias precoces e invalidez parcial ou total (LAURENTI et al., 2001).

A análise do custo-efetividade no cuidado das doenças ateroscleróticas deve estar focada no controle dos fatores de risco. No Brasil, as doenças cerebrovasculares são responsáveis por significativa parcela da morbimortalidade, apresentando, em alguns estados, coeficientes de mortalidade superiores aos das doenças isquêmicas do coração. As seqüelas clínicas da aterosclerose representam expressiva cifra nos gastos com saúde. A presença de ateromas nas artérias coronarianas e carótidas, concomitante ou sucessivamente, chama a atenção para a magnitude do problema que, freqüentemente, se apresenta como dois episódios 
independentes, multiplicando os custos sociais e o sofrimento individual (LAURENTI et al., 2001).

Fica evidente a prioridade que a saúde pública deve dar ao problema, exigindo maior atenção para a epidemiologia das doenças cardiovasculares. O conhecimento sobre a história natural desta doença crônico-degenerativa ressalta a importância da prevenção primária na medicina moderna (LOTUFO, 2000). Entretanto, na atualidade, o enfoque no tratamento das doenças cardiovasculares tem sido fortemente dirigido para a prevenção secundária ou terciária, centrando-se na população que já tem a doença, embora às vezes sem manifestações clínicas (forma assintomática) ou na população doente que já apresenta manifestações e complicações, absorvendo grande parte dos recursos disponíveis (LOTUFO, 2000).

A aterosclerose é uma doença progressiva crônica dos vasos sangüíneos, com alterações celulares e metabólicas nas paredes arteriais. Embora segmentar, a doença aterosclerótica é generalizada e afeta as artérias musculares de grande e médio calibre (STARY et al., 1992).

A lesão básica (ateroma ou placa fibrogordurosa) consiste em uma placa focal elevada, contendo um núcleo de lipídio (principalmente colesterol, via de regra, formando complexos com proteínas e ésteres de colesterol) e uma capa fibrosa de revestimento. É um processo dinâmico, evolutivo, a partir de dano endotelial de origem multifatorial, com características de reparação tecidual (STARY et al., 1992). 
Pode começar nos primeiros anos de vida, desenvolvendo-se silenciosamente durante décadas e, com o avançar da doença, formam-se placas de ateroma, que crescem por surtos, cujos determinantes ainda são mal conhecidos e que são responsáveis por complicações clínicas, oclusões trombóticas, tromboembólicas e aneurismas (BARBANO et al., 1989; STARY et al., 1992, 1994, 1995).

O desenvolvimento da aterosclerose precede o aparecimento da doença e pode ser determinado por diferentes fatores de risco, entre os quais se destacam, como características irreversíveis, a idade, o sexo e a história familiar. Outros fatores de risco de grande importância são o diabetes mellitus, tabagismo, hipertensão arterial e hiperlipidemias. Consideram-se fatores de risco menores o sedentarismo, a obesidade e o climatério (mulheres) (STARY et al., 1992).

A aterosclerose se caracteriza por alterações da íntima, representadas por acúmulo de lipídeos, carboidratos complexos, componentes do sangue, células e material intercelular. Inicia-se com a migração de monócitos da corrente sangüínea (tipo de leucócito mononuclear) para se depositarem nas paredes arteriais, acumulando gorduras (principalmente colesterol) e formando as placas ateroscleróticas ou ateromas. As artérias afetadas perdem elasticidade e se estreitam gradativamente, podendo se romper. O contato das substâncias do interior da placa com o sangue produz sua imediata coagulação e conseqüente obstrução total e súbita do vaso (BOTS et al., 1997). 
A ruptura das placas parece estar relacionada com as suas características morfológicas e bioquímicas, e não somente com seu grau de estenose. Pequenas rupturas ou tromboses podem ocorrer, ao longo da vida, determinando remodelação das placas, freqüentemente sem manifestações clínicas. Todavia, a magnitude do evento cardiovascular é determinada pelo grau de trombose sobreposta à placa rota (MOODY et al., 2003).

Com base no conceito de estabilização da doença aterosclerótica, tem sido estudado o papel de intervenções farmacológicas sobre a progressão, regressão ou diminuição do surgimento de novas placas. A aterosclerose é considerada hoje uma doença aterotrombótica, em que o acidente isquêmico agudo surge ligado ao conceito de placa instável. Sabese também que as placas menores estão na origem da maior parte dos eventos agudos (AMBROSE et al., 1986, 1988; PERDIGÃO, 1999), o que leva a crer que as alterações no tamanho da placa não são um bom indicador da situação.

Achados de autópsia demonstram associação expressiva entre aterosclerose carotídea e coronariana. Estudos epidemiológicos demonstram associação entre o espessamento do complexo íntima-média das artérias carótidas e os fatores de risco cardiovasculares conhecidos. A presença de aterosclerose carotídea pode propiciar também eventos como o acidente vascular cerebral e o ataque isquêmico transitório (FAZIO et al., 
1993; BURKE et al., 1995; CROUSE et al., 1995; KHOURY et al., 1997; NAGAI et al., 1998; O'LEARY et al., 1999a; FAYAD et al., 2001).

A progressão do espessamento do complexo íntima-média das artérias carótidas, visualizada através de ultra-sonografia, está associada à progressão da doença ateromatosa coronariana, medida quantitativamente através de angiografia coronariana (NAGAl et al., 1998).

Estudos têm demonstrado que o uso de drogas para redução de lípides leva à redução da espessura do complexo íntima-média, ressaltando o valor preventivo deste procedimento diagnóstico. Os contínuos avanços na biologia vascular têm permitido a introdução de novas terapias medicamentosas. As novas técnicas de imagem podem funcionar como instrumento para monitorar a progressão da doença, em pacientes com risco de infarto agudo do miocárdio ou de acidente vascular cerebral (GRONHOLDT et al., 1998; NAGAl et al., 1998).

Fazem-se necessários estudos que permitam a utilização da medida daquele espessamento e de sua progressão como indicadores de aterosclerose generalizada (BOTS et al., 1993; POLAK et al., 1993; BOTS et al., 1997) e preditores de doenças cerebrovasculares e cardiovasculares (SALONEN et al., 1991, 1993; BOTS et al., 1997). O grau de estenose luminal é usado como marcador indireto do tamanho da placa, subestimando, entretanto, os componentes da mesma (NASCET, 1991; ACAS, 1994; YUAN et al., 1999). É considerado, portanto, como um pobre preditor da vulnerabilidade da placa, predizendo um caso entre quatro 
episódios de acidente vascular cerebral e um caso entre dez pacientes assintomáticos (YUAN et al., 1999).

A avaliação do comprometimento carotídeo, provocado pela doença aterosclerótica, pode ser realizada através da ultra-sonografia modo B em escalas de cinza e imagens com fluxo Doppler colorido. A ultra-sonografia é amplamente utilizada na estimativa do grau de estenose e avaliação quanto à ecogenicidade das placas (SUMNER, 1990). Outro método bastante promissor é a ressonância magnética de alta resolução. Há muitas evidências de que a ressonância magnética pode ajudar na identificação dos componentes das placas, sugerindo sua habilidade em predizer eventos adversos. De acordo com as características do exame e nomenclatura específica, utilizam-se seqüências ponderadas em T1, T2 e 3D TOF. Para maior contraste na interface lúmen-parede arterial, a técnica suprime o sinal do fluxo sangüíneo ("black-blood") e promove saturação de sinal do tecido gorduroso ("fat sat"), nas seqüências ponderadas em T1 e T2. Nas seqüências 3D TOF, as imagens promovem aumento da intensidade de sinal do lúmen arterial ("bright-blood”). É possível, assim, a identificação dos componentes e do volume das placas, o que ajuda na decisão clínica sobre o melhor método de tratamento em cada caso, com base na vulnerabilidade da lesão aterosclerótica (WASSERMAN et al., 2002).

O aprimoramento diagnóstico desses métodos para detecção de placas ateroscleróticas e acesso à sua estrutura promete um grande avanço no acompanhamento daqueles pacientes. 
Os novos conhecimentos sobre as doenças cardiovasculares informam que os esforços devem ser direcionados, em termos de saúde pública, aos processos educativos e à vigilância sobre os grupos que estão expostos aos fatores de risco ou que já foram afetados pela doença, evitando-se novos eventos dela decorrentes. 


\subsection{GENERALIDADES}

A investigação médica tem identificado, nos hábitos da cultura humana moderna, os transtornos que propiciam o aumento da freqüência de doença aterosclerótica (LOTUFO, 2000). A aterosclerose é uma doença de grandes e médias artérias, caracterizada pelo acúmulo progressivo intimal de lipídios, proteínas e ésteres de colesterol. Embora considerada uma doença sistêmica, ela tende a uma distribuição segmentar e é mais freqüentemente encontrada na bifurcação de artérias maiores e em pontos de marcada angulação arterial (PERDIGÃO, 1999; YUAN et al., 2001a).

Registram-se, no Brasil, rápidas e substanciais elevações nos índices de mortalidade por causas cardiovasculares. De acordo com as projeções da Organização Mundial de Saúde (OMS), esta tendência deve persistir, levando a uma epidemia, com desastrosas conseqüências. Somente os esforços combinados de saúde pública, apoio médico e a adesão dos pacientes as doenças cardiovasculares poderão ser controladas (LOTUFO, 
2000). Tais esforços implicam também atenção na epidemiologia dessas doenças, estudando sua história natural enquanto doença crônicodegenerativa, visando o desenvolvimento de medidas em prevenção primária. O percentual de indivíduos expostos aos fatores de risco continua alto. No controle do risco de eventos isquêmicos, é necessária a identificação do tipo de placa aterosclerótica e o estabelecimento de um sistema de vigilância de sua evolução, em seguimento prospectivo, registrando e interpretando os efeitos das intervenções terapêuticas (FISHER et al., 1987; ARROYO et al., 1999; VAN DER WAL et al., 1999; YUAN et al., 2001a).

A doença aterosclerótica pode começar logo após o nascimento. Com o passar dos anos, as placas crescem lentamente, com variável aspecto morfológico e diferentes estágios de desenvolvimento. Os componentes das placas e os estágios de desenvolvimento são fatores importantes na determinação do risco de ruptura e conseqüentes morbidade e mortalidade (STARY et al., 1992). 


\subsection{FATORES DE RISCO DE DOENÇA CORONARIANA}

Os estudos epidemiológicos indicam que certos fatores genéticos ou adquiridos aumentam o risco de aterosclerose (AS). Alguns destes fatores, como idade, sexo e predisposição familiar são características irreversíveis, mas outros são clara ou potencialmente reversíveis. A idade tem influência dominante no desenvolvimento da AS clinicamente significativa. Embora algumas lesões possam estar presentes na infância, a doença clinicamente exteriorizada, com repercussões sobre as taxas de mortalidade por cardiopatia coronariana, aumenta a cada década de vida. A incidência é maior entre homens acima de 45 anos de idade e mulheres acima de 55 anos. O infarto do miocárdio é incomum nas mulheres antes da menopausa, aumentando a freqüência quando há associação a outros fatores de risco. A predisposição familiar representa outro fator de risco relevante, revelando famílias com maior freqüência de ataques cardíacos a uma idade precoce. Todavia, existem famílias com altas taxas de mortalidade por cardiopatia isquêmica $(\mathrm{CPI})$, sem que se identifiquem fatores de risco conhecidos (WILSON et al., 1998; GRUNDY et al., 1999; LOTUFO, 2000).

Destacam-se, dentre os vários fatores de risco, a hiperlipidemia, a hipertensão, o tabagismo e o diabetes mellitus. Outros fatores de risco se apresentam, como insuficiente atividade física regular, estilo de vida estressante e competitivo, obesidade, e ingestão de alto teor de carboidratos. Cada um dos fatores de risco observados anteriormente 
contribui, individualmente, para o desenvolvimento possível da AS clinicamente significativa, mas a associação de múltiplos fatores de risco tem efeito aditivo (LOTUFO, 2000).

\section{3 - CONSIDERAÇÕES FISIOPATOLÓGICAS}

Doença generalizada, embora segmentar, caracteriza-se pela formação de placas de ateroma que se desenvolvem de forma intermitente, sendo ainda mal conhecidos os determinantes daquele processo aterosclerótico, que se descreve como: inflamação, com ativação endotelial (monócitos e linfócitos T); crescimento celular, com proliferação e migração de células musculares lisas, e síntese de diversas substâncias que vão intervir ao longo de todo o processo; degeneração, com acumulação de lipídios, calcificação e morte celular; e complicações da placa aterosclerótica (ruptura, hemorragia ou trombose). É um processo vertical, onde há momentos em que se apresenta hemorragia, intercalados por necrose do endotélio, associados ou não a processo inflamatório (BOTS et al., 1997).

A habilidade em monitorar alterações precoces de lesões ateroscleróticas, em seres humanos, tem importantes aplicações no estudo da patogênese da aterosclerose, e em estudos clínicos, assegurando a eficácia nas terapias de redução das placas (THOMAS et al., 2001). 
A composição da placa de aterosclerose tem sido identificada como um importante fator no desenvolvimento dos sintomas (ARNOLD et al., 2001) e tem se tentado elucidar a patogênese de síndromes isquêmicas agudas relacionadas com a aterosclerose coronariana (YUAN et al., 2001b). As placas carotídeas cervicais são histologicamente similares às da circulação coronariana, levando a crer que o desenvolvimento de sintomas neurológicos, em pacientes com doença aterosclerótica assintomática, se baseie em eventos também similares.

Observa-se que as placas ateroscleróticas ricas em lipídios, nas artérias coronarianas, são particularmente vulneráveis a rupturas e estão associadas a maiores riscos de infarto do miocárdio e morte do que as placas fibrocalcificadas (JENSEN-URSTAD et al., 1999).

Durante o desenvolvimento da doença aterosclerótica carotídea, ocorre espessamento do complexo íntima-média, com conseqüente aumento do risco de acidente vascular cerebral (AVC) (SALONEN et al., 1991, 1993; JENSEN-URSTAD et al., 1999). A manifestação do AVC, decorrente de estenose das artérias carótidas internas extracranianas, é freqüentemente assintomática. A aterosclerose carotídea chama a atenção devido à eficácia da endarterectomia, comparada com o tratamento medicamentoso. A North American Symptomatic Carotid Edarcterectomy Trial (NASCET) e European Carotid Surgery Trial (ECST) apresentam evidências sobre os benefícios da endarterectomia de carótidas, nos pacientes sintomáticos, em que se registrou redução de diâmetro superior a $70 \%$. São menos convincentes os 
resultados em pacientes assintomáticos (NASCET, 1994; ESCT, 1998; YUAN et al., 2001b). O Asymptomatic Carotid Atherosclerosis Study (ACAS) mostrou que a endarterectomia reduziu de $11 \%$ para $5 \%$, em cinco anos, a manifestação do AVC ipsilateral, em estenoses assintomáticas superiores a 70\% (CHATURVEDI, 1999; CONNORS et al., 2000).

Além da severidade do grau de estenose e presença de sintomas prévios na identificação de pacientes em situação de risco, em relação ao AVC, é importante considerar a constituição das placas ateroscleróticas, uma vez que estudos têm demonstrado que a morfologia das placas se constitui também em fator de risco. Mesmo em placas que apresentam grau leve de estenose podem-se encontrar formas como hemorragia intraplaca ou componente lipídico, ambos associados à sua vulnerabilidade (ARNOLD et al., 2001).

Sabe-se também que placas menores estão ligadas a grande parte dos eventos agudos (AMBROSE et al., 1986, 1988), o que leva a crer que o tamanho da placa não seja um bom indicador de risco, buscando-se nas alterações bioquímicas e histopatológicas os condicionadores de sua instabilidade (SALONEN et al., 1991, 1993).

A avaliação quantitativa de doença aterosclerótica ou aterotrombótica, durante sua história natural, é importante para o entendimento da progressão e estabilização da doença e para definição apropriada de intervenção clínica ou cirúrgica. A prevalência de doenças cardiovasculares, a presença de aterosclerose em outras artérias e a intensidade da exposição 
individual aos fatores de risco parecem associadas ao espessamento do complexo íntima-média e a eventos como o infarto agudo do miocárdio e acidente vascular cerebral (FAZIO et al., 1993; BURKE et al., 1995; BOTS et al., 1997; KHOURY et al., 1997; NAGAl et al., 1998; O'LEARY et al., 1999b; FAYAD et al., 2001). Sendo a aterosclerose carotídea extracraniana causa de doença cerebrovascular isquêmica, considera-se importante a determinação do grau de estenose e a morfologia das placas, para terapêutica adequada (KOHLER et al., 1996; VALLABHAJOSULA et al., 1997).

A aterosclerose carotídea é um processo complexo e dinâmico. Rupturas e hemorragias nas placas ocorrem freqüentemente, durante a história natural da lesão aterosclerótica, e se associam ao desenvolvimento de síndromes clínicas (LUSBY et al., 1982; BARGER et al., 1984; MOFIDI et al., 2001). Uma outra forma bem reconhecida que implica o processo aterosclerótico é a angiogênese intimal. Associa-se a síndromes clínicas na circulação coronariana (O'BRIEN et al., 1994; TENAGLIA et al., 1998; MOFIDI et al., 2001) e no contexto de doença oclusiva carotídea sintomática (MOFIDI et al., 2001; McCARTHY et al., 1999; MILEI et al., 1998), sugerindo que estes vasos sangüíneos neoformados são enfraquecidos e, portanto, responsáveis pelo surgimento de hemorragia intraplaca, com súbito aumento de seu volume e conseqüente instabilidade (FRYER et al., 1987).

Estudos informam que a maioria dos eventos clínicos cárdio e cerebrovasculares é resultado de ulceração, hemorragia e ruptura das 
placas, todos podendo resultar em estreitamento agudo ou oclusão do lúmen arterial (DAVIES et al., 1985; RICHARDSON et al., 1989; DAVIES et al., 1990; LEEN et al., 1990; FALK, 1992; DAVIES et al., 1993; YUAN et al., 1997). Davies et al. (1993) mostraram, em estudos histopatológicos da aorta, ulceração e trombose como principais características das placas, que apresentavam proporção de seu volume ocupado por lipídio extracelular. Falk (1992) e Leen et al. (1990) afirmaram que a formação de uma placa com centro lipídico e o enfraquecimento da capa superficial de tecido fibroso podem predispor à ruptura. Segundo Stary (1990) e Guyton et al. (1990), o crescimento do centro lipídico pode estar associado com uma destruição e necrose progressiva no interior das placas. Davies et al. (1993), Richarddson et al. (1989) e Leen et al. (1990) sugerem que a presença de placa com centro lipídico aumenta o mecanismo de estresse sobre a capa de tecido fibroso, ampliando o risco de ruptura.

Parece, assim, que a ruptura das placas esteja mais relacionada com as suas características morfológicas e bioquímicas do que com o grau de estenose provocado. Pequenas rupturas ou tromboses, registradas ao longo da vida, determinam remodelação das placas, freqüentemente sem manifestações clínicas. A magnitude dos eventos cárdio e cerebrovasculares são determinados pelo grau de trombose sobreposta à placa rota (MOODY et al., 2003).

Trata-se, portanto, de um processo descontínuo que apresenta, ao longo da formação da placa, qualquer das alterações anatomopatológicas 
descritas, conjugadas ou não, com preponderância de qualquer delas. Tal processo sofre a interferência de abordagens farmacológicas, que podem reduzir a sua progressão ou diminuir o aparecimento de novas placas, levando, assim, ao conceito de estabilização da placa aterosclerótica.

\subsection{DIAGNÓSTICO POR IMAGEM}

O planejamento do diagnóstico da doença carotídea mudou, de modo extraordinário, nas duas últimas décadas. A ultra-sonografia carotídea é usada como método de rastreamento não invasivo e custo-eficaz melhor para avaliação da doença aterosclerótica extracraniana. As técnicas para obtenção das imagem, em escala de cinza e com fluxo Doppler colorido, são utilizadas rotineiramente. A ressonância magnética de alta resolução também é outro método diagnóstico não-invasivo ou minimamente invasivo, indolor, relativamente rápido, dotada de grande acurácia e reprodutibilidade, que está se tornando mais disponível como meio para identificação da doença aterosclerótica carotídea (YUAN et al., 1996a; JOAKIMSEN et al., 1997).

A associação entre aterosclerose carotídea e coronariana é bem conhecida (NAGAl et al., 1998; SERFATY et al., 2001). A American Heart Association (AHA) estabeleceu a avaliação rotineira das artérias carótidas internas extracraniana através de métodos de imagem, em pacientes 
coronariopatas, objetivando o diagnóstico de aterosclerose carotídea para seguimento clínico ou intervenção cirúrgica adequada (HELGASON et al., 1997).

Uma vez que as placas nas artérias carótidas e coronárias apresentam características morfológicas semelhantes, aceita-se que a ultrasonografia das carótidas possa funcionar como um método simples para avaliar indivíduos com alto risco de eventos cardiovasculares (JOAKIMSEN et al., 1997). Oferece a medida do diâmetro do lúmen vascular, o grau de espessura do complexo íntima-média (complexo I-M), a presença e a extensão da placa (HEISS et al., 1991; O'LEARY et al., 1992; BOTS et al., 1993; POLAK et al., 1998).

\subsection{INSPEÇÃO VISUAL DAS ARTÉRIAS CARÓTIDAS INTERNAS EXTRACRANIANAS, POR IMAGENS DE ULTRA-SONOGRAFIA, EM ESCALA DE CINZA}

Utiliza-se a ultra-sonografia modo B em escala de cinza, para inspeção visual da parede do vaso. As camadas da parede carotídea normal, no plano longitudinal, mostram duas linhas ecogênicas paralelas muito próximas, separadas por uma região hipoecóica a anecóica. O primeiro eco, limitando o lúmen do vaso, representa a interface luz-íntima; o segundo eco é causado pela interface média-adventícia. A média é a zona anecóica/hipoecóica entre as linhas ecogênicas. A distância entre essas 
linhas representa a espessura combinada da íntima e da média. Considerase anormal o espessamento do complexo I-M acima de $0,8 \mathrm{~mm}$, que pode representar as alterações precoces da doença aterosclerótica. Mostrou-se que a espessura da parede da artéria carótida comum correlaciona-se com a espessura histológica da íntima e da média. Esta medida é reprodutível e pode representar um método de monitorização da progressão ou regressão das alterações ateroscleróticas precoces (VELLER et al., 1993).

\subsection{ANÁLISE ESPECTRAL DOPPLER}

O espectro Doppler é uma exibição gráfica quantitativa das velocidades e direções das hemáceas, em movimento existente no volume de amostra Doppler. Valores de velocidade são, em potencial, mais exatos que as medidas de mudança de freqüência, porque o ângulo de insonação (teta) entre a linha de visão do transdutor e o vetor de fluxo de sangue é usado para converter uma mudança de freqüência em velocidade. Mudanças de freqüência variam de acordo com o ângulo de insonação e a freqüência Doppler incidente; as medidas de velocidade levam estes fatores em conta. $\mathrm{O}$ ângulo teta ideal tem $0^{\circ}$, assim como o de seu co-seno é 1 , resultando, então, na maior mudança de freqüência possível que pode ser detectada. Entretanto, raras vezes se atinge esse ângulo, no ambiente 
clínico. Portanto, considera-se aceitável uma variação de $30^{\circ}$ a $60^{\circ}$ dos ângulos de análise espectral carotídea (ZWIEBEL, 1987).

A exibição espectral Doppler representa velocidades no eixo y e tempo no eixo $x$. Por convenção, fluxo em direção ao transdutor é exibido acima da linha de base de velocidade zero e fluxo em direção oposta ao transdutor, abaixo. Na artéria carótida normal, o espectro de freqüência é estreito na sístole e um pouco mais amplo na diástole precoce e tardia. Em geral, há uma zona negra entre a linha espectral e a linha de base de velocidade zero, chamada janela espectral. Uma placa ateromatosa, que se projeta no lúmen arterial, perturba o fluxo laminar regular normal dos eritrócitos. As hemácias se movem com uma variação maior de velocidades, de modo que a linha espectral torna-se mais ampla, enchendo-se na janela espectral, normalmente negra. Este fenômeno é denominado "alargamento espectral", que aumenta em proporção à gravidade da estenose (CARROLL et al., 1988; TAYLOR et al., 1990). 


\subsection{ESTIMATIVA DO GRAU DE ESTENOSE DAS ARTÉRIAS CARÓTIDAS INTERNAS, ATRAVÉS DA ULTRA- SONOGRAFIA COM FLUXO DOPPLER COLORIDO}

A estimativa do grau de estenose das artérias carótidas internas, realizada através da USG com fluxo Doppler colorido, tem sido um método difundido desde 1975, com um protocolo de exame hoje quase universal. 0 ultra-som com Doppler colorido (UDC) exibe informação sobre o fluxo em tempo real na imagem inteira ou em uma área selecionada. As indicações de cor dependem da direção do fluxo sangüíneo, com relação ao transdutor Doppler. Fluxo sangüíneo em direção ao transdutor aparece em uma cor, e fluxo fora do transdutor, em outra. Essas indicações de cor são arbitrárias e, em geral, estabelecidas de modo que o fluxo arterial seja representado em vermelho e o fluxo venoso, em azul (SUMNER, 1990).

As estenoses carotídeas em geral causam mudanças de velocidade quando ultrapassam $50 \%$ do diâmetro. Aumentos de velocidade em geral ocorrem à medida que a estenose se agrava. Na estenose crítica (mais de 95\%) as medidas de velocidade podem reduzir e a onda tornar-se amortecida. Nesses casos, a correlação das imagens com fluxo Doppler colorido ou Doppler modo potência é essencial para se diagnosticar corretamente a gravidade da estenose. Os aumentos de velocidade são focais e mais pronunciados na estenose e imediatamente distal a ela, o que ressalta a importância da amostragem direta nessas regiões. À medida que se move mais adiante distal a partir de uma estenose, o fluxo começa a se 
reconstituir e assume um padrão mais normal, desde que não haja outra lesão distal à área inicial de estenose (SUMNER, 1990).

A magnitude de estenose baseou-se nos parâmetros escala de cinza e Doppler de onda pulsátil, incluindo velocidade sistólica máxima (VSM) da $\mathrm{ACl}$, velocidade telediastólica (VDF) da $\mathrm{ACI}, \mathrm{VSM}$ da $\mathrm{ACC}, \mathrm{VDF}$ da $A C C$, índices de velocidade sistólica máxima $A C I / A C C$ e índices de velocidade telediastólica máxima da ACI/ACC. Velocidades sistólicas máximas da $\mathrm{ACl}$ menores do que $125 \mathrm{~cm} / \mathrm{s}$ são compatíveis com estenose de menos de $50 \%$ do diâmetro; 125 a $250 \mathrm{~cm} / \mathrm{s}$ correspondem a estenose de $50 \%$ a $75 \%$ do diâmetro; maiores do que $250 \mathrm{~cm} / \mathrm{s}$ correspondem a estenose superior a $75 \%$ a $80 \%$ do diâmetro. Os índices de velocidade telediastólica revelaramse úteis na distinção dos altos graus de estenose. Não existem critérios estabelecidos de graduação das estenoses da artéria carótida externa (ACE). Placa oclusiva envolvendo a $A C E$ é menos comum que na $\mathrm{ACl}$ e raras vezes tem significado clínico. Da mesma forma, os critérios de velocidade utilizados para graduar as estenoses da artéria carótida comum (ACC) não foram bem estabelecidos (SUMNER, 1990).

De acordo com a normalização internacional (NASCET, 1991; WASSERMAN et al., 2002), classifica-se a estimativa do grau de estenose da artéria carótida interna através de UDC em:

- Grau I: normal;

- Grau II (ligeiramente estenosada ou estenose de 1\% a $29 \%$ );

- Grau III (estenose de $30 \%$ a $49 \%$ );

- Grau IV (estenose de $50 \%$ a $69 \%$ ); 
- Grau V ou severa (estenose de $70 \%$ a $99 \%$ );

- Grau VI, representando oclusão (100\%).

\subsection{ANÁLISE ULTRA-SONOGRÁFICA DA ECOGENICIDADE DAS PLACAS}

A análise da ecogenicidade das placas ateroscleróticas, nas artérias carótidas, por imagens de USG em escala de cinza e fluxo Doppler colorido, tem sido usada, freqüentemente, para descrever sua composição e para diferenciá-las quanto à sua estabilidade. Imagina-se que a estabilidade da placa esteja relacionada com a sua composição ou com sua movimentação durante o ciclo cardíaco (ARNOLD et al., 2001; YUAN et al., 2001b).

Estudos retrospectivos, baseados em ultra-sonografia em escala de cinza e fluxo Doppler colorido, têm demonstrado que o padrão hipoecóico das placas nas artérias carótidas está associado ao alto conteúdo de lipídios ou a conteúdo hemorrágico, ambos relacionados à instabilidade, e a um aumento na incidência de infartos cerebrais.

A padronização de avaliação e a acurácia na classificação detalhada dessas placas de aterosclerose são essenciais na definição da confiabilidade de identificação de pacientes que se incluem em grupo de alto risco, para o desenvolvimento de acidente vascular cerebral isquêmico (ARNOLD et al., 2001). 
As placas ateroscleróticas ricas em lipídios, nas artérias coronarianas, são particularmente vulneráveis a rupturas e estão associadas aos maiores riscos de morte por infarto do miocárdio que as placas fibrocalcificadas. A aceitação de que as placas, nas artérias carótidas e coronárias, apresentam características morfológicas semelhantes, leva à inferência de que a ultrasonografia pode ser um método simples e não-invasivo para avaliar os indivíduos com alto risco de eventos cardiovasculares (JOAKIMSEN et al., 1997).

Reilly et al. (1983) classificaram as placas, segundo sua morfologia, através da ultra-sonografia, como homogêneas (quando apresentam lesões de um único tipo) e como heterogêneas (quando compostas por uma mistura de lesões hipoecóicas, isoecóicas e hiperecóicas).

Definem-se como placas isoecóicas aquelas que apresentam ecogenicidade semelhante ao complexo íntima-média. As placas hipercóicas são mais brilhantes, enquanto as hipoecóicas não são brilhantes e são mais escuras do que as placas isoecóicas (VALLABHAJOSULA et al., 1997).

Gray-Weale et al. (1988) classificaram as placas, segundo seu tipo de ecogenicidade, em:

- Uniformemente hipoecóicas (tipo 1);

- Predominantemente hipoecóicas, com pequenas áreas hiperecóicas associadas (tipo 2); 
- Predominantemente hiperecóicas, com pequenas áreas hipoecóicas associadas (tipo 3);

- Uniformemente hiperecóicas (tipo 4).

Este grupo de investigadores aponta associação entre o evento cerebrovascular e as placas ateroscleróticas dos tipos 1 e 2 , sendo estes tipos de placas associados a hemorragia e ulcerações, uma vez que lesões tipos 3 e 4 foram principalmente assintomáticas.

DeBray et al. (1997) definiram pontos de corte na ecogenicidade das placas, indicando ecogenicidade semelhante ao músculo esternocleidomastóideo (ECOM) para placas isoecóicas, ecogenicidade semelhante ao sangue para placas hipoecóicas e a ecogenicidade semelhante ao osso para placas hiperecóicas.

Considera-se que as placas ateroscleróticas hiperecóicas sejam constituídas por fibrose e que a ecogenicidade aumente com o aumento de colágeno. Este é o tipo de placa predominante nas artérias carótidas. Os tipos de placas hipoecóicas podem conter lípides ou hemorragia. Associamse a uma pequena capa de tecido fibroso. A presença de calcificações resulta em alta quantidade de ecos em correspondência com áreas de extensas sombras acústicas posteriores (GRAY-WEALE et al., 1988).

A ultra-sonografia tem sido insuficiente na distinção entre placas compostas por componentes hemorrágicos e lipídios, devido à semelhança de ecogenicidade apresentada pelas mesmas. Ambos os tipos de placas são 
potencialmente instáveis (GEROULAKOS et al., 2000; ABURAHMA et al., 2002).

Ressalta-se, assim, a conveniência do uso de métodos diagnósticos de imagem que consigam diferenciar formas semelhantes à hemorragia intraplaca, que comprometem com a estabilidade da placa.

\section{9 - AVALIAÇÃO dA SUPERFíCIE dAS PLACAS, ATRAVÉS DE ULTRA-SONOGRAFIA}

Ainda é limitada a possibilidade de predição do evento embólico, devido à restrita possibilidade de detecção correta da forma da superfície da placa, presumivelmente causadora da embolia. Há estudos que demonstram que ao maior grau de estenose produzido pela placa aterosclerótica se associa maior irregularidade na superfície das placas, apesar de fortes indícios de que a irregularidade na superfície da placa não esteja associada exclusivamente a seu grau de estenose (TROYER et al., 2002).

A ulceração, com decorrente irregularidade na superfície das placas, é uma erosão da camada de células da íntima, que somente pode ser avaliada com exatidão através de estudo histopatológico, já que, em alguns casos, a suposta ulceração representa lúmen residual normal entre duas placas ateromatosas ou crateras ulcerosas reendotelizadas. Ulcerações 
verdadeiras estão associadas a estenose grave da $\mathrm{ACl}$ e são encontradas próximas ao maior ponto de estenose (STARY et al., 1995).

As características ultra-sonográficas das superfícies das placas são classificadas em regulares e irregulares, considerando-se como regular a placa cuja interface lesão-sangue é lisa e contínua, e como irregular, em presença de uma quebra na superfície da lesão, tornando-a desigual (TROYER et al., 2002).

\subsection{0 - AVALIAÇÃO DAS ARTÉRIAS CARÓTIDAS INTERNAS, ATRAVÉS DE RESSONÂNCIA MAGNÉTICA}

Estudos recentes têm demonstrado que imagens obtidas por ressonância magnética podem identificar a morfologia e os constituintes das placas de ateroma nas artérias carótidas internas extracranianas "in vivo" e “in vitro" (MERICKEL et al., 1993; YUAN et al., 1996a; FAYAD, 1998; KANG et al., 2000).

A intensidade de sinal em imagens de RM reflete o ambiente dos prótons de hidrogênio nos tecidos de interesse, favorecendo a flexibilidade nas seqüências de imagens e na avaliação de seus parâmetros, ajustáveis de modo a otimizar a diferenciação de tipos específicos de cada tecido. As imagens adquiridas por RM não são dependentes de ângulos ou de planos de imagens e são menos dependentes da habilidade do operador, quando 
comparadas com exames de USG. Oferecem excelente contraste entre os vasos e o lúmen adjacente, usando seqüências de pulso sensíveis a fluxo. Retratam, portanto, o lúmen vascular (fluxo sangüíneo), produzindo, ao mesmo tempo, informação tecidual que descreve a parede dos vasos (YUAN et al., 1996b, 2001b).

A ressonância magnética é uma técnica que permite a caracterização da morfologia da placa, de forma não-invasiva, auxiliando na identificação de lesões instáveis. Pode ser utilizada em estudos seriados, investigando fatores que indicam a progressão e a regressão da doença (YUAN et al., 2001b). Registra-se concordância entre imagens de RM "in vivo" e exames de cortes histológicos de artérias carótidas (MAYNOR et al., 1989; TOUSSAINT et al., 1995, 1996; YUAN et al., 1996b, 2001b).

Yuan et al. (2001b) têm utilizado seqüências ponderadas em T1 e T2 "fast spin echo", pela técnica "black-blood" e "fat sat black-blood", com o objetivo de suprimir o sinal do fluxo sangüíneo ("black-blood") e saturar o sinal do tecido gorduroso ("fat sat"). A técnica exige, entretanto, um tempo de aquisição relativamente longo. A ressonância magnética facilita a observação do fluxo laminar rápido da artéria carótida, particularmente na seqüência 3D TOF ("time-of-flight") "bright-blood". Esta técnica permite visualização da parede vascular, fazendo com que o fluxo sangüíneo se apresente com alto sinal de RM. Tais seqüências fornecem informações morfológicas que podem indicar se a lesão é instável ou não. Estas técnicas podem caracterizam a presença ou ausência de placas nas artérias 
carótidas e informar sobre seu volume, apoiando a decisão clínica na escolha do melhor método de tratamento, em cada caso.

As artérias normais são facilmente demonstradas através de ressonância magnética, com imagens de alta resolução ponderadas em T1 e T2, que apresentam intensidade de sinal intermediário na camada média e baixa intensidade de sinal na camada adventícia, permitindo demarcação entre estas duas estruturas (SERFATY et al., 2001).

Hatsukami et al. (2000) foram os primeiros a relatar o uso da seqüência 3D TOF ("time-of-flight") "bright-blood", com cortes no plano axial para identificação de capas de tecido fibroso, em carótidas com graus avançados de estenose acima de 70\%, em indivíduos vivos. A capa de tecido fibroso aparece como uma banda justaluminal de baixa intensidade de sinal, não perceptível em placas com fina capa de tecido fibroso, notando-se, adjacente ao lúmen, uma região de aumento da intensidade de sinal. Diversos estudos histológicos tipificam as lesões associadas com eventos isquêmicos, mostrando um grande centro necrótico separado por esta capa de tecido fibroso, que pode se romper. A ruptura da capa de tecido fibroso superficial, que expõe a camada central necrótica trombogênica, é um fator importante no aparecimento de eventos agudos isquêmicos, tais como AVC e ataque isquêmico transitório (AIT) (YUAN et al., 2002).

De acordo com a seqüência utilizada, cada componente da placa aterosclerótica apresenta um sinal de RM, que pode ser hipersinal, isossinal e hipossinal, conforme as imagens apresentem intensidade de sinal maior, 
igual ou menor em relação ao músculo ECOM, permitindo a diferenciação entre os tipos de placas (YUAN et al., 2001b).

Yuan et al. (2001a) introduziram o uso da técnica 3D TOF, T1 e T2 para avaliar diferenças de contraste, apurando a acurácia da identificação de centro necrótico rico em lipídio e hemorragia intraplaca aguda in vivo, em pacientes programados para endarterectomia de carótidas. Trabalharam sobre a hipótese de que a hemorragia intraplaca e um centro necrótico rico em lipídio podem elevar a intensidade de sinal em imagens ponderadas em T1, comparadas com o músculo adjacente. Entretanto, a hemorragia intraplaca pode ser diferenciada do centro necrótico rico em lipídio, pela presença desta elevação da intensidade de sinal na seqüência 3D TOF (TOUSSAINT et al., 1995; YUAN et al., 1995; VON INGERSLEBEN et al., 1997; FAYAD et al., 1998; SHINNAR et al., 1999). As imagens ponderadas em T2 apresentam intensidade de sinal intermediário na camada média normal e uma alta intensidade de sinal quando há espessamento intimal leve ou placa aterosclerótica com componente fibroso (MARTIN et al., 1997).

Além das capas de tecido fibroso, uma segunda característica morfológica importante de placas vulneráveis é a presença de área central de tecido mole, composto por região rica em lipídio acelular ou hemorragia. A experiência tem permitido estudos de avaliação, que mostram imagens de RM evidenciando estes tipos de placas nas carótidas, tendo sido identificadas camadas ricas em tecido lipídico, como área de alta intensidade de sinal nas imagens ponderadas em $\mathrm{T} 1$, sinal intermediário nas imagens 3D 
TOF, e variável intensidade de sinal em imagens ponderadas em T2. Hemorragias intraplaca recentes foram similarmente identificadas, em termos da sua aparência, como áreas de alta intensidade de sinal em 3D TOF, sinal intermediário em T1, e variável em T2 (TOUSSAINT et al., 1996; YUAN et al., 1996a, 1997, 2001b; QUICK et al., 2002).

Segundo vários autores (MERICKEL et al., 1988; YUAN et al., 1994; MARTIN et al., 1995; SKINNER et al., 1995; TOUSSAINT et al., 1996; YUAN et al., 1996a; VON INGERSLEBEN et al., 1997; YUAN et al., 2001b; QUICK et al., 2002), tais resultados, correlacionados com estudos histopatológicos, mostraram, nos exames de RM:

- Placas contendo calcificações, onde há redução da intensidade de sinal, nas seqüências ponderadas em T1, T2 e 3D TOF.

- Placas fibrosas, com predomínio do aumento da intensidade de sinal (algumas vezes em intensidade intermediária), nas seqüências ponderadas em T1 e T2; predominam com uma redução da intensidade de sinal na seqüência 3D TOF, podendo também se apresentar com elevação desta intensidade de sinal.

- Placas com conteúdo lipídico, onde há aumento da intensidade de sinal, nas seqüências ponderadas em T1; predominam com uma redução da intensidade de sinal e, algumas vezes, elevação da intensidade de sinal nas seqüências ponderadas em T2; registra-se aumento ou redução da intensidade de sinal, na seqüência 3D TOF. 
- Placas contendo hemorragia, com predomínio do aumento da intensidade de sinal, nas seqüências ponderadas em T1; redução da intensidade de sinal em T2, registrando-se variabilidade; aumento da intensidade de sinal na presença de trombos recentes, na seqüência 3D TOF.

A angiografia por ressonância magnética (ARM) sem ou com administração do contraste paramagnético, vem sendo utilizada como método de caracterização de estenose da parede arterial, sendo um exame minimamente invasivo e que oferece excelente resolução de imagem (RANDOUX et al., 2001).

A avaliação dos vasos carotídeos, através da ARM com e sem injeção do meio de contraste, fornece informações anatômicas independentes do fluxo e apresenta vantagens, como um mínimo efeito de defasagem. A rápida circulação no território carotídeo requer um tempo curto de aquisição, para evitar a adição de estruturas venosas (LEUNG et al., 1996; ALLEY et al., 1998; AOKI et al., 2000).

A qualidade das imagens de angiografias por RM tem melhorado sensivelmente, devido ao uso de tempos de eco curtos e pequenos volumes de voxel, para minimizar a perda de sinal de fluxo turbulento (ANDERSON, 1992).

A angiografia por RM é um método para a avaliação do lúmen vascular, porém é pouco sensível na detecção de lesões estenóticas precoces e na estimativa do volume dessas lesões (STARY et al., 1995). 
Não demonstra a morfologia das placas, evidenciando apenas a ulceração luminal e o grau de estenose produzido. Não é eficaz na detecção dos contituintes das placas, o que recomenda o uso de técnicas especiais nãoinvasivas, que permitam demonstrar tal tipo de alteração (FALK, 1992).

Outra limitação do exame é a não-visualização da camada adventícia do vaso. Há casos em que a doença da parede vascular pode promover uma expansão externa pela camada adventícia e formar uma placa grande, complicada e potencialmente instável. Esta placa pode não comprometer o lúmen e não promover um grau significante de estenose, não permitindo, assim, o diagnóstico de possíveis placas vulneráveis (RANDOUX et al., 2001). 
Definiram-se como objetivos da investigação:

1) Identificar a presença de ateromas carotídeos, através de ultrasonografia e ressonância magnética, em pacientes coronariopatas, com indicação de terapia cirúrgica.

2) Comparar a estimativa do grau de estenose através de UDC das artérias carótidas internas com a avaliação visual do grau de estenose por ARM com e sem contraste.

3) Comparar a ecogenicidade das placas visualizadas através de ultrasonografia, com a intensidade de sinal adquirida pelos exames de ressonância magnética.

4) Avaliar a qualidade das imagens dos exames de ressonância magnética.

5) Avaliar a confiabilidade inter-observadores, nos exames de ressonância magnética. 
Trata-se de estudo descritivo e analítico, realizado prospectivamente sobre uma coorte de pacientes portadores de coronariopatia, visando avaliação das condições das artérias carótidas internas. Os pacientes eram provenientes do ambulatório de Aterosclerose, do Instituto do CoraçãoInCor- HCFMUSP.

A Comissão Científica e de Ética do Instituto do Coração aprovou o Protocolo de Pesquisa SDC - 1975/01/163, na sessão número 400/01/22, de 20/12/2001.

Os pacientes foram convocados verbalmente ou por telefone, para comparecerem com data e horário previamente estabelecidos, no período compreendido entre julho e novembro do ano 2002.

Depois de informados sobre os objetivos do trabalho, as técnicas diagnósticas adotadas e os possíveis riscos do procedimento, todos os indivíduos que participaram deste estudo apuseram sua firma em termo de consentimento específico, conforme determina a resolução número 196, de 13 de outubro de 1996, do Conselho Regional de Saúde. 
Foram incluídos, no estudo, 50 pacientes (39 homens e 11 mulheres), na faixa etária contida entre 34 e 77 anos, diagnosticados como portadores de coronariopatias, com prescrição terapêutica cirúrgica, encaminhados para revascularização do miocárdio. O diagnóstico de aterosclerose coronariana foi comprovado por cateterismo cardíaco.

Os pacientes foram examinados e consideraram-se como fatores de exclusão do indivíduo da amostra a presença de corpos estranhos, de material ferromagnético, clipes em aneurismas cerebrais, implantes magnéticos ativados (marcapasso/desfibrilador cardíaco) e algumas próteses metálicas que possuem uma esfera de material ferromagnético, embora não estejam em uso há mais de trinta anos (Starr-Edwards). Também foram excluídos da amostra os indivíduos que não se submeteram a todos os procedimentos que compõem o protocolo da pesquisa.

A avaliação clínica dos indivíduos, os exames de ultra-sonografia modo-B em escala de cinza e análise com fluxo Doppler colorido, e a ressonância magnética foram realizados na Seção de Diagnóstico por Imagem, do Instituto do Coração-InCor, do HCFMUSP.

Um questionário foi anexado ao prontuário individual, registrando a manifestação de sintomas, história de doença cardiovascular e hábitos pessoais.

Aceitou-se como relato de infarto agudo do miocárdio o registro de episódio de hospitalização, com diagnóstico através do ECG e investigação laboratorial, durante a estada no hospital. Os resultados do cateterismo 
cardíaco, quanto ao grau de comprometimento da circulação coronária, foram obtidos através de revisão dos prontuários dos pacientes.

Registrou-se como acidente vascular cerebral o evento que desencadeou hospitalização, com comprovação diagnóstica de AVC.

Assinalaram-se como fatores de risco principais, associados à aterosclerose, a idade, o sexo e história familiar. Outros fatores de risco de grande importância avaliados foram a hipertensão arterial sistêmica, hiperlipidemia, tabagismo e diabetes mellitus. Fatores de risco menores, como sedentarismo, obesidade, climatério (nas mulheres) e estresse também foram motivos de investigação. Assumiram-se as comprovações laboratoriais de hipercolesterolemias, com colesterol total $>210 \mathrm{mg} / \mathrm{dL}$, nos 12 meses prévios, ou o uso atual de drogas para redução de lipídios. Aceitou-se a informação verbal sobre o diagnóstico de diabetes mellitus.

Todos os pacientes se submeteram ao exame de ultra-sonografia modo-B em escala de cinza e fluxo Doppler colorido, respectivamente. $\mathrm{O}$ tempo médio de realização de cada exame de ultra-sonografia foi de, aproximadamente, 20 minutos. Os exames de USG foram realizados cerca de uma hora após a entrevista médica.

Foram avaliados os segmentos carotídeos extracranianos esquerdo e direito das artérias carótidas internas, com o paciente em decúbito dorsal, o pescoço levemente estendido e a cabeça voltada para o lado oposto a ser examinada. 
Para análise destes segmentos, foi utilizado transdutor linear de 7.5 MHz (Philips Medical Systems Company - SD 800). A abordagem das artérias carótidas internas foi realizada com o transdutor anteriormente ao músculo esternocleidomastóideo. Iniciou-se o exame ultra-sonográfico com imagens em escala de cinza, no plano transversal, onde identificou-se o bulbo carotídeo como uma leve dilatação da artéria carótida comum, próximo da bifurcação. Vistas transversais da bifurcação carotídea estabeleceram a orientação das artérias carótidas internas e ajudaram a definir o plano longitudinal ideal, para que se realizasse a análise Doppler espectral com o ângulo teta mantido em 60 graus ou menos, posicionando-se o cursor paralelo à parede do vaso.

A posição da curva de ganho das imagens foi ajustada de acordo com características individuais, decorrentes das diferenças de espessura da gordura subcutânea da região cervical e com a ecogenicidade das paredes das artérias, a fim de se obter uma visualização ótima de sua morfologia.

As camadas da parede carotídea normal, no plano longitudinal, mostram a parede anterior (mais próxima ao transdutor) e posterior (mais afastada do transdutor), dispostas como duas linhas brancas, separadas por um espaço hipoecóico. Pode haver alteração de ecogenicidade da camada, devido ao espessamento do complexo íntima-média ou à presença de placas de ateromas, associados à protrusão do vaso, em direção ao lúmen, reduzindo-o. 
As características ultra-sonográficas das superfícies das placas foram classificadas em regulares e irregulares, considerando-se como regular a placa cuja interface lesão-sangue é lisa e contínua, e como irregular, em presença de uma quebra na superfície da lesão, tornando-a desigual.

Realizou-se, posteriormente, uma classificação baseada no tipo de ecogenicidade das placas, divididas em 4 subgrupos: hipoecóicas (tipo 1), predominantemente hipoecóicas, com pequenas áreas hiperecóicas associadas (tipo 2), predominantemente hiperecóicas, com pequenas áreas hipoecóicas associadas (tipo 3), e hiperecóicas (tipo 4). Este trabalho inclui, neste último subgrupo, também as placas hiperecóicas, produtoras de sombras acústicas posteriores, correspondendo a calcificações (GRAYWEALE et al., 1988).

Foram realizadas, também, estimativas do grau de estenose promovido pelas placas de ateroma, nas artérias carótidas internas, segundo normas da North American Symtomatic Carotid Endarterectomy Trial (NASCET), em: grau I (normal); grau II ou estenose leve (entre 1\% e 29\%); estenose moderada, nos graus III (entre 30 e 49\%) e IV (entre 50 e 69\%); estenose severa, no grau V (entre 70 e 99\%) e oclusão, no grau VI (100\%) (RANDOUX et al., 2001).

Os exames de ultra-sonografia foram realizados por um único radiologista (autor da tese). A análise das imagens de USG das artérias carótidas internas (direita e esquerda) foi realizada em conjunto com um ultra-sonografista, com Certificado de Habilitação em Ultra-sonografia pelo 
Colégio Brasileiro de Radiologia (CE), obtendo-se um consenso. Os exames foram analisados e arquivados, através de fitas de vídeo cassete, e os filmes, documentados em vídeo printer.

Os exames de ressonância magnética foram realizados com intervalo aproximado de uma hora, após o exame de ultra-sonografia.

As imagens de ressonância magnética de alta resolução das artérias carótidas foram obtidas com um aparelho de 1,5 Tesla, Signa, da marca GE Medical Systems, Milwaukee - USA. Foram realizadas seqüências ponderadas em T1 e T2 "fast spin eco" (spin-eco rápido), pela técnica "blackblood" e "fat sat black-blood", com o objetivo de suprimir o sinal do fluxo sangüíneo ("black-blood") e saturar o sinal do tecido gorduroso ("fat sat"). As imagens 3D TOF ("time-of-flight") "bright-blood" foram adquiridas promovendo-se o aumento da intensidade de sinal do lúmen arterial. A seqüência ponderada em T1, no plano axial, constou de cortes com $4 \mathrm{~mm}$ de espessura, sem intervalo entre cortes, com tempo de repetição entre 1875 ms e 2448 ms, tempo de eco entre 44 e 45 ms, matriz 384 x 224, FOV $18 \times 18$ cm, num total de 12 cortes, com uma aquisição (nex). A seqüência ponderada em T2, no plano axial, constou de cortes com $4 \mathrm{~mm}$ de espessura, sem intervalo entre cortes, com tempo de repetição entre 2000 ms e 2500 ms, tempo de eco entre 66 e 67 ms, matriz 256 x 192, FOV $18 \times 16$ cm, num total de 12 cortes, com uma aquisição (nex). A seqüência 3D TOF, no plano axial, constou de cortes com 1,6 mm de espessura, $-0,8 \mathrm{~mm}$ de intervalo entre cortes, com tempo de repetição entre $25 \mathrm{~ms}$, tempo de eco 
entre $6,9 \mathrm{~ms}$, matriz $256 \times 192$, FOV $18 \times 16 \mathrm{~cm}$, num total entre 72 e 92 cortes, com uma aquisição (nex).

Observaram-se, em todas as seqüências obtidas nos exames de RM, as diversas alterações de sinal produzidas pelas paredes arteriais. A interpretação desta intensidade de sinal foi baseada em padrões já consagrados. Compararam-se as alterações de intensidade de sinal, produzidas pelas paredes arteriais, com o músculo esternocleidomastóideo (ECOM). Caracterizaram-se como isointensas, quando se apresentam com os mesmos sinais de RM que o músculo ECOM, hipointensas, quando se apresentam com redução do sinal e hiperintensas, quando se apresentam com aumento da intensidade de sinal.

Trabalhando "in vivo", com base em avaliações histopatológicas de estudos experimentais anteriores (MERICKEL et al., 1988; YUAN et al., 1994; MARTIN et al., 1995; SKINNER et al., 1995; TOUSSAINT et al., 1996; YUAN et al., 1996a; VON INGERSLEBEN et al., 1997; YUAN et al., 2001a; QUICK et al., 2002), buscou-se estabelecer associação entre as alterações de intensidade de sinal obtidas em cada seqüência e os diversos constituintes das placas:

Placas contendo calcificações:

- Redução da intensidade de sinal, nas seqüências ponderadas em T1, T2 e 3D TOF. 
Placas fibrosas:

- Predominam com um aumento da intensidade de sinal e, algumas vezes, esta intensidade de sinal encontra-se intermediária, nas seqüências ponderadas em T1 e T2;

- Predominam com uma redução da intensidade de sinal, na seqüência 3D TOF, podendo também se apresentar com elevação desta intensidade de sinal.

Placas com conteúdo lipídico:

- Aumento da intensidade de sinal, nas seqüências ponderadas em T1;

- Predominam com uma redução da intensidade de sinal e, algumas vezes, elevação desta intensidade de sinal, nas seqüências ponderadas em T2;

- Aumento ou redução da intensidade de sinal, na seqüência 3D TOF;

Placas contendo hemorragia:

- Predominam com um aumento da intensidade de sinal, nas seqüências ponderadas em T1;

- Redução da intensidade de sinal em T2, registrando-se variabilidade;

- Aumento da intensidade de sinal, na presença de trombos recentes, na seqüência 3D TOF. 
A qualidade das imagens dos exames de ressonância magnética foi avaliada nas seqüências 3D TOF("time-of-flight") "bright-blood", T1 e T2 "black-blood" e "fat sat black-blood", com cortes no plano axial, sobre uma escala de cinco pontos, que as classificou individualmente, segundo a relação sinal-ruído total, aparência visual, presença de artefatos de fluxo, conspicuidade da margem e da arquitetura da parede vascular.

Definiram-se os critérios de avaliação para todas as imagens em:

- Grau I ou baixa relação sinal-ruído (RSR): não identificação da parede arterial e das margens dos vasos, impedindo o diagnóstico.

- Grau II ou regular RSR, quando a parede arterial é visível e são indistintos as subestruturas, o lúmen e outros bordos. Oferece inadequado suporte diagnóstico.

- Grau III ou média RSR, quando as estruturas da parede são identificáveis e o lúmen e outros bordos se apresentam parcialmente obscurecidos, oferecendo, entretanto, apoio para o diagnóstico.

- Grau IV ou alta RSR, quando se registra um movimento mínimo ou poucos artefatos de fluxo, deixando claramente definidos a parede vascular, o lúmen e outros bordos, dando boa garantia diagnóstica.

- Grau V, quando a RSR se apresenta sem artefatos de movimento ou de fluxo, a arquitetura da parede é retratada com detalhes, e o lúmen e outros bordos são claramente definidos, caracterizando-se como condição de excelência para o diagnóstico (YUAN et al., 2001b). 
A angiografia por ressonância magnética (ARM) foi realizada posteriormente, com e sem administração do meio de contraste. Utilizou-se o contraste paramagnético gadopentetato dimeglumínico (GD-DTPA), na dose de $0,4 \mathrm{ml} / \mathrm{kg}$ de peso corporal, injetado por via intravenosa na fossa antecubital, usando bomba injetora na razão de $1,5 \mathrm{ml} / \mathrm{segundo}$. Imediatamente após a administração do contraste paramagnético, administraram-se $20 \mathrm{ml}$ de solução salina.

Através de ARM, foi classificado o grau de estenose produzido pelas placas nas artérias carótidas internas, com base na aparência visual das mesmas, segundo normas da North American Symtomatic Carotid Endarterectomy Trial (NASCET), em: grau I (normal); grau II ou estenose leve (entre 1\% e 29\%); estenose moderada, nos graus III (entre 30 e $49 \%$ ) e IV (entre 50 e 69\%); estenose severa, no grau V (entre 70 e 99\%) e oclusão, no grau VI (100\%) (RANDOUX et al., 2001).

Também foram avaliadas a qualidade total das imagens dos exames de angiografia por ressonância magnética, antes e após a administração do contraste paramagnético. Foi realizada uma classificação em cinco grupos, sendo unificados os critérios de avaliação para todas as imagens: $1=$ sem diagnóstico; 2= menos que adequado para o diagnóstico; 3= adequado para o diagnóstico; 4= mais que adequado para o diagnóstico; $5=$ excelente (RANDOUX et al., 2001).

As artérias carótidas são estruturas superficiais, cujo diâmetro longitudinal é maior do que a distância entre o vaso e a superfície cutânea. 
As bobinas de superfície se adaptam bem a esta configuração e coletam os dados simultaneamente. Foram utilizadas para este estudo duas bobinas retangulares, colocadas em íntimo contato com a pele do paciente, na região cervical, de modo a receberem sinais simultâneos, de ambas as artérias carótidas.

Acopladas a um suporte retangular rígido, tais bobinas se prendem a mecanismos que permitem movimentos de rotação e translação com variados graus de liberdade, e ajustam a sua posição junto ao pescoço e em volta da mandíbula, maximizando a recepção de sinal das artérias carótidas.

Um fotosensor, capaz de detectar o pulso capilar e sincronizar a sua seqüência, foi acoplado a um dedo do paciente, permitindo o registro de dados na mesma fase do ciclo cardíaco, minimizando os artefatos de movimento relacionados com a pulsatilidade dos vasos, durante o exame.

O tempo total para a aquisição de todas as imagens de RM foi de, aproximadamente, 50 minutos. As imagens obtidas pelas seqüências ponderadas em T1 e T2, "black-blood" e "fat sat black-blood", foram fotografadas no plano axial, no sentido crânio-caudal. As imagens da seqüência 3D TOF, obtidas no plano axial, foram fotografadas no sentido inverso. As imagens de angiografia por ressonância magnética foram processadas através de reconstruções multiplanares e fotografadas separadamente. Nenhuma correlação cirúrgica foi realizada. 
Os exames de ressonância magnética foram lidos por dois radiologistas (LVS e CCC). Os exames foram escolhidos de forma aleatória. Cada revisor não tinha informações a respeito dos resultados do outro.

Os exames de RM foram armazenados em filmes e discos magnetoópticos. As análises das imagens foram feitas através de filmes em negatoscópio.

Foi realizada avaliação de confiabilidade inter-observadores, através do índice Kappa, nos exames de ressonância magnética, em todas as seqüências adquiridas.

Nas figuras 1 a 4 (anexo), são mostrados exemplos de exames USG e $\mathrm{RM}$, correlacionando os métodos de imagem para cada tipo de alterações do complexo íntima-média das artérias carótidas internas. Cada figura reproduz o segmento carotídeo de um indivíduo, totalizando quatro pacientes.

Nas figuras 5, 6, 7 e 8 (anexo), são mostrados exemplos de angiografia por ressonância magnética, com e sem a administração do contraste. Cada figura também reproduz o segmento carotídeo de um indivíduo, totalizando quatro pacientes.

Quanto à análise estatística, foram realizadas análises descritiva e comparativa. 
Análise descritiva: para a variável quantitativa (idade), esta analise foi realizada através da observação dos valores mínimo e máximo, e do cálculo de média e desvio-padrão, e mediana. Para as variáveis qualitativas (presença ou não de determinado parâmetro) foram calculadas as freqüências absolutas e relativas.

Análise comparativa: para se testar a homogeneidade dos grupos de estenose, em relação às proporções da intensidade do sinal, foi utilizado o teste exato de Fisher, indicado para a comparação de proporções, quando caselas de respostas apresentam freqüências esperadas menores que cinco (ROSNER, 1996).

As comparações de variáveis quantitativas entre os sexos foi realizada através do teste não-paramétrico de Mann-Whitney. Para se estudar a reprodutibilidade entre dois métodos, USG e RM, foi utilizado o teste nãoparamétrico de McNemar (ROSNER, 1986) e também o índice de concordância Kappa (ROSNER, 1986). Este índice varia de 0 a 1, sendo que:

Kappa $<0,45$, temos reprodutibilidade marginal;

Entre 0,45 < Kappa $<0,75$, temos boa reprodutibilidade;

Kappa $>0,75$, temos ótima reprodutibilidade.

Foi utilizado o programa estatístico EPI-INFO, na sua última versão, para o registro dos dados e o tratamento estatístico básico. 
Todos os testes foram realizados admitindo-se nível de significância de $5 \%$. 
Foram examinados 50 pacientes, dos quais $39(78 \%)$ eram do sexo masculino, considerando-se a artéria carótida interna extracraniana esquerda e direita como unidades independentes, o que constitui uma amostra de 100 casos.

A idade dos pacientes variou entre 34 e 77 anos, com média de 60,36 anos, desvio-padrão de 10,62 anos e mediana de 63,5 anos. Os dados da anamnese mostraram que, além de serem candidatos a revascularização do miocárdio, todos estiveram expostos a um ou mais dos fatores de risco conhecidos e selecionados para esta abordagem.

Foi realizada associação entre os fatores de risco e a estimativa do grau de estenose, através de UDC. Através do teste não-paramétrico de Mann-Whitney, observou-se que os segmentos carotídeos considerados normais apresentaram valores de idade menores que os dos outros grupos. Através do teste exato de Fisher, não houve correlação entre os demais fatores de risco estudados e o grau de estenose das artérias carótidas internas. 
Pela revisão de prontuários dos pacientes, obtivemos os resultados do cateterismo cardíaco, referentes ao comprometimento da circulação coronária. Observou-se que o comprometimento uniarterial foi diagnosticado em 9 pacientes, biarterial, em 16 e triarterial, em 25.

Também não há associação entre a estimativa do grau de estenose, avaliado por UDC, com a gravidade de comprometimento coronariano, através de análises pelo teste exato de Fisher.

$\mathrm{Na}$ tabela abaixo, estão apresentadas as freqüências dos fatores de risco a que estes pacientes estavam expostos:

TABELA 1 - Fatores de risco avaliados nos pacientes estudados.

\begin{tabular}{lcc}
\hline Fatores de risco & $\mathrm{n}$ & $\%$ \\
\hline Obesidade & 11 & 22,0 \\
Tabagismo & 26 & 52,0 \\
Estresse & 20 & 40,0 \\
Sedentarismo & 35 & 70,0 \\
HAS & 36 & 72,0 \\
História familiar & 33 & 66,0 \\
Hiperlipidemia & 39 & 78,0 \\
DM & 18 & 36,0 \\
\hline
\end{tabular}

HAS = hipertensão arterial sistêmica;

$\mathrm{DM}=$ diabetes mellitus

Dos pacientes em estudo, 28 (56,0\%) apresentaram história de IAM e $5(10,0 \%)$ com quadro de AVC. 
A presença de ateromas carotídeos, através de USG, pode ser visualizada no gráfico 1 , que registra $81 \%$ das artérias examinadas com algum tipo de alteração quanto à ecogenicidade das paredes, sendo que 88,8\% são classificadas como placas hiperecóicas (tipo 4).

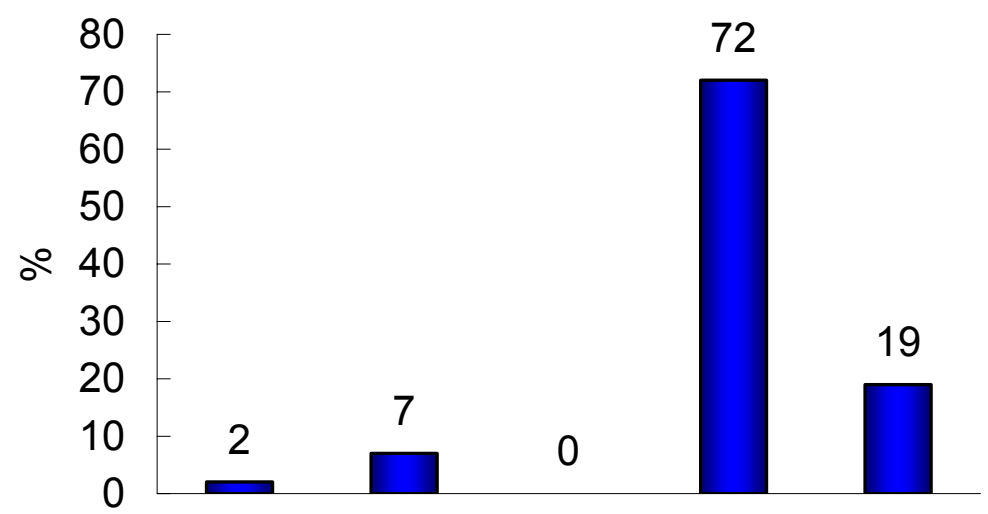

Tipo 1 Tipo 2 Tipo 3 Tipo 4 Normal Ecogenicidade das paredes arteriais

Gráfico 1. Distribuição dos casos, segundo o tipo de ecogenicidade das paredes das artérias carótidas internas, examinadas pela ultra-sonografia.

O diagnóstico feito pela USG incluiu a avaliação da superfície interna das artérias carótidas internas, quanto à sua regularidade e o gráfico 2 mostra irregularidade em $14 \%$ dos casos. 
Superfície interna

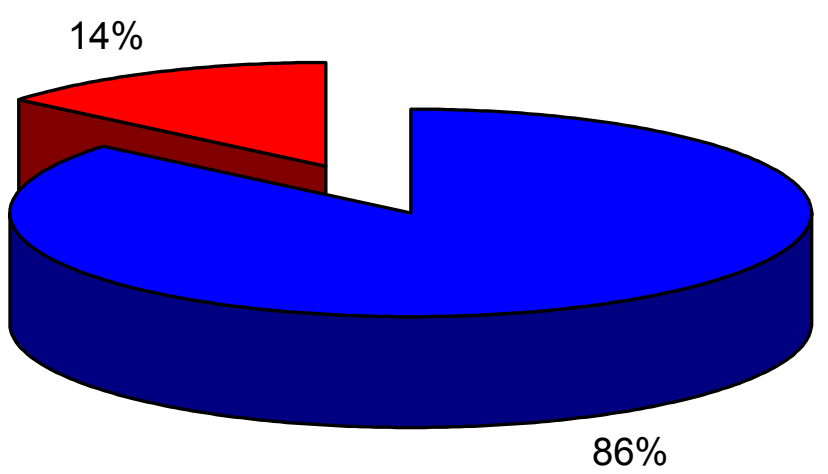

$\square$ Regular $\square$ Irregular

Gráfico 2. Distribuição de freqüência em relação à regularidade da superfície interna das artérias carótidas internas, examinadas pela USG.

O gráfico 3 mostra a ordenação dos ateromas carotídeos visualizados pela USG com fluxo Doppler colorido, na estimativa do grau de estenose, onde se percebe que, de $81 \%$ das artérias que apresentam algum tipo de estenose, o grau II (leve) foi detectado em $72,8 \%$.

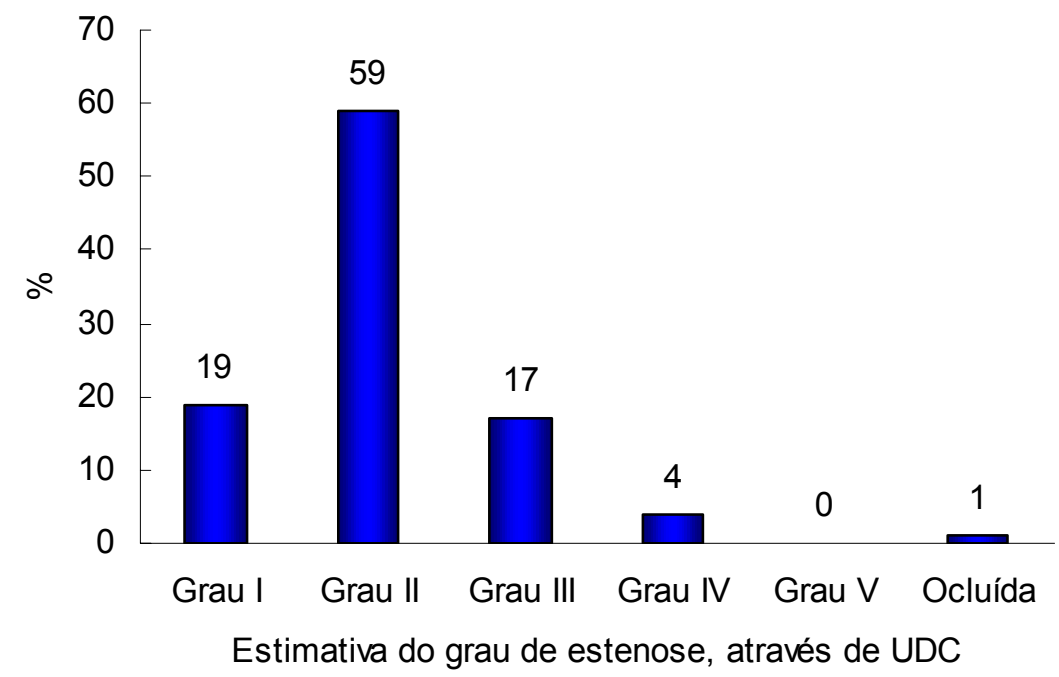

Gráfico 3. Distribuição de estimativa do grau de estenose das artérias carótidas internas, segundo avaliação feita pela USG com fluxo Doppler colorido. 
O gráfico 4 mostra a freqüência de ateromas carotídeos visualizados através da ressonância magnética, nas diferentes seqüências examinadas, evidenciando visível diferença nos resultados encontrados, quando da avaliação na seqüência 3D TOF.

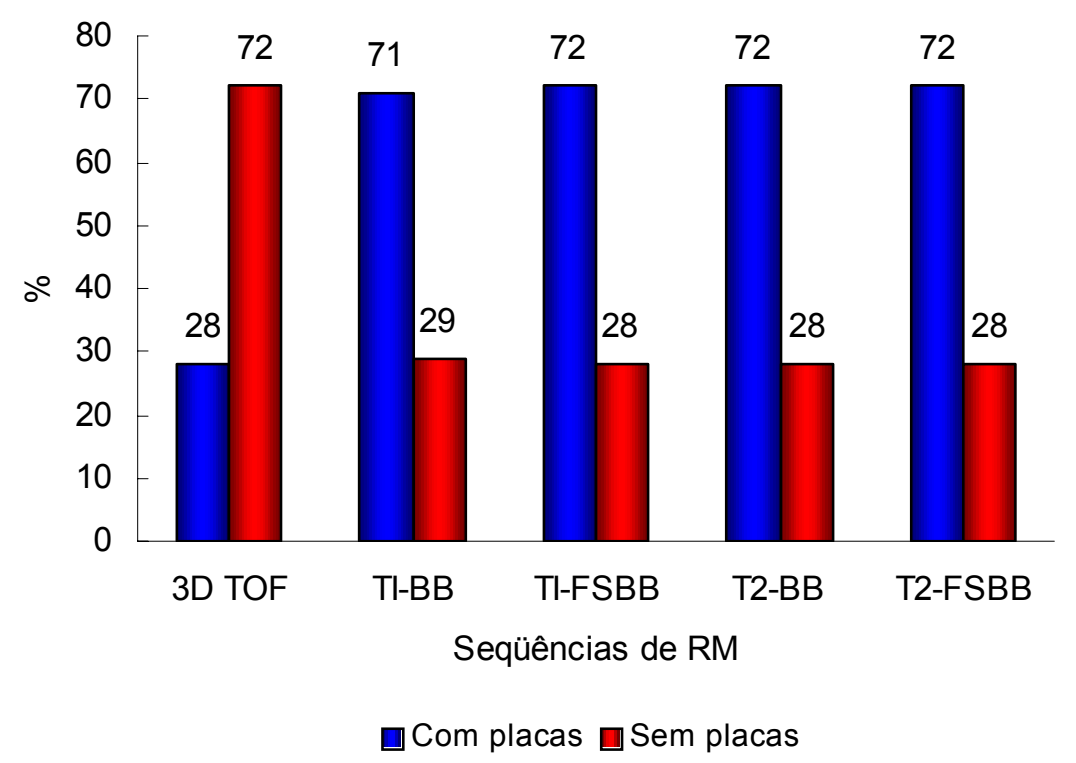

Gráfico 4. Distribuição de freqüência da presença de placas visualizadas nas artérias carótidas internas, quando examinadas pela ressonância magnética.

As características de intensidade de sinal das artérias carótidas internas foram avaliadas visualmente, através da ressonância magnética, nas seqüências de pulso 3D TOF, T1-BB, T1-FSBB, T2-BB, T2-FSBB, apresentando os resultados contidos na Tabela 2. A seqüência 3D TOF apresenta mais diferença significativa na detecção de presença de placas que as demais seqüências (teste de McNemar, $p<0,001$ ). As demais seqüências não apresentam diferenças significativas entre si. Quando as imagens de ressonância magnética foram adquiridas pela técnica 3D TOF, registraram-se 72 segmentos sem alteração de sinal das paredes arteriais. 
TABELA 2 - Distribuição segundo as características de intensidade de sinal, visualizadas através da RM, nas diferentes seqüências de pulso.

\begin{tabular}{lccccc}
\hline Intensidade de sinal & 3D TOF & T1-BB & T1-FSBB & T2-BB & T2-FSBB \\
\hline Normal & 72 & 29 & 28 & 28 & 28 \\
Hipointenso & 8 & - & - & 2 & 2 \\
Isointenso & - & 11 & 7 & 7 & 5 \\
Hiperintenso & 18 & 59 & 64 & 62 & 64 \\
Misto * & 2 & 1 & 1 & 1 & 1 \\
\hline Total & 100 & 100 & 100 & 100 & 100 \\
\hline
\end{tabular}

* áreas de redução e aumento da intensidade de sinal

Nas Tabelas 3 a 7, estão apresentadas as associações entre alterações encontradas nos exames de USG, referentes aos diferentes tipos de placas com a intensidade de sinal observada pelos exames de RM nas diferentes seqüências de pulso.

TABELA 3 - Associação entre os tipos de placas encontradas nos exames de USG e a intensidade de sinal nos exames de RM, na seqüência 3D TOF.

\begin{tabular}{|c|c|c|c|c|c|c|c|c|c|}
\hline \multirow{3}{*}{$\begin{array}{l}\text { Alterações } \\
\text { pela ultra- } \\
\text { sonografia }\end{array}$} & \multicolumn{9}{|c|}{ Intensidade de sinal pela RM } \\
\hline & \multicolumn{2}{|c|}{ Normal } & \multicolumn{2}{|c|}{ Hipointenso } & \multicolumn{2}{|c|}{ Hiperintenso } & \multicolumn{2}{|c|}{ Misto } & \multirow[t]{2}{*}{ Tota } \\
\hline & $\mathbf{n}$ & $\%$ & $\mathbf{n}$ & $\%$ & $\mathbf{n}$ & $\%$ & $\mathbf{n}$ & $\%$ & \\
\hline Tipo 1 & 1 & 50,0 & 0 & 0,0 & 1 & 50,0 & 0 & 0,0 & 2 \\
\hline Tipo 2 & 3 & 42,9 & 0 & 0,0 & 3 & 42,9 & 1 & 14,3 & 7 \\
\hline Tipo 4 & 54 & 75,0 & 7 & 9,7 & 10 & 13,9 & 1 & 1,4 & 72 \\
\hline Normal & 14 & 73,7 & 1 & 5,3 & 4 & 21,1 & 0 & 0,0 & 19 \\
\hline
\end{tabular}

Teste exato de Fisher, $p=0,188$. 
Observamos que não há associação entre as alterações encontradas nos exames de USG, referentes aos tipos de placas e a intensidade de sinal da RM, na seqüência 3D TOF, com cortes no plano axial.

TABELA 4 - Associação entre os tipos de placas encontradas nos exames de USG e a intensidade de sinal nos exames de RM na seqüência T1-BB.

\begin{tabular}{|c|c|c|c|c|c|c|c|c|c|c|c|}
\hline \multirow{3}{*}{$\begin{array}{l}\text { Alterações } \\
\text { pela ultra- } \\
\text { sonografia }\end{array}$} & \multicolumn{11}{|c|}{ Intensidade de sinal pela RM } \\
\hline & \multicolumn{2}{|c|}{ Normal } & \multicolumn{2}{|c|}{ Hipointenso } & \multicolumn{2}{|c|}{ Isointenso } & \multicolumn{2}{|c|}{ Hiperintenso } & \multicolumn{2}{|c|}{ Misto } & \multirow[t]{2}{*}{ Total } \\
\hline & $\mathbf{n}$ & $\%$ & $\mathbf{n}$ & $\%$ & $\mathbf{n}$ & $\%$ & $\mathrm{n}$ & $\%$ & $\mathbf{n}$ & $\%$ & \\
\hline Tipo 1 & 1 & 50,0 & 0 & 0,0 & 0 & 0,0 & 1 & 50,0 & 0 & 0,0 & 2 \\
\hline Tipo 2 & 0 & 0,0 & 0 & 0,0 & 1 & 14,3 & 5 & 71,4 & 1 & 14,3 & 7 \\
\hline Tipo 4 & 20 & 27,8 & 0 & 0,0 & 9 & 12,5 & 43 & 59,7 & 0 & 0,0 & 72 \\
\hline Normal & 8 & 42,1 & 1 & 5,3 & 1 & 5,3 & 9 & 47,4 & 0 & 0,0 & 19 \\
\hline
\end{tabular}

Teste exato de Fisher, $p=0,084$.

Observamos que não há associação entre as alterações encontradas nos exames de USG, referentes aos tipos de placas, e a intensidade de sinal da RM, na seqüência T1-BB. 
TABELA 5 - Associação entre os tipos de placas encontradas nos exames de USG e a intensidade de sinal nos exames de RM na seqüência T1-FSBB.

\begin{tabular}{|c|c|c|c|c|c|c|c|c|c|}
\hline \multirow{3}{*}{$\begin{array}{l}\text { Alterações } \\
\text { pela ultra- } \\
\text { sonografia }\end{array}$} & \multicolumn{9}{|c|}{ Intensidade de sinal pela RM } \\
\hline & \multicolumn{2}{|c|}{ Normal } & \multicolumn{2}{|c|}{ Isointenso } & \multicolumn{2}{|c|}{ Hiperintenso } & \multicolumn{2}{|c|}{ Misto } & \multirow[t]{2}{*}{ Total } \\
\hline & $\mathbf{n}$ & $\%$ & $\mathbf{n}$ & $\%$ & $\mathbf{n}$ & $\%$ & $\mathbf{n}$ & $\%$ & \\
\hline Tipo 1 & 1 & 50,0 & 0 & 0,0 & 1 & 50,0 & 0 & 0,0 & 2 \\
\hline Tipo 2 & 0 & 0,0 & 1 & 14,3 & 5 & 71,4 & 1 & 14,3 & 7 \\
\hline Tipo 4 & 20 & 27,8 & 5 & 6,9 & 47 & 65,3 & 0 & 0,0 & 72 \\
\hline Normal & 7 & 36,8 & 1 & 5,3 & 11 & 57,9 & 0 & 0,0 & 19 \\
\hline
\end{tabular}

Teste exato de Fisher, $\mathrm{p}=0,169$.

Observamos que não há associação entre as alterações encontradas nos exames de USG, referentes aos tipos de placas, e a intensidade de sinal da RM, na seqüência T1-FSBB.

TABELA 6 - Associação entre os tipos de placas encontradas nos exames de USG e a intensidade de sinal nos exames de RM, na seqüência T2-BB.

\begin{tabular}{|c|c|c|c|c|c|c|c|c|c|c|c|}
\hline \multirow{3}{*}{$\begin{array}{l}\text { Alterações } \\
\text { pela ultra- } \\
\text { sonografia }\end{array}$} & \multicolumn{11}{|c|}{ Intensidade de sinal pela RM } \\
\hline & \multicolumn{2}{|c|}{ Normal } & \multicolumn{2}{|c|}{ Hipointenso } & \multicolumn{2}{|c|}{ Isointenso } & \multicolumn{2}{|c|}{ Hiperintenso } & \multicolumn{2}{|c|}{ Misto } & \multirow[t]{2}{*}{ Total } \\
\hline & $\mathbf{n}$ & $\%$ & $\mathbf{n}$ & $\%$ & $\mathbf{n}$ & $\%$ & $\mathbf{n}$ & $\%$ & $\mathbf{n}$ & $\%$ & \\
\hline Tipo 1 & 1 & 50,0 & 0 & 0,0 & 0 & 0,0 & 1 & 50,0 & 0 & 0,0 & 2 \\
\hline Tipo 2 & 0 & 0,0 & 0 & 0,0 & 0 & 0,0 & 6 & 85,7 & 1 & 14,3 & 7 \\
\hline Tipo 4 & 20 & 27,8 & 1 & 1,4 & 6 & 8,3 & 45 & 62,5 & 0 & 0,0 & 72 \\
\hline Normal & 7 & 36,8 & 1 & 5,3 & 1 & 5,3 & 10 & 52,6 & 0 & 0,0 & 19 \\
\hline
\end{tabular}

Teste exato de Fisher, $p=0,217$. 
Observamos que não há associação entre as alterações encontradas nos exames de USG, referentes aos tipos de placas, e a intensidade de sinal da RM, na seqüência T2-BB.

TABELA 7 - Associação entre os tipos de placas encontradas nos exames de USG e a intensidade de sinal nos exames de RM, na seqüência T2-FSBB.

\begin{tabular}{|c|c|c|c|c|c|c|c|c|c|c|c|}
\hline \multirow{3}{*}{$\begin{array}{l}\text { Alterações } \\
\text { pela ultra- } \\
\text { sonografia }\end{array}$} & \multicolumn{11}{|c|}{ Intensidade de sinal pela RM } \\
\hline & \multicolumn{2}{|c|}{ Normal } & \multicolumn{2}{|c|}{ Hipointenso } & \multicolumn{2}{|c|}{ Isointenso } & \multicolumn{2}{|c|}{ Hiperintenso } & \multicolumn{2}{|c|}{ Misto } & \multirow[t]{2}{*}{ Tota } \\
\hline & $\mathbf{n}$ & $\%$ & $\mathbf{n}$ & $\%$ & $\mathbf{n}$ & $\%$ & $\mathbf{n}$ & $\%$ & $\mathbf{n}$ & $\%$ & \\
\hline Tipo 1 & 1 & 50,0 & 0 & 0,0 & 0 & 0,0 & 1 & 50,0 & 0 & 0,0 & 2 \\
\hline Tipo 2 & 0 & 0,0 & 0 & 0,0 & 1 & 14,3 & 5 & 71,4 & 1 & 14,3 & 7 \\
\hline Tipo 4 & 20 & 27,8 & 1 & 1,4 & 3 & 4,2 & 48 & 66,7 & 0 & 0,0 & 72 \\
\hline Normal & 7 & 36,8 & 1 & 5,3 & 1 & 5,3 & 10 & 52,6 & 0 & 0,0 & 19 \\
\hline
\end{tabular}

Teste exato de Fisher, $p=0,132$.

Observamos que não há associação entre as alterações encontradas nos exames de USG, referentes aos tipos de placas, e a intensidade de sinal da RM, na seqüência T2-FSBB.

A avaliação visual do grau de estenose das artérias carótidas internas foi realizada através da angiografia por ressonância magnética, com e sem contraste, apresentando-se os resultados nos gráficos 5 e 6 . 


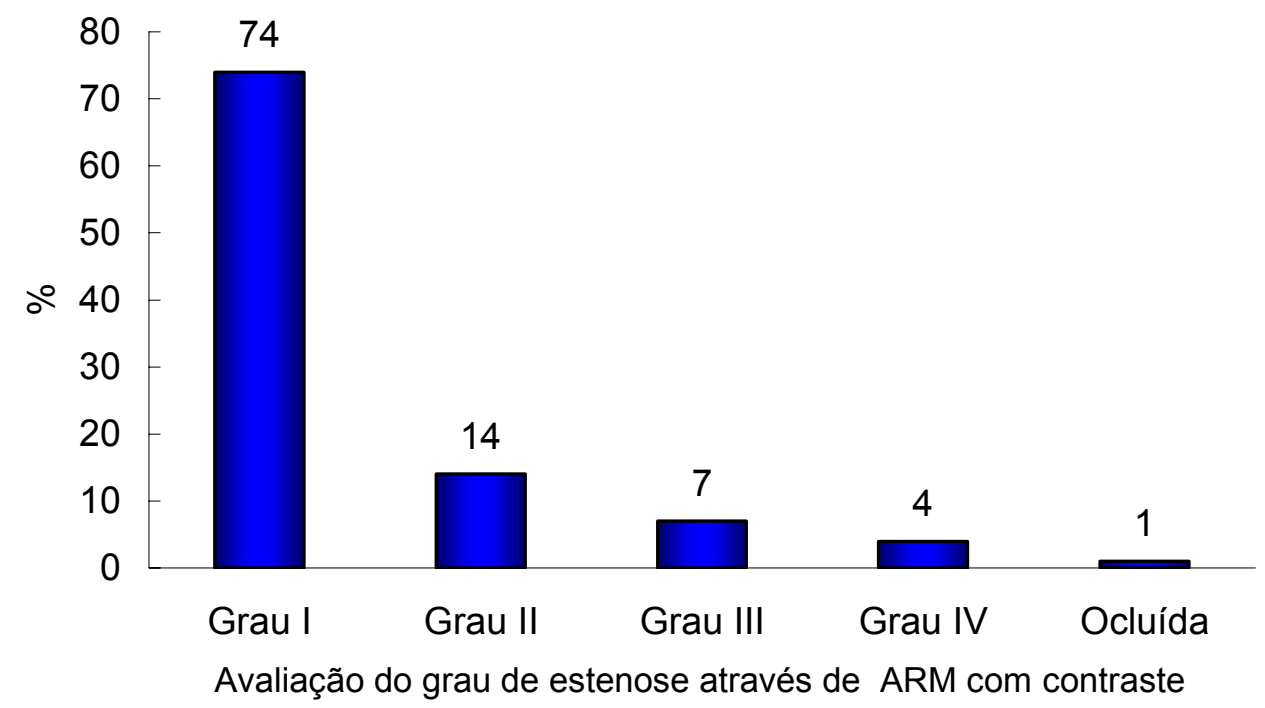

Gráfico 5. Distribuição dos casos, segundo o grau de estenose visualizado pela angiografia por ressonância magnética, com contraste.

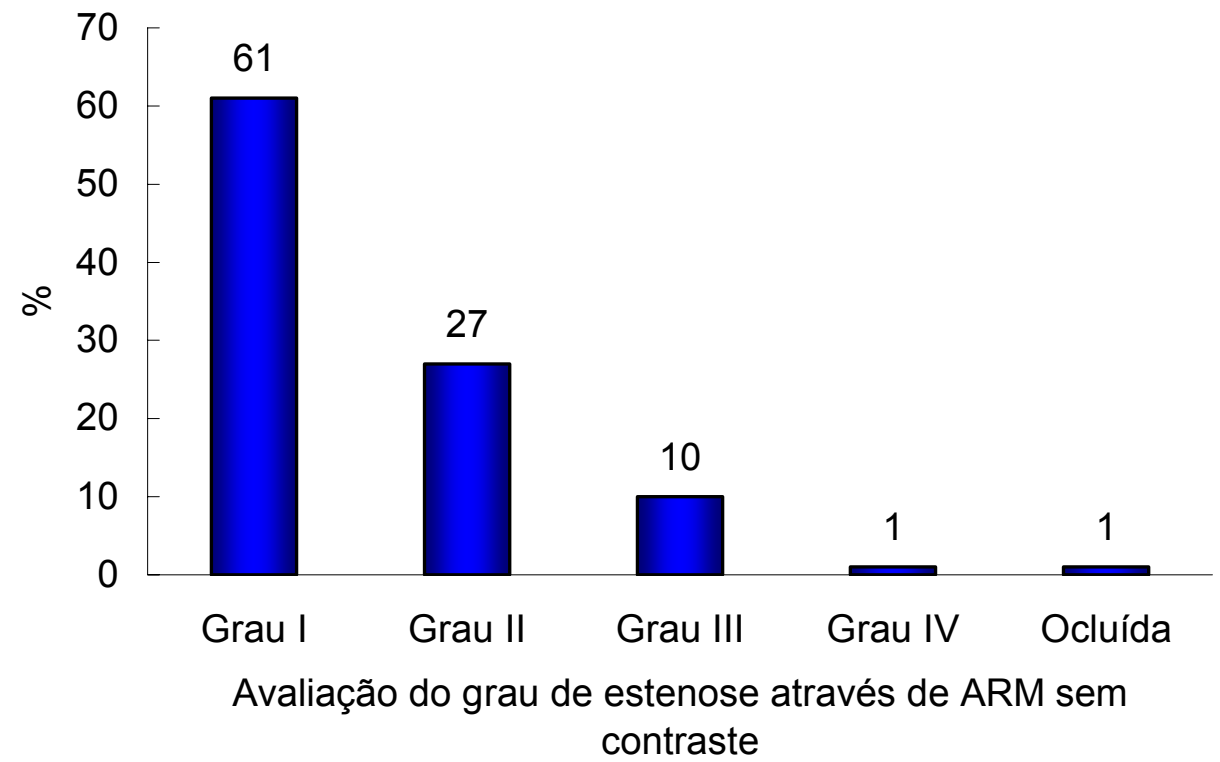

Gráfico 6. Distribuição dos casos segundo o grau de estenose visualizado pela angiografia por ressonância magnética, sem contraste. 
O grau de associação entre estas duas medidas foi avaliado através do índice Kappa, que apresentou valor de 0,563 ( $p<0,001)$, o que caracteriza boa reprodutibilidade entre os métodos (ARM com e sem contraste).

TABELA 8 - Associação entre a estimativa do grau de estenose visualizado através de USG com fluxo Doppler colorido e angiografia por RM, com contraste.

\begin{tabular}{lccccc}
\hline & \multicolumn{6}{c}{ Grau de estenose, através de ARM, com contraste } \\
\cline { 2 - 6 } Grau de estenose por UDC & I & II & III & IV & Ocluída \\
\hline I & 13 & 3 & 3 & - & - \\
II & 36 & 19 & 3 & 1 & - \\
III & 10 & 4 & 3 & - & - \\
IV & 2 & 1 & 1 & - & - \\
V & - & - & - & - & - \\
Ocluída & - & - & - & - & 1 \\
\hline
\end{tabular}

Através do índice Kappa, observamos que há reprodutibilidade marginal entre o UDC e a ARM, com contraste, em relação ao grau de estenose, sendo Kappa $=0,095, p=0,040$. 
TABELA 9 - Associação entre a estimativa do grau de estenose visualizado através de USG com fluxo Doppler colorido e angiografia por RM, sem contraste.

\begin{tabular}{lccccc}
\hline & \multicolumn{6}{c}{ Grau de estenose, através de ARM, sem contraste } \\
\cline { 2 - 6 } Grau de estenose por UDC & I & II & III & IV & Ocluída \\
\hline I & 17 & 1 & 1 & - & - \\
II & 44 & 10 & 2 & 3 & - \\
III & 11 & 2 & 3 & 1 & - \\
IV & 2 & 1 & 1 & - & - \\
V & - & - & - & - & - \\
Ocluída & - & - & - & - & 1 \\
\hline
\end{tabular}

Através do índice Kappa, observamos que há reprodutibilidade marginal entre o UDC e a ARM, sem contraste, em relação ao grau de estenose, sendo Kappa $=0,096, p=0,011$.

Foi realizada avaliação de qualidade das imagens obtidas pela ARM, com e sem contraste, e nas diversas seqüências de pulso, classificando-se os resultados como boa, muito boa e excelente. Os resultados se encontram nos gráficos 7 e 8 . 


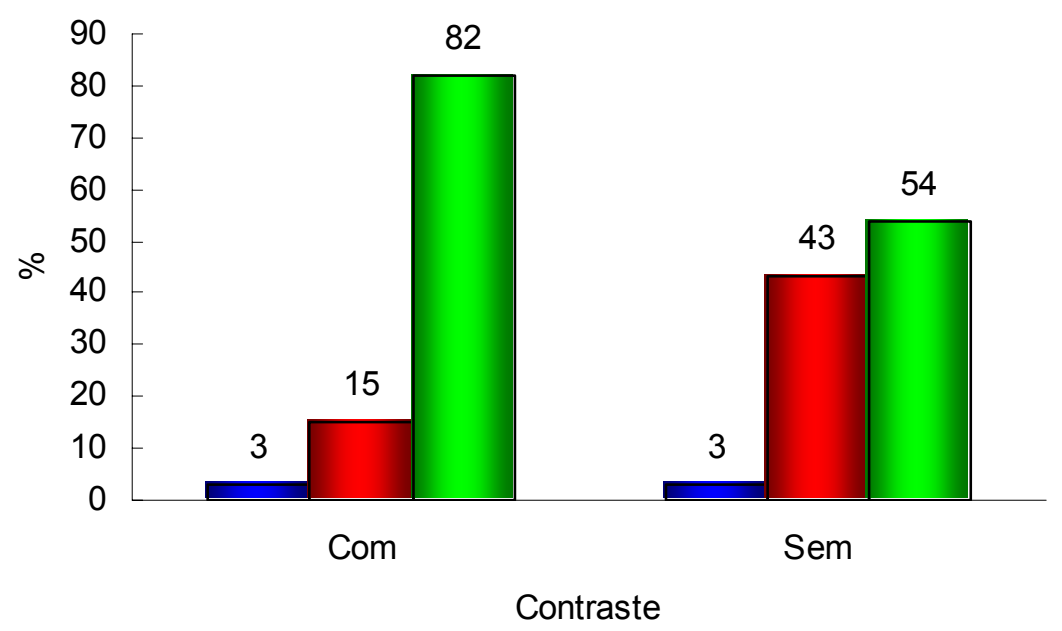

口 Boa Muito boa $\square$ Excelente

Gráfico 7. Distribuição dos casos segundo a qualidade de imagem dos exames de angiografia por ressonância magnética, de acordo com a utilização de contraste.

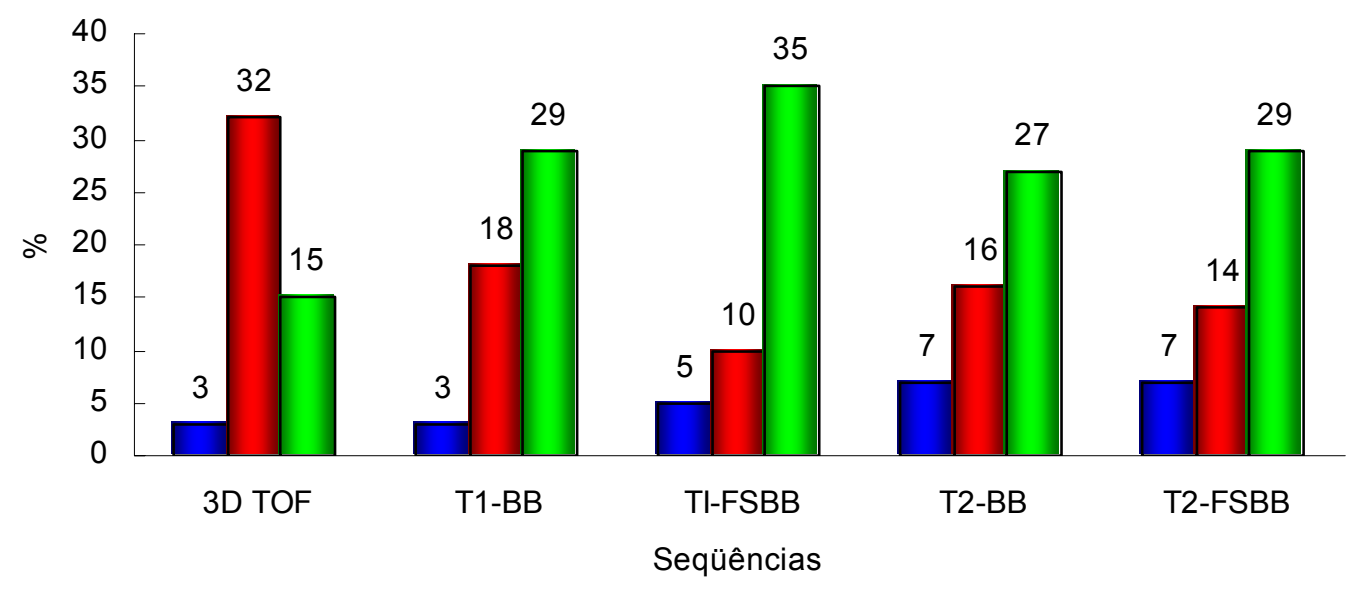

$\square$ Boa $\square$ Muito boa $\square$ Excelente

Gráfico 8. Distribuição dos casos segundo a qualidade de imagem dos exames de ressonância magnética, nas diversas seqüências de pulso realizadas. 
Para a análise de reprodutibilidade inter-observadores, foram utilizados os parâmetros de avaliação da qualidade das imagens de RM, intensidade de sinal nas seqüências 3D TOF, T1-BB, T1-FSBB, T2-BB, T2FSBB e o grau de estenose visualizado através de angiografia por RM, com e sem a administração do contraste. Na análise do índice Kappa, registrouse ótima reprodutibilidade, com valores acima de 0,71.

TABELA 10 - Confiabilidade inter-observadores na avaliação dos exames de ressonância magnética

\begin{tabular}{llc}
\hline Variáveis & Kappa & p \\
\hline Intensidade de sinal em 3D TOF & 0,779 & $\mathrm{p}<0,001$ \\
Intensidade de sinal em T1 BB & 0,832 & $\mathrm{p}<0,001$ \\
Intensidade de sinal em T1 FSBB & 0,833 & $\mathrm{p}<0,001$ \\
Intensidade de sinal em T2 BB & 0,870 & $\mathrm{p}<0,001$ \\
Intensidade de sinal em T2 FSBB & 0,884 & $\mathrm{p}<0,001$ \\
Estenose ARM sem contraste & 0,868 & $\mathrm{p}<0,001$ \\
Estenose ARM com contraste & 0,709 & $\mathrm{p}<0,001$ \\
Qualidade de imagem 3D TOF & 0,781 & $\mathrm{p}<0,001$ \\
Qualidade de imagem T1 BB & 0,807 & $\mathrm{p}<0,001$ \\
Qualidade de imagem T1 FSBB & 0,840 & $\mathrm{p}<0,001$ \\
Qualidade de imagem T2 BB & 0,864 & $\mathrm{p}<0,001$ \\
Qualidade de imagem T2 FSBB & 0,894 & $\mathrm{p}<0,001$ \\
\hline
\end{tabular}


A avaliação das artérias carótidas internas foi realizada por métodos diagnósticos não-invasivos, indolores, relativamente rápidos, dotados de grande acurácia e reprodutibilidade: ultra-sonografia e ressonância magnética.

O presente estudo utilizou a ultra-sonografia para uma avaliação preliminar da ateromatose carotídea por considerá-lo um método confiável e que apresenta alta sensibilidade e boa especificidade (GEROULAKOS et al., 2000).

Uma segunda avaliação foi realizada através de ressonância magnética, método mais recentemente utilizado na caracterização de placas (MERICKEL et al., 1988; YUAN et al., 1994; MARTIN et al.,1995; SKINNER et al., 1995; TOUSSAINT et al., 1996; YUAN et al., 1996a; VON INGERSLEBEN et al., 1997; YUAN et al., 2001b; QUICK et al., 2002). Tratase, porém, de um procedimento que apresenta alto custo, cujo uso está limitado, no caso da clientela do Sistema Único de Saúde e de muitos planos particulares de saúde, à realização prévia de ultra-sonografia. Importa 
conhecer a magnitude e a transcendência dos ganhos advindos do uso desta técnica, a fim de que se redefinam as políticas de saúde e se ofereçam as melhores alternativas para a população.

Esta pesquisa foi complementada com a realização de angiografia por ressonância magnética, na reavaliação da estimativa do grau de estenose, visualizado pela UDC.

O perfil da população abordada mostrou um grupo de 50 pacientes, onde a predominância recaiu sobre o sexo masculino $(78 \%)$, ainda que a inclusão dos casos tenha se dado através da busca espontânea do serviço (convite pessoal ou telefônico dentre uma clientela de candidatos à revascularização do miocárdio). Segundo a literatura, esta distribuição deve ser esperada, uma vez que as taxas de mortalidade por CPI são significativamente maiores em homens (WILSON et al., 1998; GRUNDY et al., 1999).

Todos os indivíduos que compuseram a amostra estiveram expostos a mais de dois dos fatores de risco selecionados para o estudo, o que é importante diante da informação em literatura que considera a exposição a múltiplos fatores de risco como um efeito aditivo (LOTUFO, 2000). Todas as mulheres aqui avaliadas estavam no climatério e $82 \%$ delas são consideradas portadoras de hipertensão arterial sistêmica, justificando a presença de nove casos, no grupo amostral. A pressão arterial eleva-se, progressivamente, com a idade, em ambos os sexos. Abaixo dos 50 anos de idade, a HAS é mais freqüente nos homens, porém, acima de 60 anos passa 
a predominar nas mulheres, principalmente da raça negra, chegando a comprometer mais de $60 \%$ delas (HALL, 1990). Registram-se $17 \%$ de indivíduos tabagistas, avaliando 20.000 indivíduos, em dados de 1999, do Estudo Transversal da Sociedade de Cardiologia do Estado de São Paulo. O Censo Populacional de 1991 registrou 15\% de hipertensão arterial no país, enquanto estudos transversais mostraram 25\%, em São Paulo, e 30\%, no Rio de Janeiro (DATASUS). Dados do Censo Nacional de Diabetes, constantes do DATASUS (datasus.gov.br/), falam de 7,6\% de diabéticos, no Brasil. O Ministério da Saúde afirmou, em 1993, que 32\% da população brasileira apresentavam sobrepeso $(\mathrm{IMC}>25)$ e $8 \%$ foram considerados obesos (IMC>30). Pesquisa realizada em nove capitais brasileiras estimou em $8,8 \%$ a freqüência de níveis séricos de colesterol total elevados. Kligman et al. (1992) verificaram que apesar da atividade física regular determinar benefícios evidentes após os 65 anos, 60 a 70\% dos idosos são sedentários e menos de $25 \%$ participam de um programa de exercícios adequado para a prevenção de doenças cardiovasculares.

Nossos resultados demonstraram que os pacientes apresentaram elevados índices dos fatores de risco avaliados, estando a maioria acima da média da população geral, exceto o fator obesidade, que acometeu $22 \%$ dos indivíduos.

Wilson et al. (1998), avaliando pacientes idosos, encontraram associação entre estenose moderada das artérias carótidas com os fatores de risco. Neste estudo, a gravidade da estenose aumentava, de acordo com 
o acúmulo desses fatores. Não houve correlação semelhante em nosso grupo amostral. Em nossas avaliações, observou-se que os segmentos carotídeos, considerados normais, apresentaram valores de idade menores que os outros grupos.

O'Leary et al. (1992) associam o espessamento do complexo íntimamédia das artérias carótidas com a gravidade de comprometimento das artérias coronárias. Notamos que houve alteração da ecogenicidade das paredes arteriais em $81 \%$ dos segmentos carotídeos. O comprometimento coronário, verificado por cateterismo cardíaco, demonstrou que em $50 \%$ dos casos o acometimento foi triarterial, em $32 \%$, biarterial e em $18 \%$, uniarterial. Há alta ocorrência de aterosclerose carotídea, em coronariopatas (NAGAI et al., 1998), confirmando os dados de literatura.

A análise da ecogenicidade das placas nas artérias carótidas internas, em imagens de USG, tem sido usada, freqüentemente, para descrever sua composição e para diferenciá-las quanto à sua estabilidade (ARNOLD et al., 2001; YUAN et al., 2001b).

Através de avaliações histopatológicas, as placas hiperecóicas (tipo 4) apresentam predominância de tecido fibroso, portanto, relacionadas a maior estabilidade. Este tipo de placa foi predominante em nossos achados e a literatura o menciona como o tipo predominante nas artérias carótidas (GRAY-WEALE et al., 1988).

A USG é um método ainda limitado na identificação de formas semelhantes à hemorragia intraplaca, presentes no desenvolvimento de 
sintomas neurológicos (ABURAHMA et al., 2002). As placas ateroscleróticas ricas em lipídios, nas artérias coronárias, são particularmente vulneráveis a rupturas e associadas a maior risco de infarto do miocárdio e de morte do que as placas fibrocalcificadas. Se os achados mostram que placas das artérias carótidas e coronárias apresentam características morfológicas semelhantes, pode-se valorizar a eficiência da ultra-sonografia, método simples e não-invasivo, na avaliação de indivíduos em situação de risco, para eventos cardiovasculares (JOAKIMSEN et al., 1997; MOODY et al., 2003).

Os resultados apresentados neste trabalho mostraram a presença de 7\% de placas do tipo 2 (hipoecóicas, com pequenas áreas hiperecóicas associadas) e $2 \%$ do tipo 1 (hipoecóicas), não permitindo a diferenciação entre placas contendo lipídeo ou hemorragia, uma das razões por que se propôs a reavaliação dos casos através de RM, tentando melhor identificação.

A superfície das placas foi classificada, segundo suas características ultra-sonográficas, como regular, quando a interface lesão-sangue é lisa e contínua, e como irregular, na presença de uma quebra na superfície da lesão, tornando-a desigual (GEROULAKOS et al., 2000).

A avaliação da superfície das artérias carótidas internas, feita neste estudo através da USG, mostrou irregularidade em 14\% dos casos (Gráfico 2), achado importante, uma vez que muitos eventos cerebrovasculares estão 
associados a rupturas das capas de tecido fibroso, causando instabilidade nas placas.

As placas consideradas irregulares apresentaram graus de estenose leve e moderado, em $92,8 \%$ dos casos, e a ecogenicidade das mesmas foi definida como tipo 4 em $85,7 \%$.

Há estudos que associam o maior grau de estenose produzido pelas placas ateroscleróticas a maiores irregularidades nas superfícies das mesmas, embora se afirme que tais irregularidades não estejam associadas unicamente ao grau de estenose por elas provocadas (TROYER et al., 2002). Geroulakos et al. (2000) afirmaram que a USG apresenta boa sensibilidade na detecção de irregularidade na superfície das placas ateroscleróticas, que apresentam graus de estenose leve a moderado, e que esta sensibilidade diminui com o aumento do grau de estenose.

Moody et al. (2003) afirmaram que a ruptura das placas está mais relacionada com as suas características morfológicas e bioquímicas do que com o grau de estenose provocado.

Chama-se atenção para o fato de que, avaliando as artérias carótidas internas através de UDC, observou-se estenose grau II em 59\% dos casos, ou seja, em processo inicial de formação, passível, portanto, de controle através de medidas preventivas ou terapêuticas. Deste total, a ecogenicidade das placas foi classificada como tipo 4 em 94,9\%. 
Pouco se sabe sobre as alterações de sinal encontradas nos exames de RM, onde há processo inicial de ateromatose carotídea. Cai et al. (2002) foram os primeiros a avaliar estas alterações, correlacionando os exames de RM com análises histopatológicas. Seus resultados demonstraram sensibilidade de $67 \%$ na detecção dessas lesões, nas seqüências ponderadas em T2.

Estudos recentes têm demonstrado que imagens obtidas por ressonância magnética podem identificar a morfologia e os constituintes das placas de ateroma, com graus avançados de estenose, nas artérias carótidas internas extracraniana "in vivo" e "in vitro" (MERICKEL et al., 1993; YUAN et al., 1996a; FAYAD, 1998; KANG et al., 2000). Método de alta resolução é ideal para exame seriado de doenças da parede arterial, porque é uma técnica não-invasiva, com boa capacidade de discriminação das características teciduais (MAYNOR et al., 1989; TOUSSAINT et al., 1995, 1996; YUAN et al., 1996b).

Favorece avaliação sistemática dos contornos dos vasos, permitindo diferenciação entre as camadas média e adventícia. Os bordos externos também podem ser claramente definidos nas seqüências ponderadas em T1 e T2, assim como os tecidos adjacentes (YUAN et al., 1996b).

Foram detectadas na seqüência 3D TOF, em cortes axiais, diferenças significativas na identificação de alterações de intensidade de sinal das paredes das artérias carótidas internas, em relação às seqüências ponderadas em T1 e T2. Prováveis explicações estariam ligadas à presença 
de artefatos de fluxo ou ao alto índice de casos com graus leves de estenose. Outra explicação possível adviria da insuficiente resolução espacial da ressonância magnética para detecção de aterosclerose carotídea de grau leve "in vivo", nesta seqüência. Não ocorreram diferenças significativas entre si nas demais seqüências na identificação de alterações de intensidade de sinal, nas paredes arteriais. Houve supremacia em relação a alterações de intensidade de sinal nas paredes arteriais, pelas seqüências ponderadas em T1 e T2, quando comparadas com 3D TOF.

A elevação da intensidade de sinal na parede vascular, nas seqüências ponderadas em T1 e T2, pode corresponder, principalmente, a um componente fibroso (YUAN et al., 2001b). Através de avaliações histopatológicas, realizadas por Gray-Weale et al. (1988), as placas hiperecóicas (tipo 4), detectadas por USG, correspondem a placas constituídas por componente fibroso. Tais alterações, tanto de intensidade de sinal quanto de ecogenicidade de placas, também foram encontradas em nossos casos.

Comparando as alterações de ecogenicidade das placas visualizadas através de ultra-sonografia, com alterações de intensidade de sinal pela ressonância magnética, nas seqüências ponderadas em T1 e T2, obtivemos os resultados seguintes.

Em 19 segmentos carotídeos, a USG apresentou-se normal, isto é, sem alteração de ecogenicidade nas paredes das artérias carótidas internas. Comparando as alterações encontradas nos exames de USG com a RM, 
observa-se que entre $36,8 \%$ e $42,1 \%$ dos casos as seqüências ponderadas em T1 e T2 não apresentaram alterações de intensidade de sinal, sendo estes exames também considerados normais. A intensidade de sinal da parede vascular foi caracterizada como hiperintensa, entre $47,4 \%$ a $57,9 \%$ dos casos.

Em 72 segmentos carotídeos, as placas foram consideradas com ecogenicidade tipo 4. Comparando as alterações encontradas nos exames de USG com a RM, observa-se que em $27,8 \%$ dos casos as seqüências ponderadas em T1 e T2 não apresentaram alterações de intensidade de sinal, sendo estes exames considerados normais. Tal fato talvez se explique pela razão de a RM não haver captado alteração de sinal, em alguns casos com grau leve de espessamento do complexo íntima-média.

A intensidade de sinal da parede vascular foi caracterizada como hiperintensa, entre $59,7 \%$ a $66,7 \%$ dos casos. Tal fato sugere que o sinal de RM, nas seqüências ponderadas em T1 e T2, é preferencialmente hiperintenso nas placas do tipo 4, visualizadas através de USG.

Em 7 segmentos carotídeos, as placas foram consideradas com ecogenicidade tipo 2. Comparando as alterações encontradas nos exames de USG com a RM, observa-se que entre $71,4 \%$ a $85,7 \%$ dos casos as seqüências ponderadas em T1 e T2 apresentaram elevação da intensidade de sinal. Não houve casos considerados normais através de RM, neste tipo de placa. 
Em 2 segmentos carotídeos, as placas foram consideradas com ecogenicidade tipo 1. Comparando as alterações encontradas nos exames de USG com a RM, observa-se que em $50 \%$ dos casos as seqüências ponderadas em T1 e T2 apresentaram elevação da intensidade de sinal e que em $50 \%$, o exame foi considerado normal.

Segundo a literatura, a elevação da intensidade de sinal ou o sinal intermediário em T1 e T2 podem corresponder, principalmente, a um componente fibroso na parede vascular e, em escassos casos, a placas com conteúdo lipídico ou hemorrágico (MERICKEL et al., 1988; YUAN et al., 1994; MARTIN et al.,1995; SKINNER et al., 1995; TOUSSAINT et al., 1996; YUAN et al., 1996a; VON INGERSLEBEN et al., 1997; YUAN et al., 2001b; QUICK et al., 2002).

Randoux et al. (2001) afirmaram que a RM apresenta capacidade suficiente para detectar alterações precoces nas paredes vasculares, embora não seja capaz de caracterizar com certeza os seus elementos constituintes.

A habilidade em monitorar alterações precoces de lesões ateroscleróticas, em seres humanos, tem importantes aplicações no estudo da patogênese da aterosclerose e em estudos clínicos, assegurando a eficácia nas terapias de redução das placas (THOMAS et al., 2001).

Vale ressaltar que placas com conteúdo lipídico ou hemorrágico se comportam na RM como placas hiperintensas, nas seqüências ponderadas em T1. Em T2, a intensidade de sinal varia (MERICKEL et al., 1988; YUAN 
et al., 1994; MARTIN et al.,1995; SKINNER et al., 1995; TOUSSAINT et al., 1996; YUAN et al., 1996a; VON INGERSLEBEN et al., 1997; YUAN et al., 2001b; QUICK et al., 2002).

Fica evidente que a ressonância magnética pôde detectar alterações de intensidade de sinal nas paredes vasculares na doença aterosclerótica carotídea, onde o grau leve de estenose foi predominante, sendo encontrado em maior proporção o aumento da intensidade de sinal, nas seqüências ponderadas em T1 e T2. Não pôde, portanto, diferenciar os componentes das placas. Estas alterações devem ser avaliadas com cautela. Não houve correlação entre as alterações encontradas nos exames de USG, referentes aos tipos de ecogenicidade das placas, com a intensidade de sinal nos exames de RM.

A angiografia por ressonância magnética é um método de investigação de irregularidades nas superfícies arteriais e avaliação do grau de estenose. O grau de estenose é considerado indicador do grau de severidade da doença aterosclerótica, embora não esteja sempre associado ao risco de eventos, como o ataque isquêmico transitório ou o acidente vascular cerebral (ANDERSON et al., 1992).

Os exames de angiografia por RM não identificam sinais de hemorragia intraplaca, o que recomenda o uso de técnicas especiais nãoinvasivas, que permitam demonstrar este tipo de alteração.

A angiografia por RM é um método para a avaliação do lúmen vascular, fornece boa resolução de imagem, porém não permite a 
caracterização morfológica das placas. Apresenta pouca sensibilidade na detecção de lesões precoces e na estimativa do volume das lesões (STARY et al., 1995). A maior limitação deste método diagnóstico, tanto nos exames com, quanto nos sem a administração do contraste paramagnético é a resolução espacial, notadamente nos graus de estenose leve e moderado (RANDOUX et al., 2001).

A ultra-sonografia com fluxo Doppler colorido é bastante utilizada na estimativa do grau de estenose e da severidade da doença (STARY et al., 1995) e seu uso é respaldado por consagrados estudos anteriores, que a recomenda como técnica de rastreamento de aterosclerose carotídea (ROEDERER et al., 1984; MONETA et al., 1989).

A limitação primária, tanto da angiografia por RM, quanto da ultrasonografia é a não visualização da expansão externa da placa aterosclerótica pela camada adventícia. Conseqüentemente, uma placa potencialmente instável pode não ser detectada, por não comprometer o lúmen e não causar estenose significativa (YUAN et al., 2001a).

Em nossos achados, houve reprodutibilidade marginal referente à estimativa do grau de estenose entre a UDC e ARM, com e sem contraste.

Durante o desenvolvimento da doença aterosclerótica, ocorre o espessamento do complexo íntima-média das artérias, que expõe ao risco de um acidente vascular cerebral, principalmente, aqueles indivíduos assintomáticos expostos aos demais fatores de risco conhecidos, dentre os quais se incluem a severidade do grau de estenose, a evidência de sintomas 
prévios e a constituição das placas ateroscleróticas (JENSEN-URSTAD et al., 1999).

A hipertensão arterial se caracteriza também como importante fator de risco para a doença cerebrovascular, estando mais freqüentemente associada ao AVC do que à doença coronariana (LOTUFO, 2000).

A freqüência de hipertensão arterial sistêmica na população estudada foi de $64,1 \%$ entre os indivíduos do sexo masculino e de $82 \%$ no sexo feminino. Dos 50 pacientes avaliados, cinco apresentaram história de AVC (três homens e duas mulheres), dos quais quatro com história de hipertensão arterial sistêmica. Avaliação detalhada das artérias carótidas internas do paciente não-hipertenso, realizada através de USG com fluxo Doppler colorido, classificou a estenose provocada pela placa aterosclerótica, na artéria carótida interna esquerda, como de grau VI (oclusão arterial). A ecogenicidade daquela placa foi classificada como do tipo 2 (predominantemente hipoecóicas com pequenas áreas hiperecóicas associadas). A identificação da área hipoecóica não pôde ser feita quanto à sua composição, pela dificuldade inerente à técnica de USG, que não consegue diferenciar a hemorragia de um componente lipídico. As áreas hiperecóicas associadas foram identificadas como calcificações, porque produziram sombras acústicas posteriores, levando a uma interpretação já bem documentada por ultra-sonografia.

Este mesmo segmento carotídeo foi avaliado através de RM, buscando-se caracterizar o grau de estenose e estudar as alterações da 
intensidade de sinal produzidas pela placa. A avaliação quanto ao grau de estenose, através de angiografia por ressonância magnética, confirmou a oclusão arterial visualizada através de análise ultra-sonográfica. A avaliação de alterações de intensidade de sinal, produzidas pelas placas nos exames de RM, mostrou áreas de aumento e redução da intensidade de sinal em todas as seqüências.

A comparação entre os achados de alterações da ecogenicidade das placas através da USG e as áreas de aumento e redução da intensidade de sinal pela RM mostrou:

- Áreas hiperecóicas produtoras de sombras acústicas posteriores, que correspondem a calcificações pelo exame de USG, apresentaram redução da intensidade de sinal em todas as seqüências avaliadas através da RM.

Não foi possível confirmar a composição das áreas que apresentaram redução da ecogenicidade da placa, através de USG e aumento da intensidade de sinal pela RM, já que nas seqüências ponderadas em 3D TOF, T1 e T2 o aumento da intensidade de sinal pode corresponder a áreas com componente lipídico ou hemorragia. Não se dispondo de confirmação histológica, não é possível firmar diagnóstico, podendo-se, entretanto, perceber a sensibilidade da ressonância magnética na detecção de alterações de sinal em placas ateroscleróticas.

A análise ultra-sonográfica da artéria carótida interna direita, do mesmo paciente, classifica o grau de estenose provocado pela placa aterosclerótica 
como leve (grau II), considera regular a superfície da artéria e caracteriza a ecogenicidade da placa como do tipo 4 (placa hiperecóica).

Avaliando-se o grau de estenose, agora utilizando a angiografia por RM, fica o mesmo classificado como moderado (grau III), quando examinado sem contraste e grau IV, quando se utilizou o contraste paramagnético. Registraram-se, portanto, diferenças de classificação quanto ao grau de estenose da artéria carótida interna direita deste paciente, segundo os métodos de diagnóstico utilizados.

Comparando-se a intensidade de sinal de RM com a ecogenicidade das placas, através de USG (tipo 4), percebe-se aumento da intensidade do sinal nas seqüências ponderadas em T1 e T2. Na seqüência ponderada em 3D TOF, observam-se áreas de aumento e redução da intensidade de sinal. As áreas de redução da intensidade de sinal, em todas as seqüências de RM, quando correlacionadas a áreas hiperecóicas, produtoras de sombras acústicas posteriores através de USG, correspondem a áreas de calcificações. As áreas que apresentaram aumento da intensidade de sinal em T1 e T2, em concordância com placas hiperecóicas, podem estar associadas a áreas de fibrose. Pelas características ultra-sonográficas, as placas do tipo 4 (hiperecóicas) correspondem à fibrose. Não foram detectadas zonas de redução de intensidade de sinal em T1 e T2.

Os demais quatro casos de acidente vascular cerebral apresentaram história de hipertensão arterial sistêmica. A avaliação das carótidas internas destes pacientes, feita pela USG, considerou como regular a superfície de 7 
segmentos, sendo 1 irregular. Estes apresentaram graus leve a moderado de estenose. A ecogenicidade das placas foi considerada como tipo 4 .

A avaliação destes segmentos carotídeos pela RM demonstrou variabilidade na deteç̧ão de alterações de intensidade de sinal. Houve aumento de intensidade de sinal em $37,5 \%$ dos casos e encontramos paredes consideradas normais em $62,5 \%$, nas seqüências ponderadas em T1 e T2 ("black-blood" e "fat sat black-blood").

As alterações de intensidade de sinal não foram captadas na seqüência 3D TOF, provavelmente devido à pouca sensibilidade do método, em caso de graus leves de estenose.

No primeiro caso, supõe-se que o AVC tenha sido decorrente da aterosclerose carotídea e, nos demais, de hipertensão arterial sistêmica.

A qualidade das imagens dos exames de ressonância magnética foram avaliadas em cada seqüência, com base em uma escala de cinco pontos, que classificou cada uma individualmente, segundo a relação sinalruído total, baseado na aparência visual, na presença de artefatos de fluxo, na conspicuidade e na arquitetura da parede vascular.

Foram excluídos do estudo os exames que apresentaram graus de qualidade I e II, oferecendo inadequado suporte diagnóstico. A qualidade total dos exames de ressonância magnética, nas diversas seqüências observadas, foi considerada como excelente (grau V) e muito boa (grau IV). 
Chama atenção o fato de que entre $54 \%$ a $70 \%$ dos exames, a qualidade das imagens foi considerada excelente, nas seqüências ponderadas em T1 e T2 "black-blood" e "fat sat black-blood". Na seqüência 3D TOF, 30\% dos exames apresentaram excelente qualidade.

As técnicas ponderadas em T1 e T2 permitiram melhor definição da interface lúmen-parede arterial, sendo possível a identificação dos bordos externos dos vasos, individualizando a camada adventícia em relação aos planos gordurosos adjacentes. A banda de redução da intensidade de sinal produzida pela camada média foi bem definida nestas seqüências. Foi possível perceber, entretanto, que na seqüência 3D TOF, apesar de muito boa qualidade de imagem, sendo percebida em $64 \%$ dos casos, observou-se facilmente a definição da interface lúmen-parede arterial devido ao efeito "bright-blood”, porém não foi possível a individualização do complexo íntimamédia ou da camada adventícia. Registraram-se também, nesta seqüência, a presença de artefatos de fluxo, responsáveis pela diminuição da qualidade das imagens. Observou-se que $52 \%$ das imagens adquiridas pela seqüência 3D TOF apresentaram distúrbio intraluminal de fluxo, que pode justificar a pouca sensibilidade desta seqüência na identificação de placas. Por ser a conspicuidade da capa de tecido fibroso dependente do contraste presente na mesma (interface lúmen/complexo íntima-média) foi difícil sua determinação, quando havia áreas de baixa intensidade de sinal adjacente ao espaço luminal. Assim, os estados de bandas hipointensas justaluminais em imagens 3D TOF foram obscurecidas, quando apresentaram artefatos de fluxo, não contribuindo, portanto, para a diferenciação proposta. 
A acurácia da análise das artérias carótidas foi influenciada, principalmente:

1. Pela calcificação justaluminal: em casos com calcificação no espaço justaluminal da placa, o lúmen pode ser superestimado nas imagens "black-blood", devido à redução da intensidade de sinal produzida pelo cálcio e o efeito "black-blood" (sangue preto); imagens ponderadas em 3D TOF podem, entretanto, fornecer informações complementares, devido à alta intensidade de sinal do sangue (efeito "bright-blood"), enquanto o cálcio permanece com redução da intensidade de sinal.

2. Pelo pequeno lúmen arterial: áreas com um lúmen reduzido podem produzir alterações na análise da parede vascular, pela falta de resolução espacial.

Analisamos também a qualidade das imagens nos exames de ARM. Sendo as imagens geradas em rotação lateral, torna-se possível a análise precisa do contorno vascular. Foram realizadas seqüências de angiografia por ressonância magnética, antes e após a administração do contraste paramagnético. Notou-se em nossos achados a supremacia de qualidade de imagem dos exames de angiografia por RM com contraste, considerados como excelentes, quando comparados com os exames sem o uso do contraste.

Dificuldades técnicas foram encontradas nos exames de USG, relacionadas à bifurcação carotídea alta e tortuosidade dos vasos, em alguns exames. 
A principal limitação do estudo nos exame de RM foi a movimentação do paciente, principalmente com a deglutição, assim como movimentos involuntários.

Embora tenhamos obtido em nosso estudo "in vivo" excelente qualidade de imagens, a resolução espacial não foi suficiente no detalhamento de placas, principalmente pela seqüência 3D TOF. Nesta seqüência, a presença de artefatos de fluxo também foi fator limitante.

Os resultados do estudo devem ser interpretados com moderação. O grau leve de estenose das lesões ateroscleróticas foi predominante na maior parte dos pacientes, não sendo possível maiores detalhamentos em lesões avançadas. Um estudo representativo na definição destas lesões requer um número maior de pacientes.

E finalmente, é difícil obter confirmação histológica dos resultados apresentados, embora não tenha sido objetivo do estudo. 


\section{CONCLUSÕES}


1. Foi observado, através de ressonância magnética e ultra-sonografia, alta incidência de aterosclerose carotídea, em pacientes coronariopatas, com indicação de terapia cirúrgica.

2. Houve boa correlação entre a estimativa do grau de estenose das artérias carótidas internas, realizadas por UDC com a avaliação visual do grau de estenose através de ARM com e sem contraste.

3. Não houve correlação entre a ecogenicidade das placas visualizadas através da ultra-sonografia, com a intensidade de sinal observada nos exames de ressonância magnética.

4. A qualidade das imagem dos exames de ressonância magnética, nas seqüências ponderadas em T1 e T2, foi considerada excelente e, em 3D TOF, muito boa. A qualidade de imagem dos exames de angiografia por ressonância magnética, com e sem contraste, foi considerada excelente.

5. Houve ótima reprodutibilidade inter-observadores, na avaliação dos exames de ressonância magnética. 
8. ANEXOS 
FIGURA 1 - Exemplo de artéria carótida interna direita, com características normais de sua parede, através de USG e RM. Imagens de ultra-sonografia em escalas de cinza e UDC. Imagens de ressonância magnética, com seqüências ponderadas em 3D TOF, T1-BB, T1-FSBB, T2-BB, T2-FSBB, além de angiografia por ressonância magnética, com e sem contraste. 


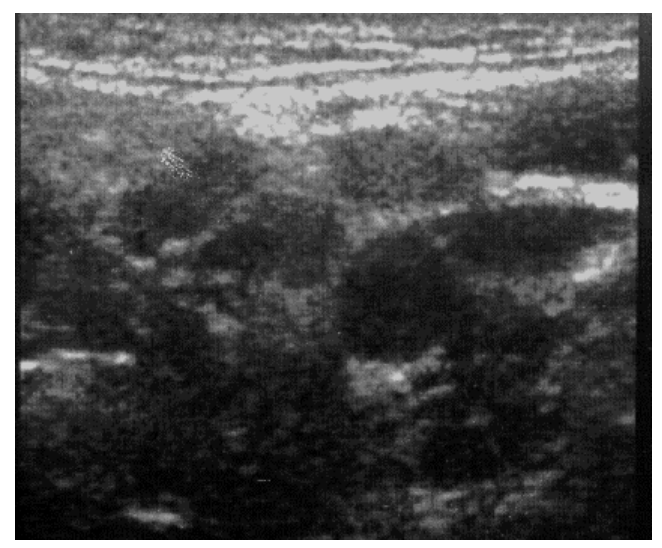

USG em escala de cinza

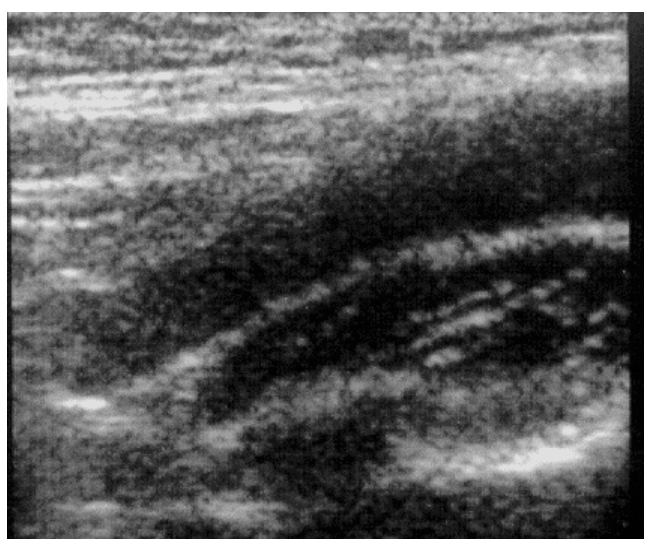

USG em escala de cinza

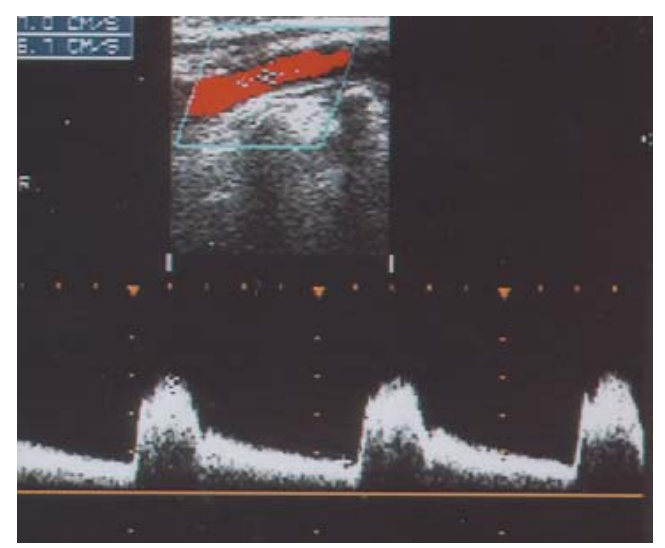

USG com fluxo Doppler colorido

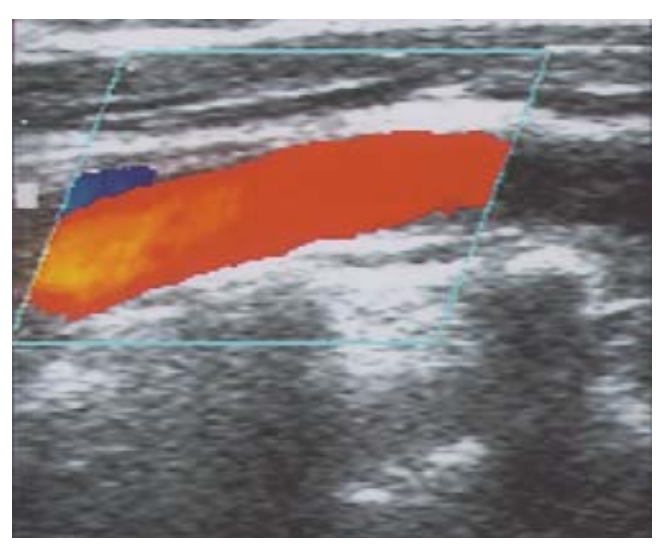

USG com fluxo Doppler colorido 


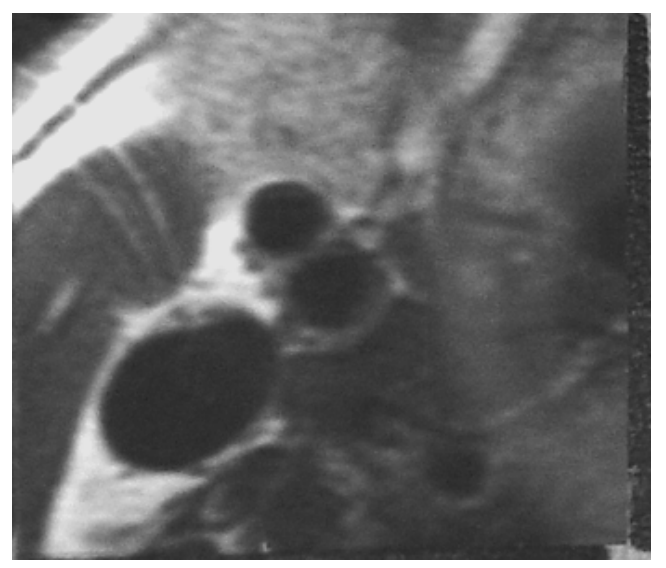

T1 - BB

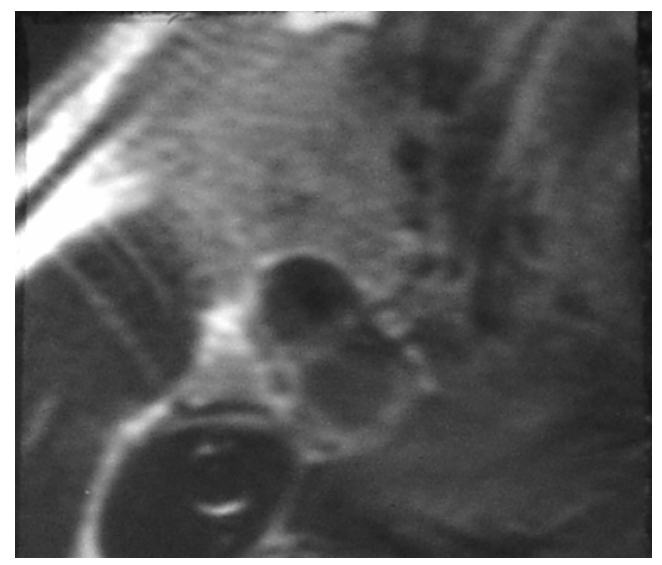

T2 - BB

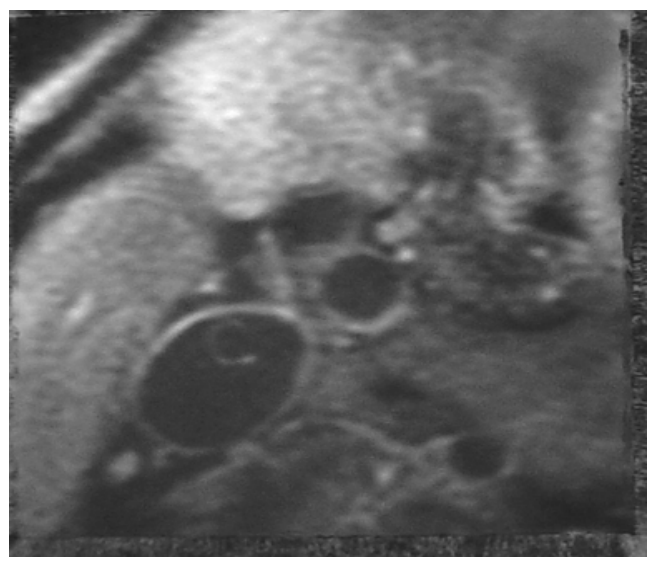

T1 - FSBB

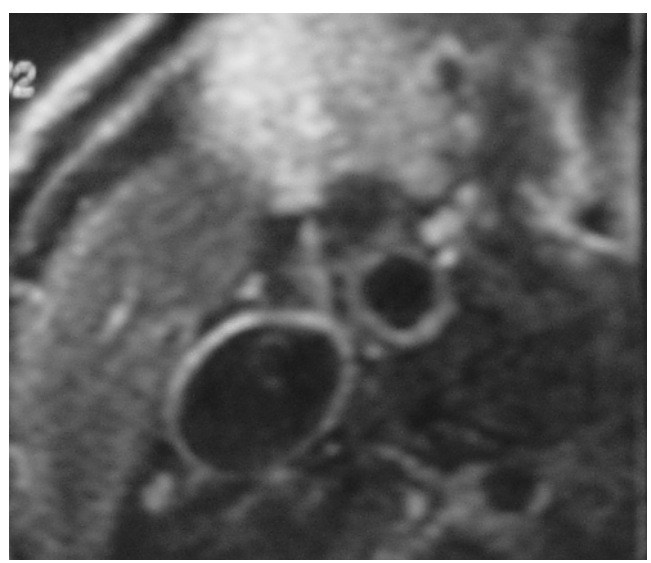

T2 - FSBB

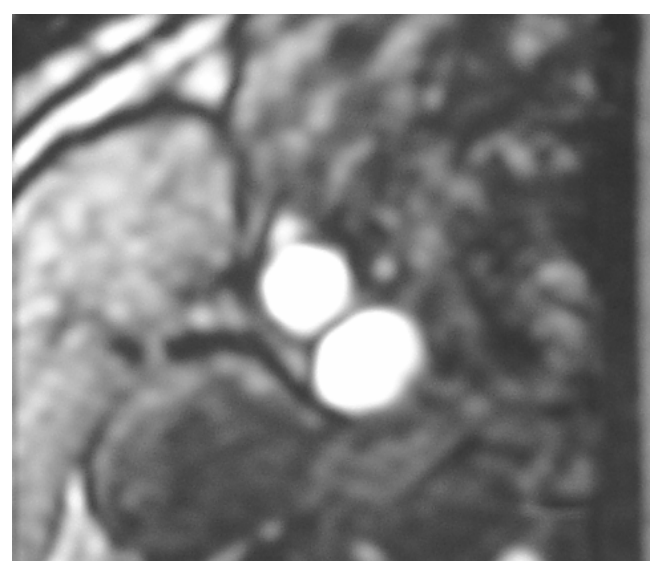

3D - TOF 


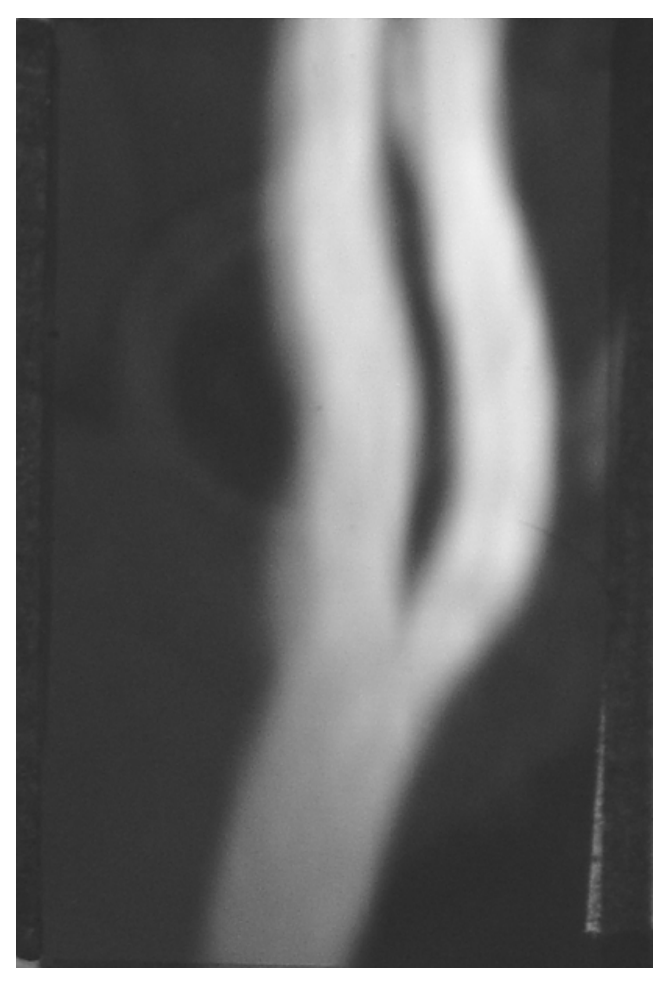

ARM sem contraste

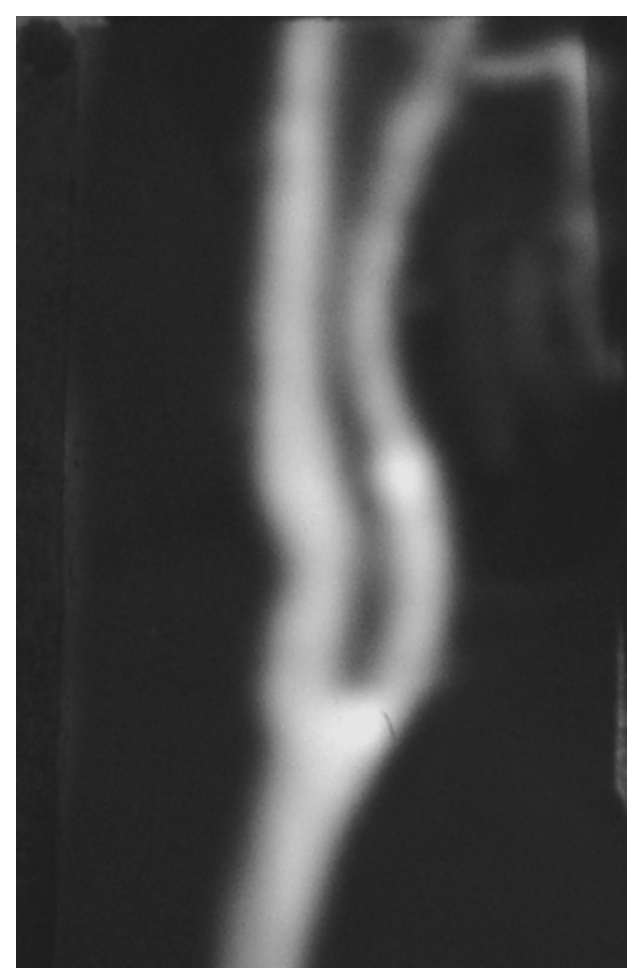

ARM com contraste 
FIGURA 2 - Exemplo de artéria carótida interna esquerda, apresentando leve espessamento parietal, caracterizando placa tipo 4, através de USG, e ausência de alteração de sinal nas imagens de RM. Imagens de ultra-sonografia em escalas de cinza e UDC. Imagens de ressonância magnética, com seqüências ponderadas em 3D TOF, T1-BB, T1-FSBB, T2-BB, T2-FSBB, além de angiografia por ressonância magnética, com e sem contraste. 


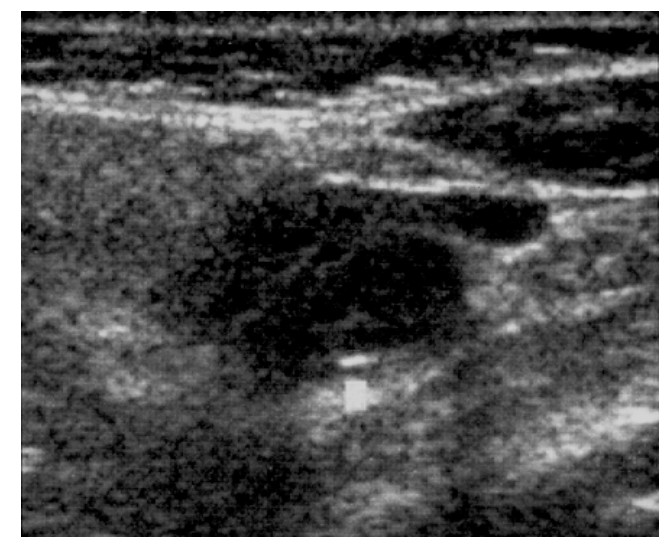

USG em escala de cinza

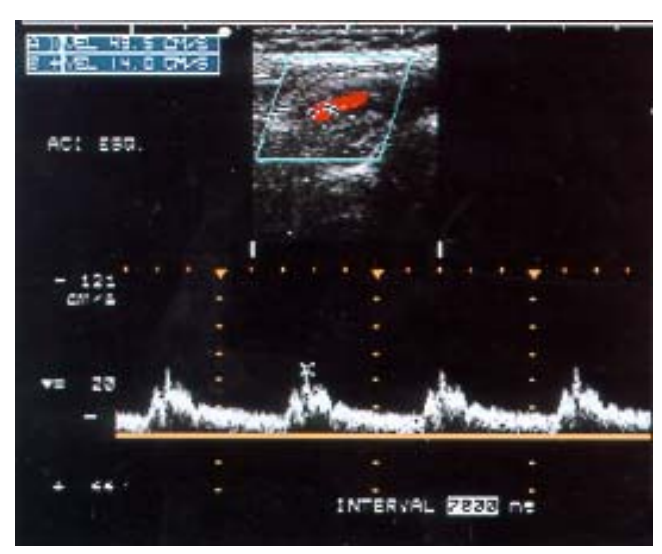

USG com fluxo Doppler colorido

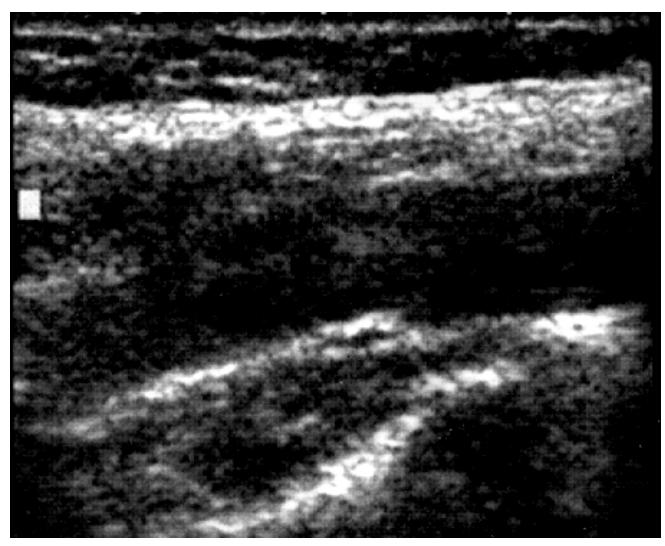

USG em escala de cinza

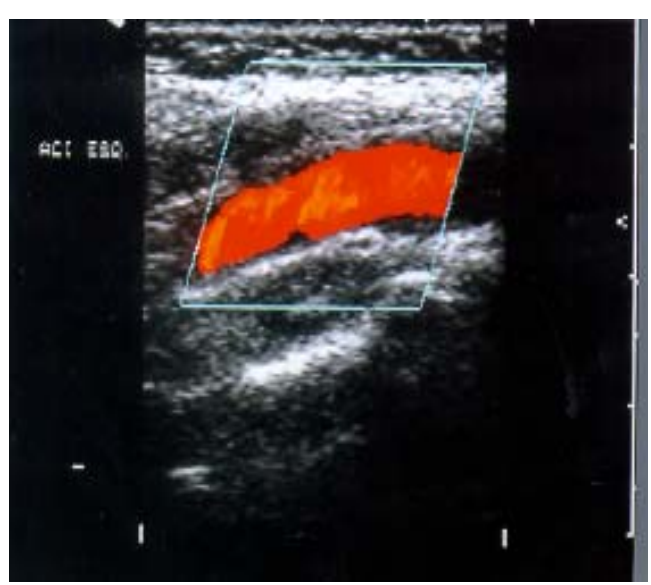

USG com fluxo Doppler colorido 


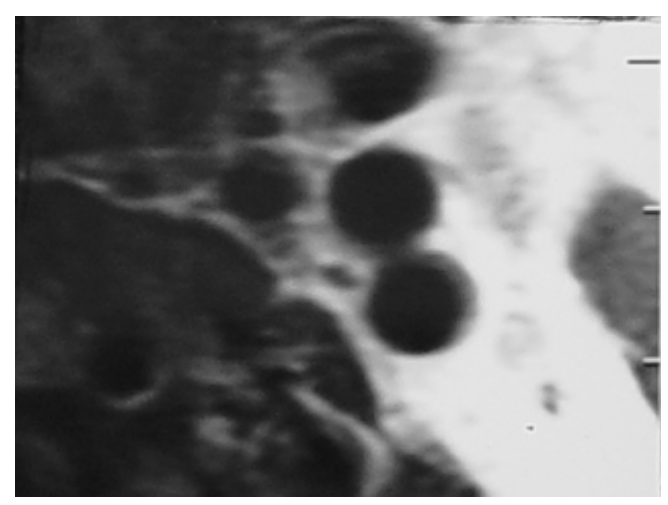

T1 - BB

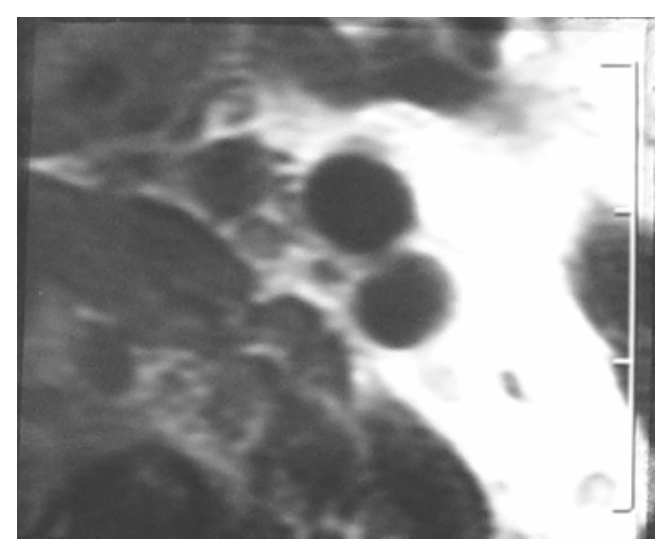

T2 - BB

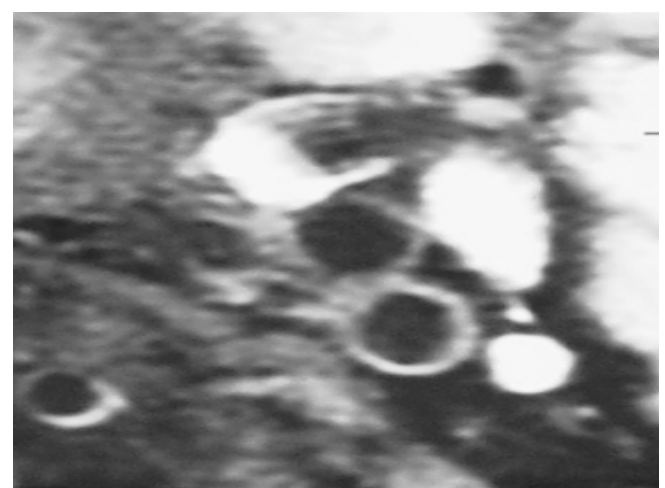

T1 - FSBB

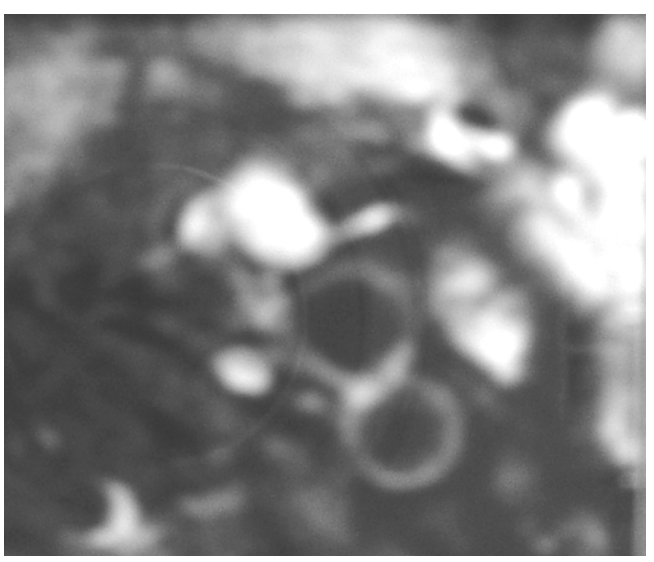

T2 - FSBB

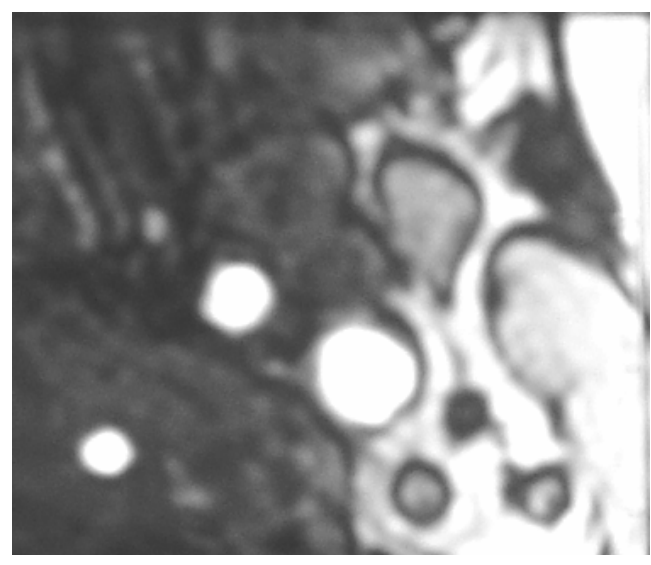

3D - TOF 


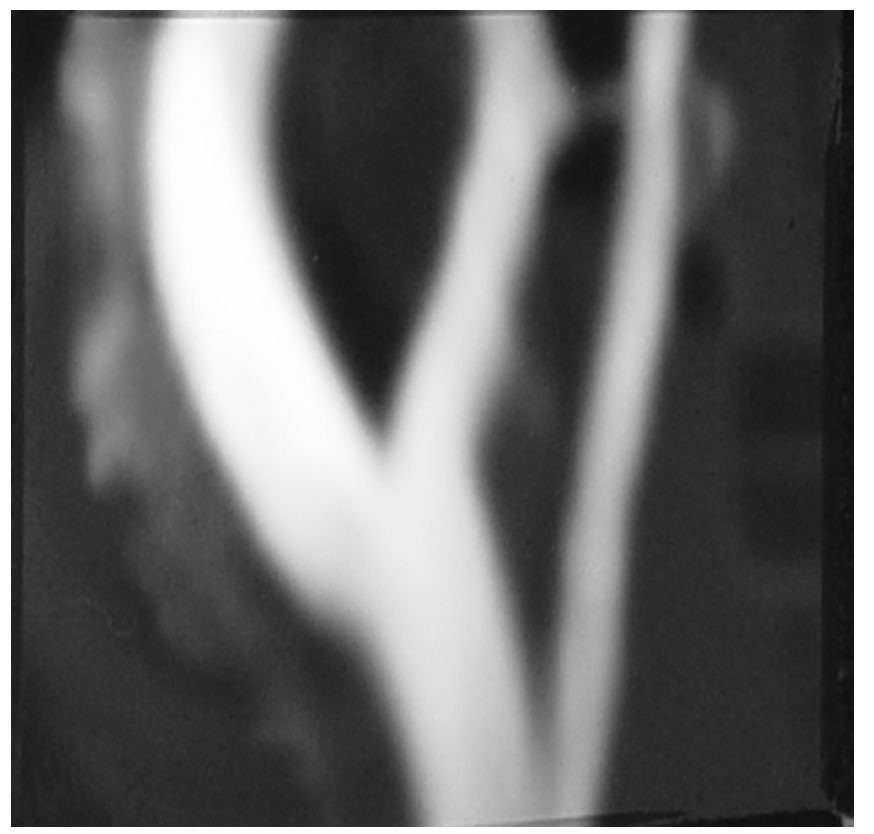

ARM com contraste

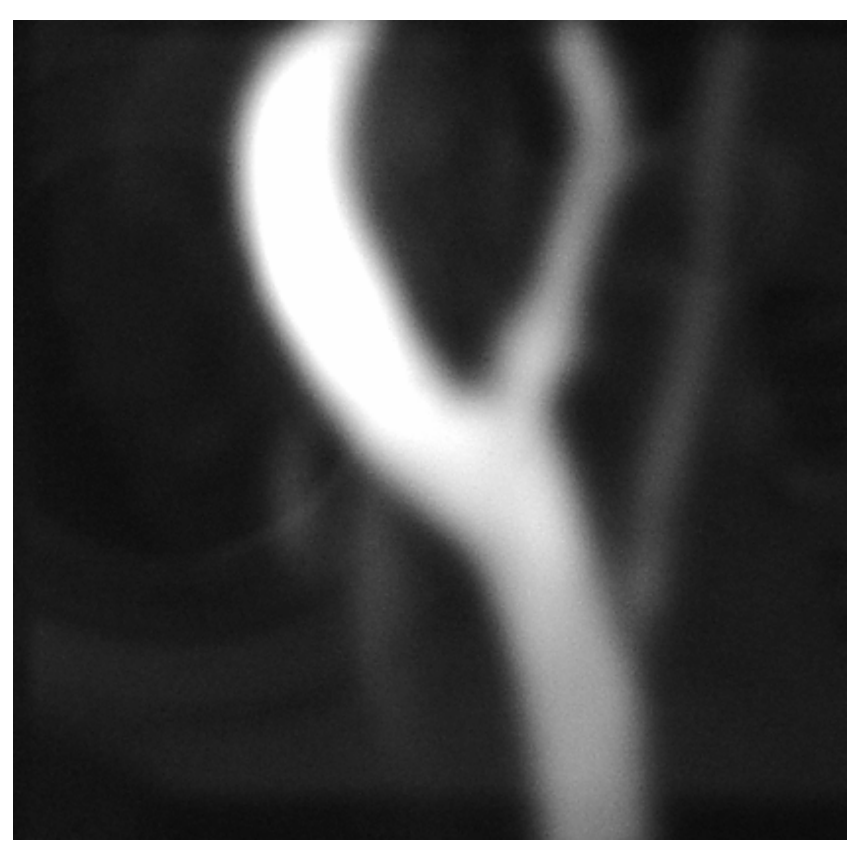

ARM sem contraste 
Figura 3 - Exemplo de artéria carótida interna esquerda, com espessamento do complexo íntima-média. Presença de placa tipo 4, ao exame de USG. Alteração de sinal nos exames de ressonância magnética, com predomínio de hipersinal, nas seqüências ponderadas em T1 e T2. Ausência de alteração de sinal, pela seqüência 3 D TOF. Presença de estenose grau II, através de UDC, e ausência de estenose, pelos exames de ARM, com e sem contraste. Imagens de ultra-sonografia em escalas de cinza e UDC. Imagens de ressonância magnética, com seqüências ponderadas em 3D TOF, T1-BB, T1-FSBB, T2-BB, T2-FSBB, além de angiografia por ressonância magnética, com e sem contraste. 


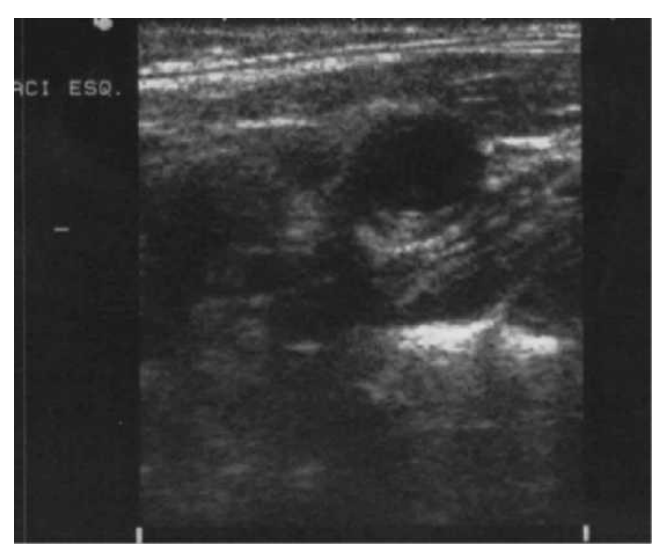

USG em escala de cinza

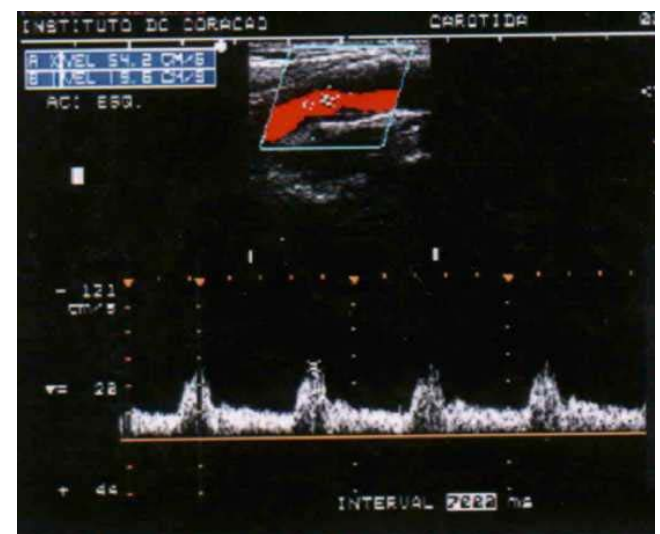

USG com fluxo Doppler colorido

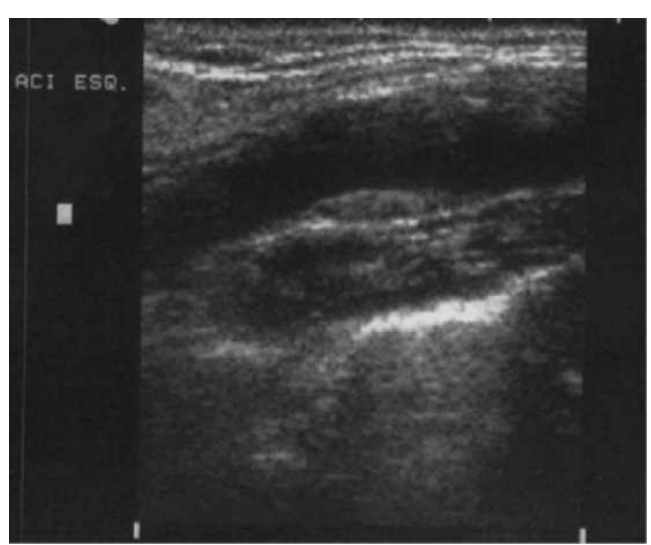

USG em escala de cinza

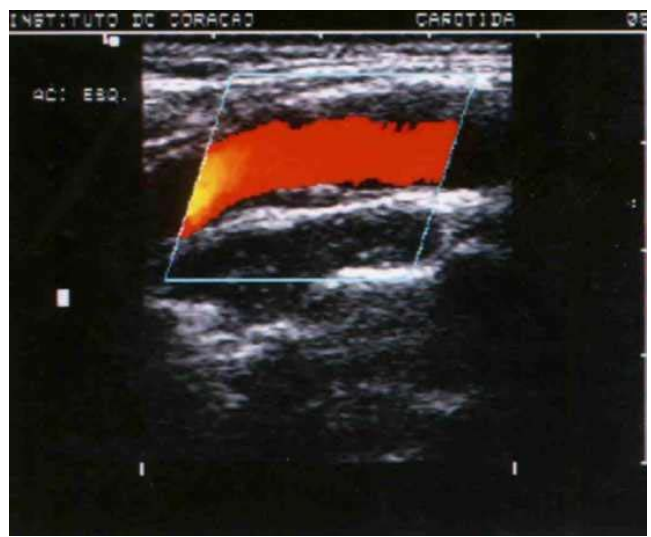

USG com fluxo Doppler colorido 


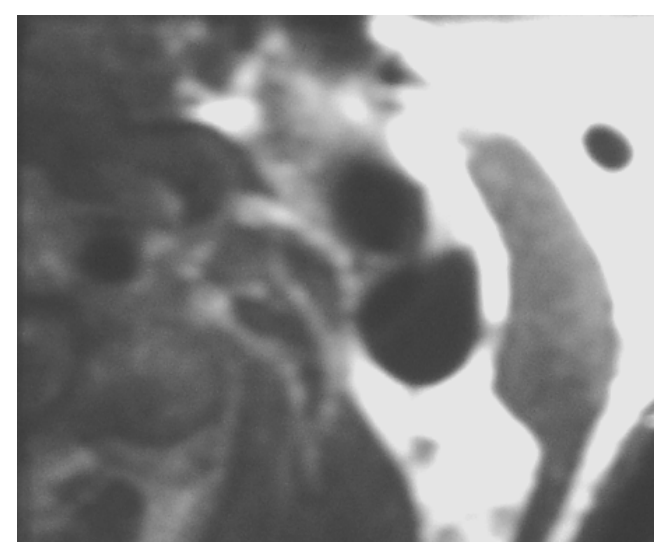

T1 - BB

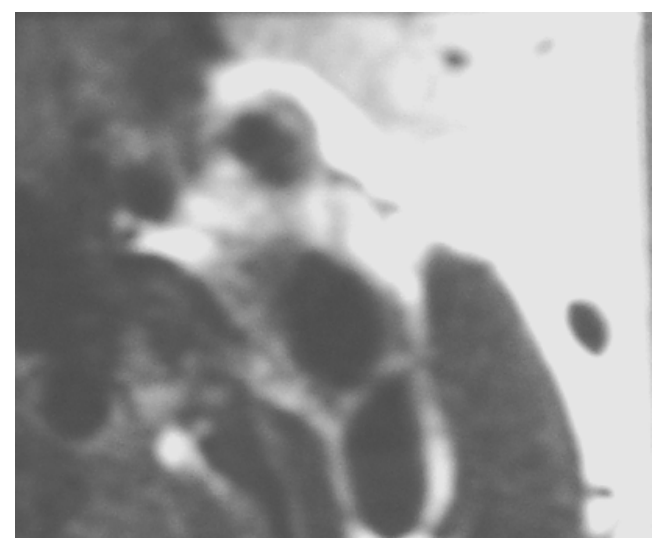

T2 - BB

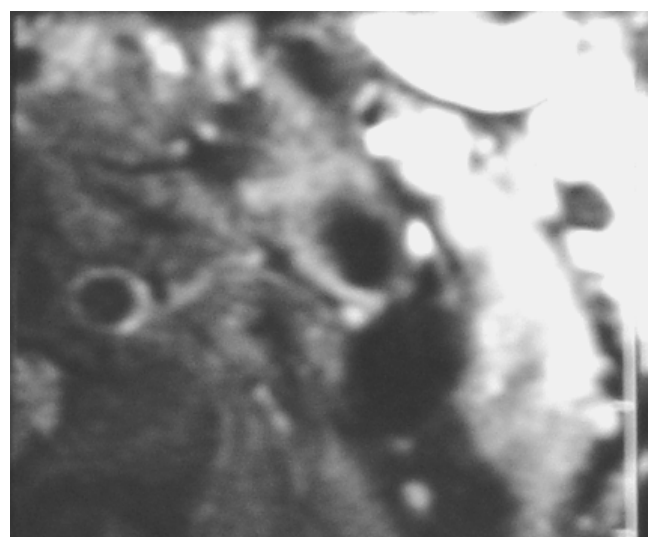

T1 - FSBB

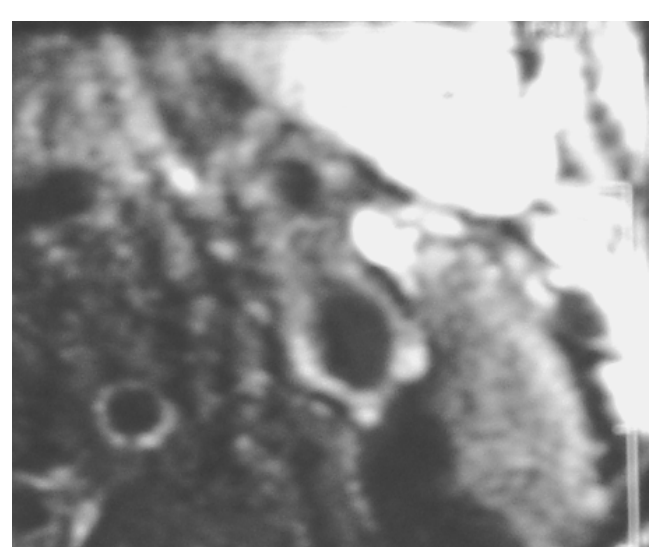

T2 - FSBB

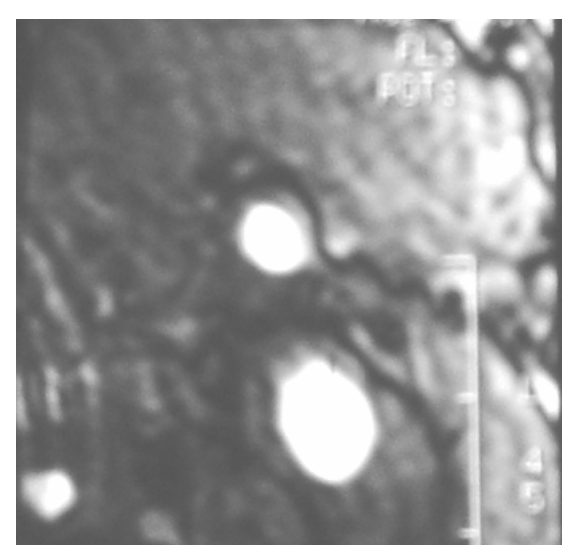

3D - TOF 


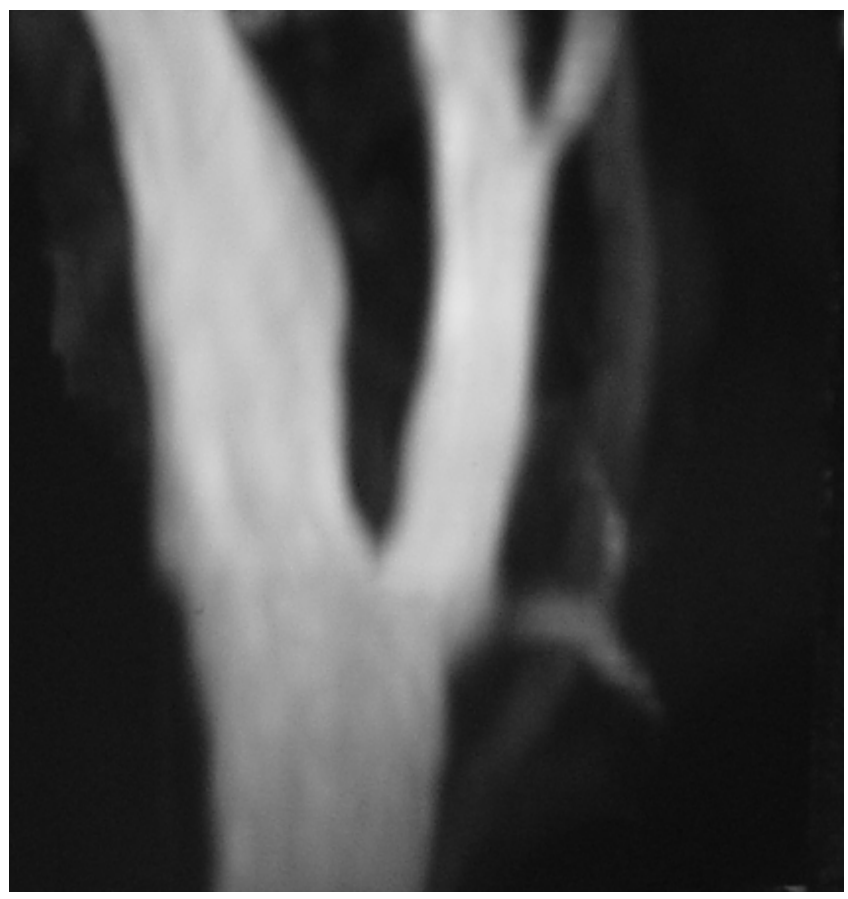

ARM sem contraste

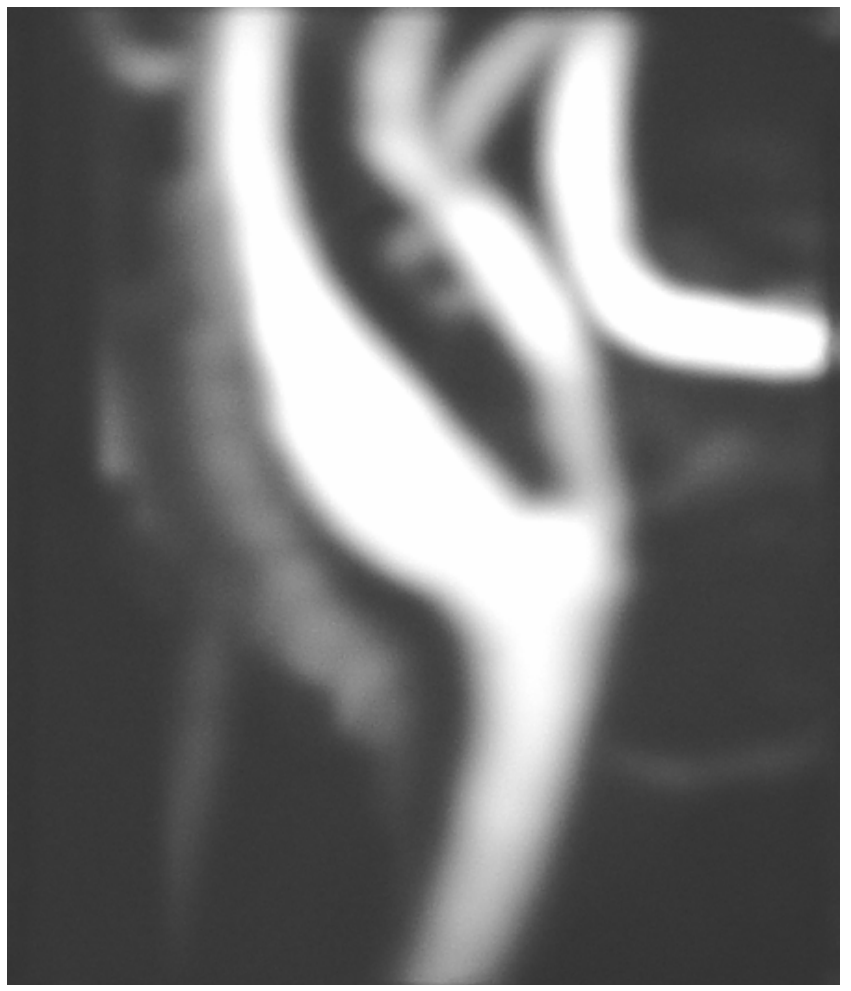

ARM com contraste 
FIGURA 4 - Exemplo de artéria carótida interna esquerda, com espessamento do complexo íntima-média. Presença de placa tipo 2, ao exame de USG. Alteração de sinal, nos exames de ressonância magnética, com predomínio de hipersinal, nas seqüências ponderadas em T1 e T2 (FSBB). Presença de estenose grau II, através de UDC, e ausência de estenose, pelos exames de ARM, com e sem contraste. Imagens de ultra-sonografia em escalas de cinza e UDC. Imagens de ressonância magnética, com seqüências ponderadas em $3 D$ TOF, T1-BB, T1-FSBB, T2-BB, T2-FSBB, além de angiografia por ressonância magnética, com e sem contraste. 


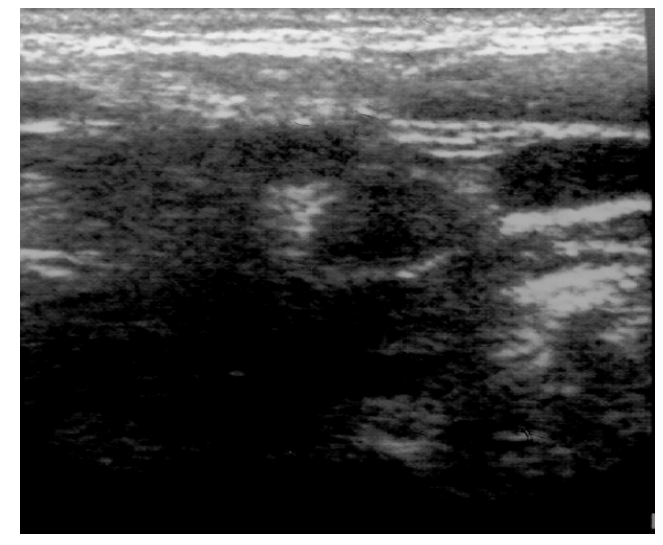

USG em escala de cinza

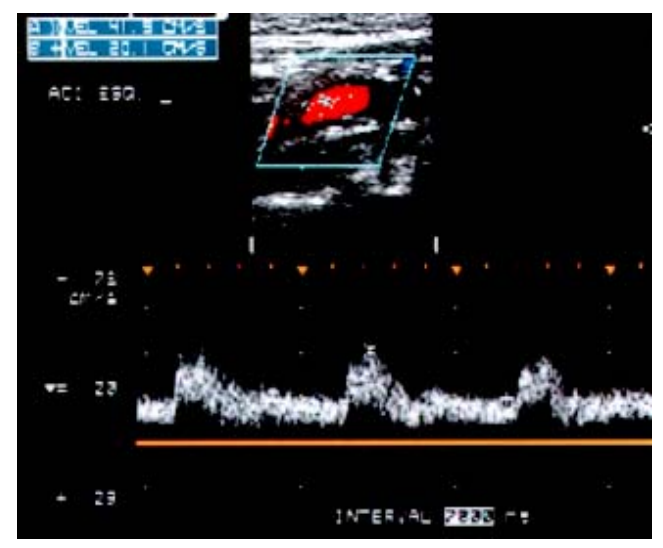

USG com fluxo Doppler colorido

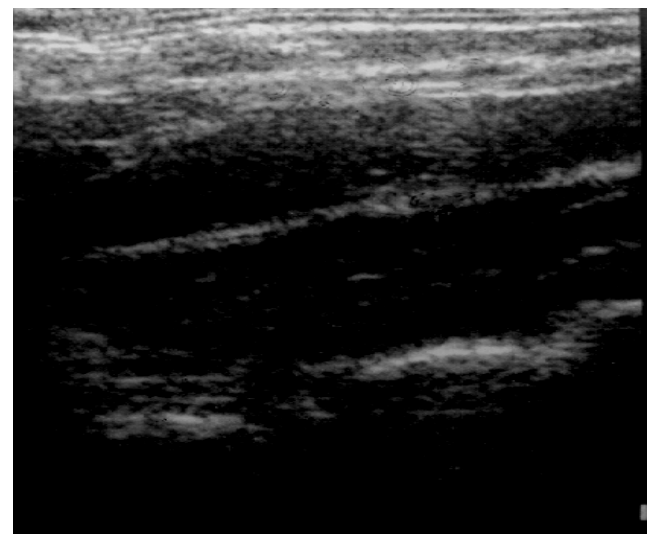

USG em escala de cinza

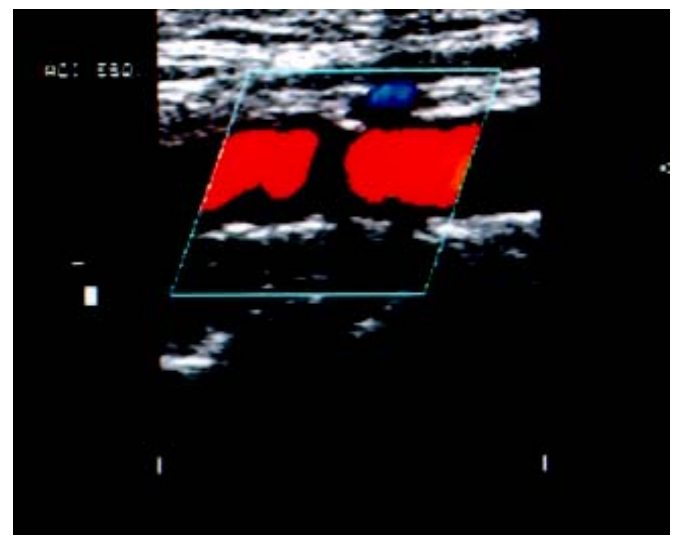

USG com fluxo Doppler colorido 


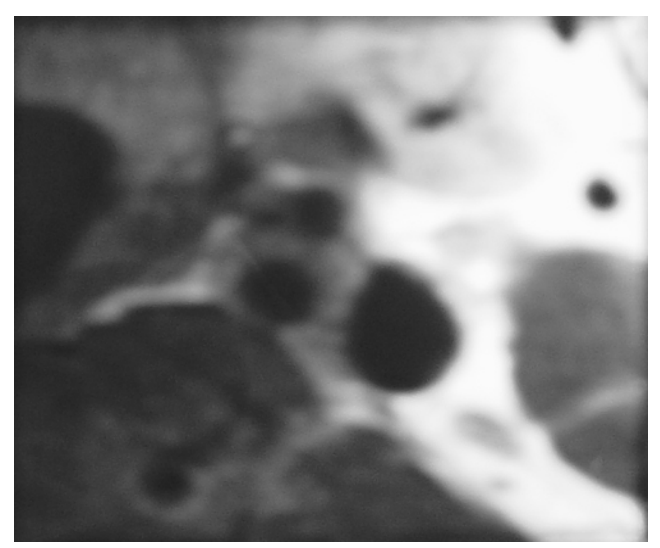

T1- BB

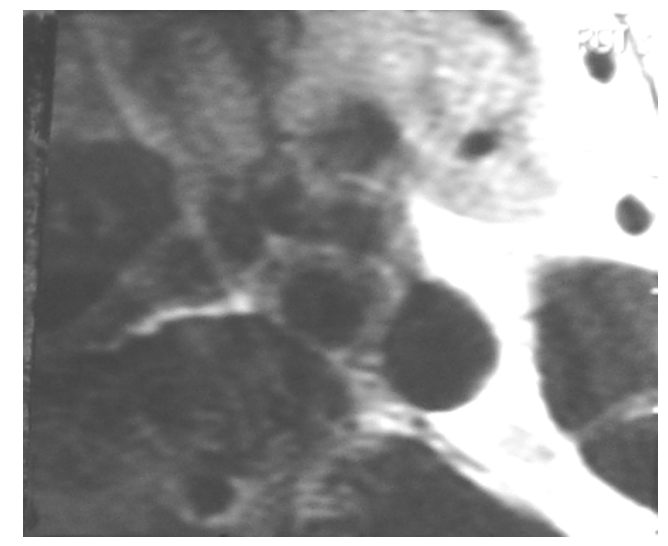

T2 - BB

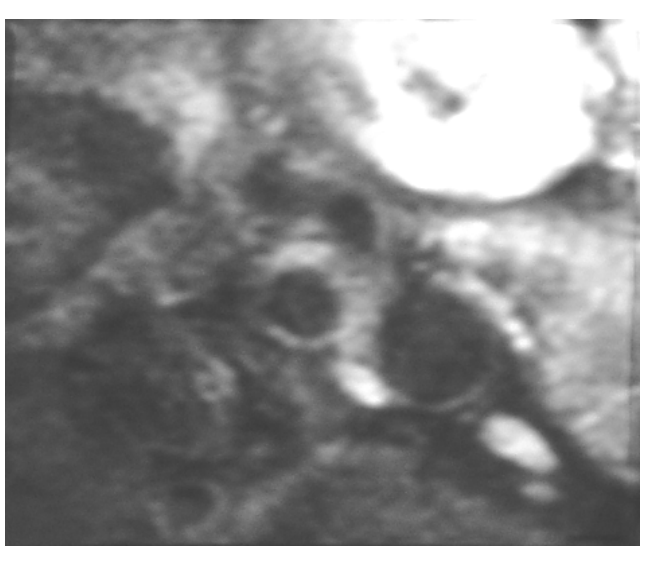

T1- FSBB

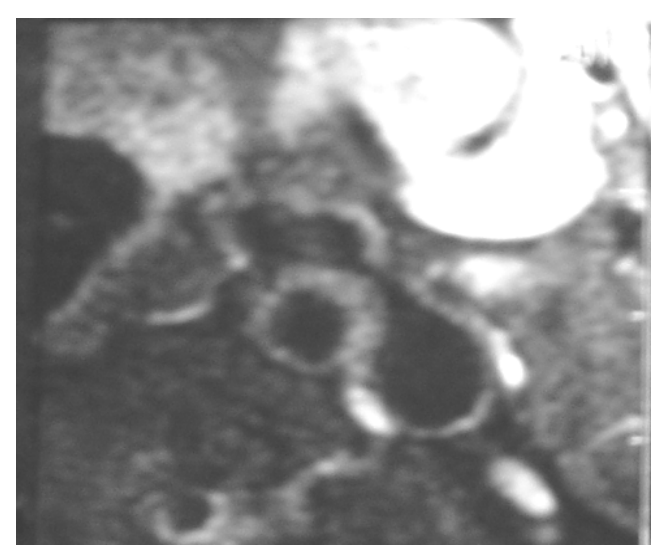

T2 - FSBB

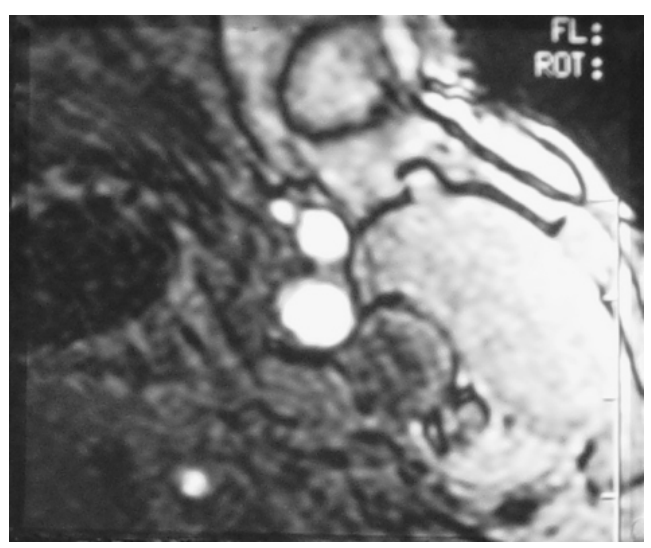

3D TOF 


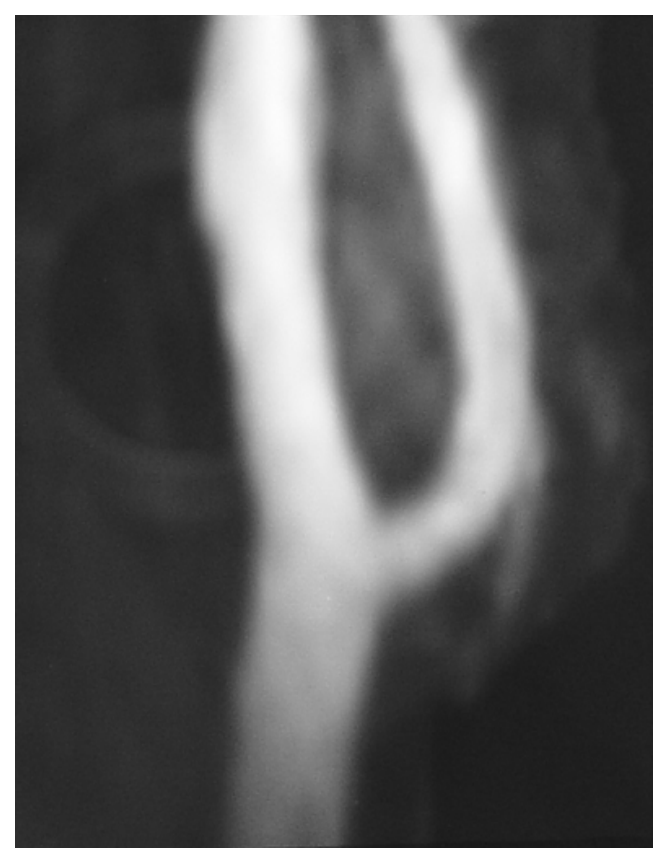

ARM sem contraste

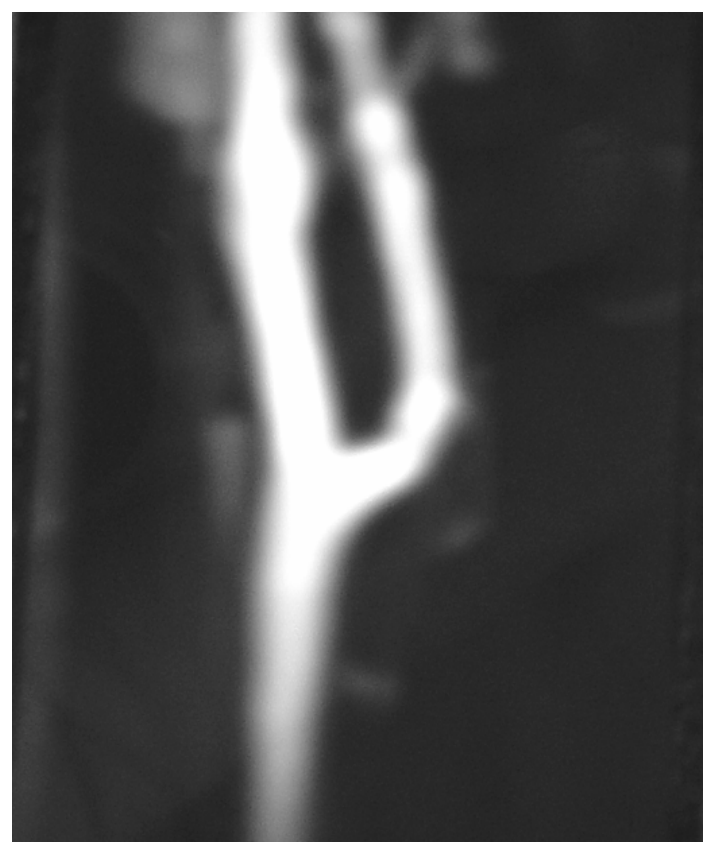

ARM com contraste 
FIGURA 5 - Exemplos de ARM, com e sem contraste, das artérias carótidas, avaliando graus de estenose e qualidade de imagens, em quatro casos. 


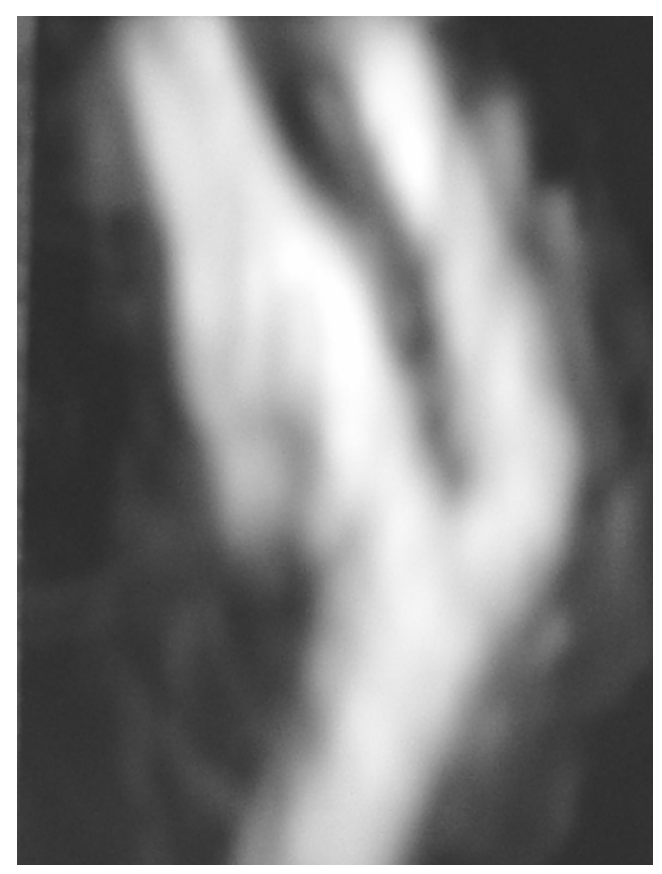

ARM sem contraste

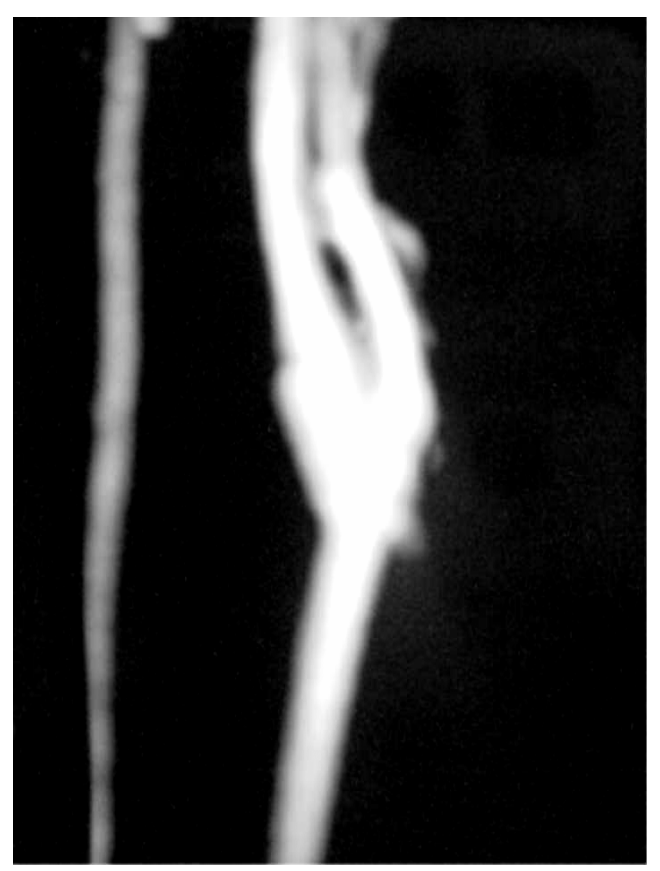

ARM com contraste 


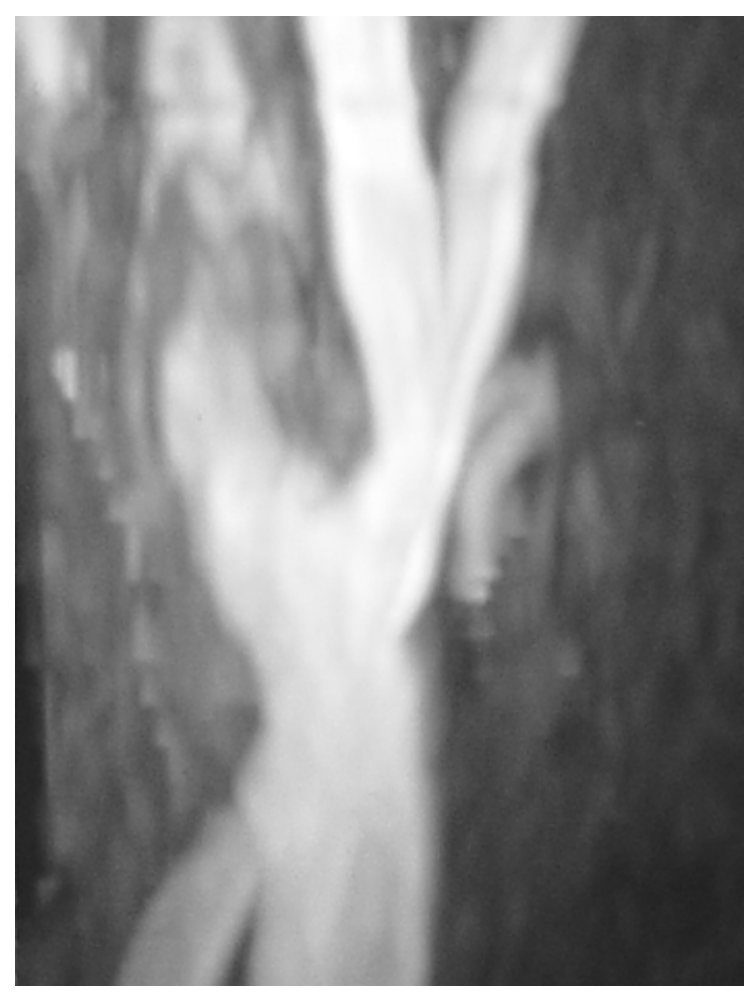

ARM sem contraste

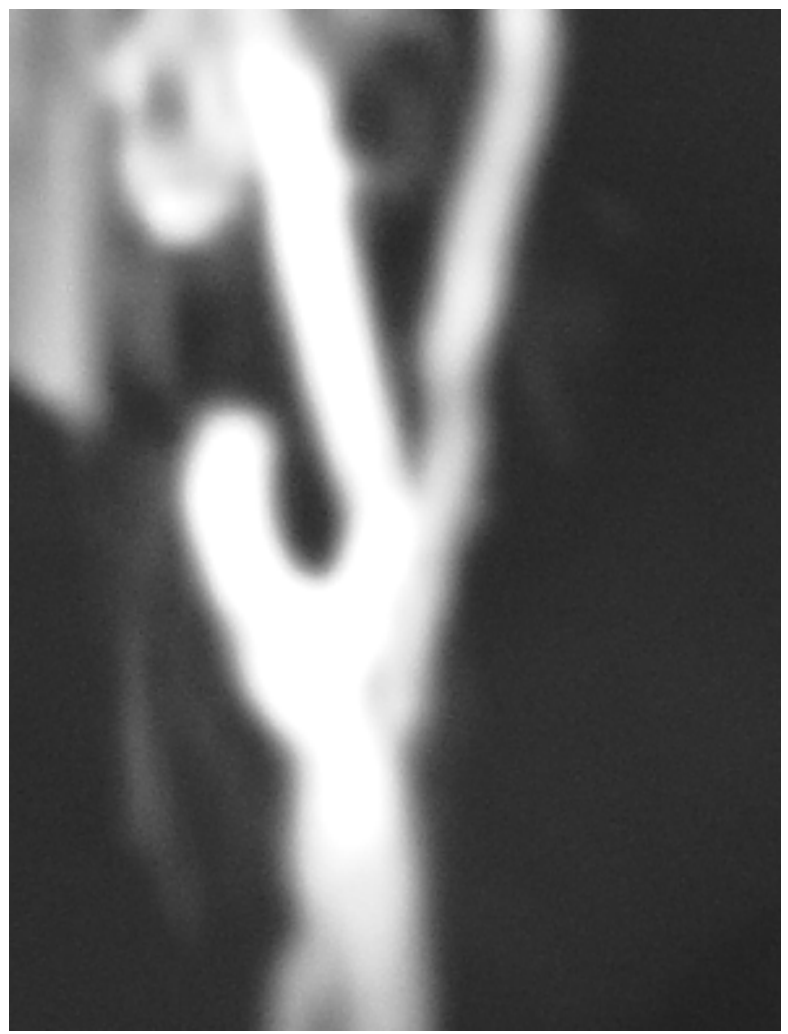

ARM com contraste 


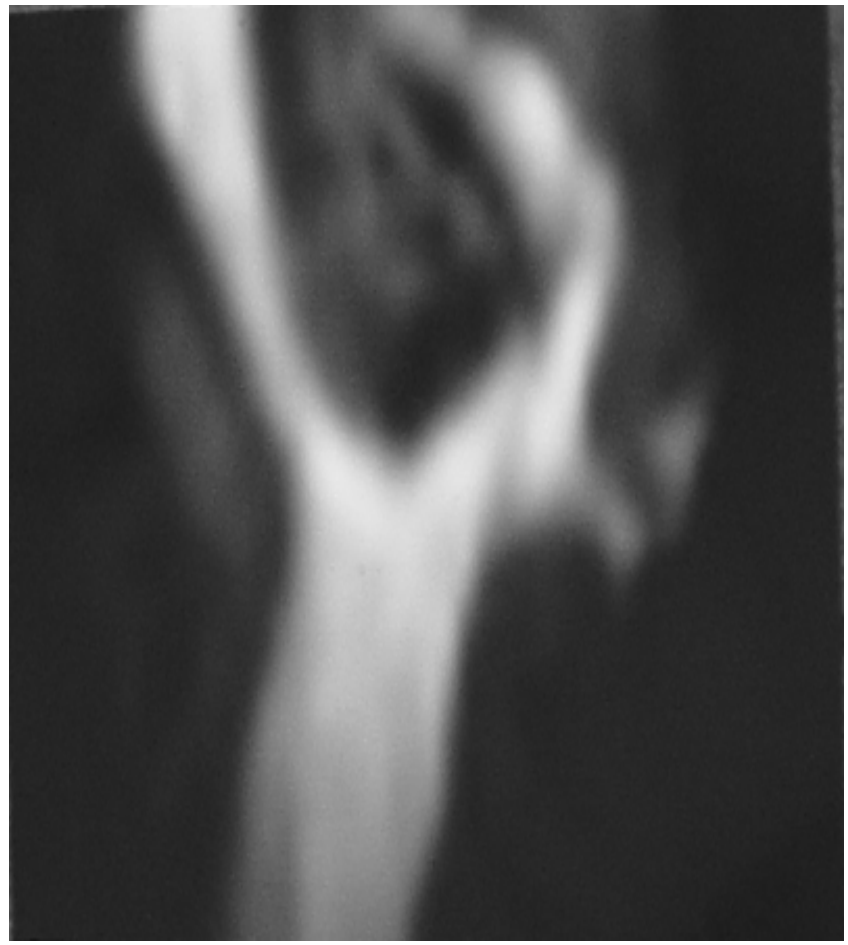

ARM sem contraste

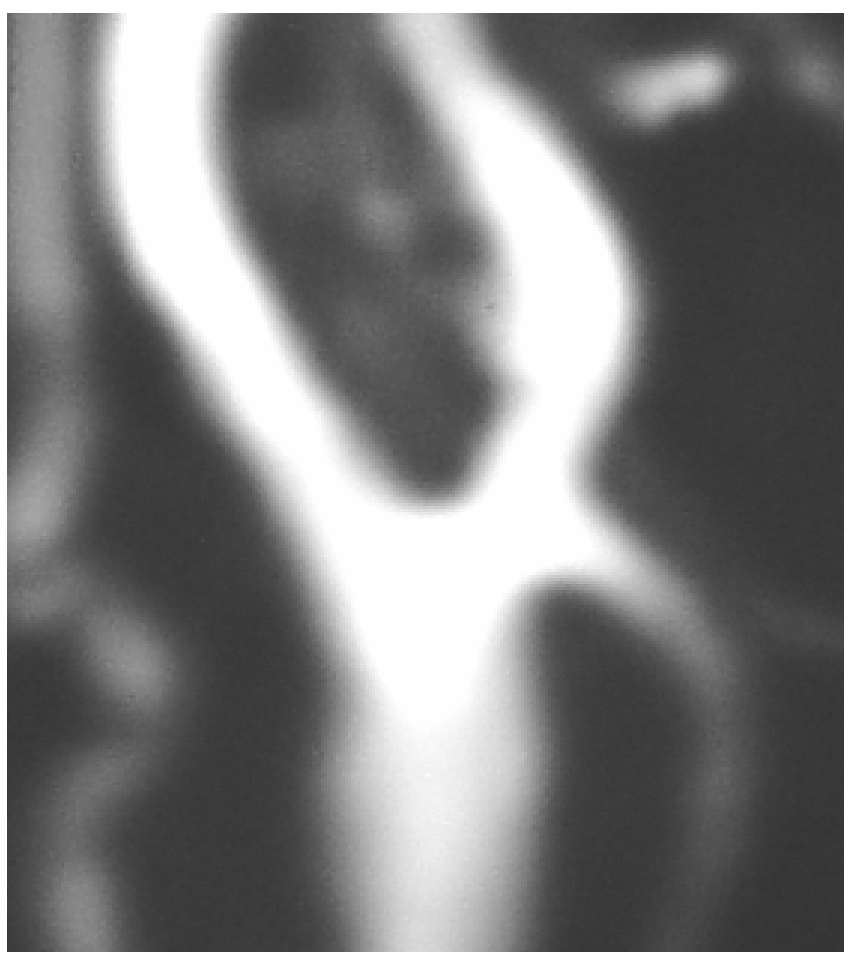

ARM com contraste 


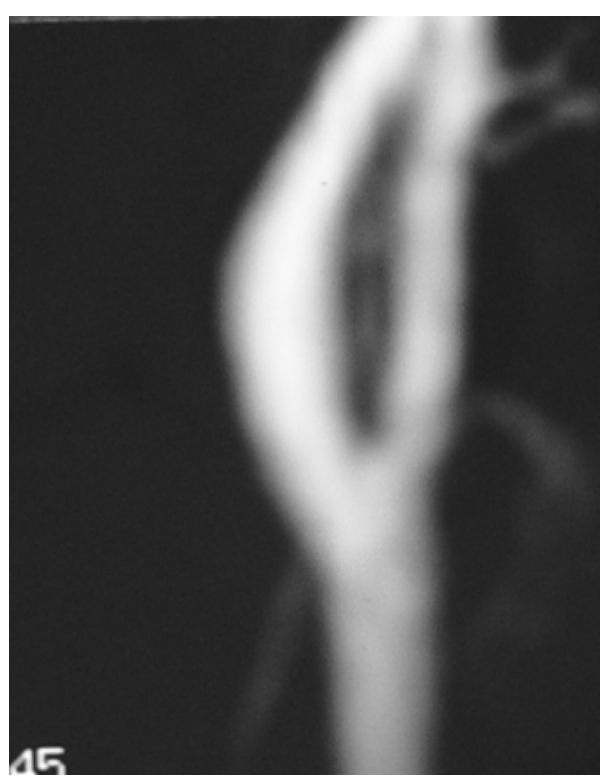

ARM sem contraste

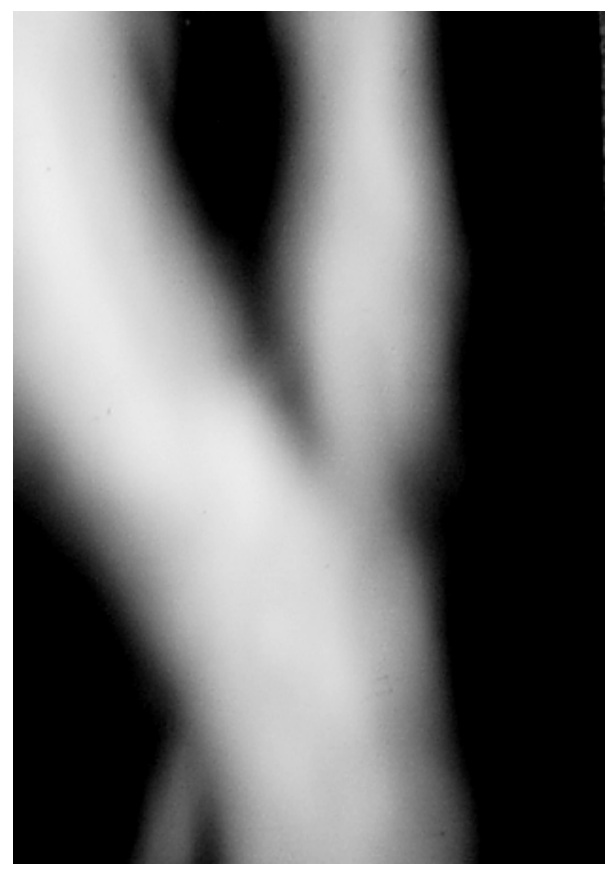

ARM com contraste 
ACAS. Clinical advisory: Carotid endarterectomy for patients with asymptomatic internal carotid artery stenosis. Stroke 1994;25:2523-24.

Aburahma AF, Wulu JT Jr., Crotty B. Carotid plaque ultrasonic heterogeneity and severity of stenosis. Stroke 2002;33:1772-5.

Alley MT, Shifrin RY, Pelc NJ, Herfkens RJ. Ultrafast contrast-enhanced three-dimensional MR angiography: state of the art. Radiographics 1998;18:273-85.

Anderson CM, Saloner D, Lee R, Griswold VJ, Shapeero LG, Rapp JH, Nagarkar S, Pan X, Gooding GAW. Assessment of carotid artery stenosis by MR angiography: comparison with x-ray angiography and color-coded Doppler ultrasound. Am J Neuroradiol 1992;3:989-1003.

Arnold A, Taylor P, Poston R, Modaresi K, Padayachee S. An objective method for grading ultrasound images of carotid artery plaques. Ultrasound Med Biol 2001;27(Suppl 8):1041-7.

Arroyo LH, Lee RT. Mechanisms of plaque rupture: mechanical and biologic interaction. Cardiovasc Res 1999;41:334-44.

Ambrose JA, Winters SL, Arora RR. Angiografic evolution of coronary artery morphology in instable angina. J Am Coll Cardiol 1986;7:472-8.

Ambrose JA, Tannenbaum MA, Alexoponlos D. Angiographic progression of coronary artery disease and the development of miocardial infarction. $J \mathrm{Am}$ Coll Cardiol 1988;12:56-62.

Aoki S, Nakajima H, Kumagai H, Araki T. Dynamic contrast-enhanced MR angiography and MR imaging of the carotid artery: high-resolution sequences in different acquisition planes. Am J Neuroradiol 2000;21:381-5. 
Barbano EF, Newman GE, McCann RL, Hackel DB, Stack RS, Palmos LE. Correlation of clinical history with quantitative histology of lower extremity atheroma biopsies obtained with the Simpson atherectomy catheter. Atherosclerosis 1989;78:183-96.

Barger AC, Beeuwkes R, Lainey LL, Silverman KJ. Hypothesis: vasa vasorum and neovascularization of human coronary arteries. A possible role in the pathophysiology of atherosclerosis. N Engl J Med 1984;310:175-7.

Belcaro G, Laurora G, Cesarone MR, De Sanctis MT, Incandela L, Fascetti E. Ultrasonic classification of carotid plaques causing less than $60 \%$ stenosis according to ultrasound morphology and events. J Cardiovasc Surg 1993;34:287-94.

Bots ML, Witteman JCM, Grobbee DE. Carotid intima-media wall thickness in elderly women with and without atherosclerosis of the abdominal aorta. Atherosclerosis 1993;102:99-105.

Bots M.L, Hoes AW, Koudstaa PJ, Hofman A, Grobbee DE. Common carotid intima-media thickness and risk of stroke and myocardial infarction. Circulation 1997;96:1432-7.

Burke GL, Evans GW, Riley WA, Sharrett AR, Howard G, Barnes RW. Arterial wall thickness is associated with prevalent cardiovascular disease in middle-aged adults. The Atherosclerosis Risk in Communities (ARIC) Study Stroke 1995;26:386-91.

Cai JM, Hatsukami TS, Ferguson MS, Small R, Polissar NL, Yuan C. Classification of human carotid atherosclerotic lesions with in vivo multicontrast magnetic resonance imaging. Circulation 2002;106:1368-73. 
Carroll BA, Von Ramm OT. Fundamentals of current Doppler technology. Ultrasound Q 1988;6:275-98.

Chaturvedi S. Public health impact of carotid endarterectomy. Neuroepidemiology 1999;18:15-21.

Connors JJ, Seidenwurm D, Wojak JC. Treatment of atherosclerotic disease at the cervical carotid bifurcation: current status and review of the literature. $A$ J Neuroradiol 2000;21:444-50.

Crouse JR, Craven TE, Hagaman AP, Bond MG. Association of coronary disease with segment-specific intimal-medial thickening of the extracranial carotid artery. Circulation 1995;92:1141-7.

DATASUS. Secretaria Executiva do Ministério da Saúde. http://www.datasus.gov.br/.

Davies MJ, Thomas AC. Plaque fissuring: the cause of acute myocardial infarction, sudden ischemic death, and crescendo angina. $\mathrm{Br}$ Heart $\mathrm{J}$ 1985;53:363-73.

Davies MJ. A macro and micro view of coronary vascular insult in ischemic heart disease. Circulation 1990;82:1138-146.

Davies MJ, Richardson PD, Woolf N, Katz DR, Mann J. Risk of thrombosis in human atherosclerotic plaques: role of extracellular lipid, macrophage, and smooth muscle cell content. Br Heart J 1993;69:377-81.

DeBray JM, Baud JM. Dauzat M. Consensus concerning the morphology and the risk of carotid plaques. Carotid Plaque Ultrasonic Heterogeneity and Severity of Stenosis. Cerebrovasc Dis 1997;7:289-96. 
ESCT. Randomised trial of endarterectomy for recently symptomatic carotid stenosis. European Carotid Surgery Trial. Lancet 1998;351:1379-87.

Falk E. Why do plaques rupture? Circulation 1992;86(Suppl 3):30-42.

Fazio GP, Redberg RF, Winslow T, Schiller NB. Transesophageal echocardiographically detected atherosclerotic aortic plaque is a marker for coronary artery disease. J Am Coll Cardiol 1993,21:144-50.

Fayad ZA, Fallon JT, Shinnar M, Wehrli S, Dansky HM, Poon M. Noninvasive in vivo high-resolution magnetic resonance imaging of atherosclerotic lesions in genetically engineered mice. Circulation 1998;15:1541-7.

Fayad ZA, Fuster V. Clinical imaging of the high-risk or vulnerable atherosclerotic plaque. Circulation 2001;89:305-16.

Fisher M, Blumenfeld AM, Smith TW. The importance of carotid artery plaque disruption and hemorrhage. Arch Neurol 1987;44:1086-9.

Fryer JA, Myers PC, Appleberg M. Carotid intraplaque hemorrhage: the significance of neovascularity. J Vasc Surg. 1987;6:341-9.

Geroulakos G, Sabetai MM. Ultrasonic carotid plaque morphology. Archives of Hellenic Medicine 2000;17(Suppl 2):141-5.

Gray-Weale AC, Graham JC, Burnett JR, Byrne K, Lusby R. Carotid artery atheroma: comparison of preoperative B-mode ultrasound appearance with carotid endarterectomy specimen pathology. $J$ Cardiovasc Surg 1988;29:676-81. 
Gronholdt MLM, Nordestgaard BG, Wiebe MB, Wilhjelm JE, Sillesen H. Echo-lucency of computerized ultrasound images of carotid atherosclerotic plaques are associated with increased levels of triglyceride-rich lipoproteins as well as increased plaque lipid content. Circulation 1998;97:34-40.

Grundy SM, Pasternak R, Greenland P, Smith S Jr., Fuster V. Assessment of cardiovascular risk by use of multiple-risk-factor assessment equations: a statement for healthcare professionals from the American Heart Association and the American College of Cardiology. Circulation 1999;100:1481-92.

Guyton JR, Black BL, Seidel CL. Focal toxicity of oxysterols in vascular smooth muscle cell culture: a model of the atherosclerotic core region. Am J Pathol 1990;137:425-34.

Hall PM. Hypertension in women. Cardiology 1990;77(Suppl 2):25-30.

Hatsukami TS, Ross R., Polissar NL, Yuan C. Visualization of fibrous cap thickness and rupture in human atherosclerotic carotid plaque in vivo with high-resolution magnetic resonance imaging. Circulation 2000;102:959-64.

Heiss G, Sharett AR., Barnes R., Chambless LE, Szklo M, Alzola C, and the ARIC investigators. Carotid atherosclerosis measured by B-mode ultrasound in populations: associations with cardiovascular risk factors in the ARIC study. Am J Epidemiol 1991;134:250-6.

Helgason CM, Wolf PA. American Heart Association Prevention Conference IV: Prevention and Rehabilitation of Stroke. Circulation 1997;67:701-7.

Jensen-Urstad K, Jensen-Urstad MM, Johansson J. Carotid artery diameter correlates with risk factors for cardiovascular disease in a population of 55 year-old subjects. Stroke 1999;30:1572-6. 
Joakimsen O, Bonaa KH, Bugge ES. Reproducibility of Ultrasound Assessment of Carotid Plaque Occurrence, Tromso Study. Stroke 1997;28:2201-7.

Kang X, Polissar NL, Han C, Lin E, Yuan C. Analysis of the measurement precision of arterial lumen and wall areas using high-resolution MRI. Mag Reson Imaging 2000;44:968-72.

Khoury Z, Schwartz R., Gottlieb S, Chenzbraun A, Stern S, Keren A. Relation of coronary artery disease to atherosclerotic disease in the aorta, carotid, and femoral arteries evaluated by ultrasound. Am J Cardiol 1997;80:1429-33.

Kligman EW, Pepin E. Prescribing physical activity for older patients. Geriatrics 1992;47:33-47.

Kohler TR. Imaging of carotid artery lesions: a surgeon's view. In: Fuster V. Syndromes of atherosclerosis: correlations of clinical imaging and pathology. Armonk, NY: Futura Publishing Company, Inc.;1996:205-23.

Laurenti R. Aterosclerose: importância, aspectos epidemiológicos. Estudo central do problema no Brasil e em São Paulo. Cardiologia 1987;1:162-9.

Leen EJ, Feeley TM, Colgan M.P, O'Malley MK, Moore DJ, Hourihane DO, Shanik GD. "Haemorrhagic" carotid plaque does not contain haemorrhage. Eur J Vasc Surg 1990;4:123-8.

Leung DA, McKinnon GC, Davis CP, Pfammatter T, Krestin GP, Debatin JF. Breath-hold, contrast-enhanced, three-dimensional MR angiography. Radiology 1996;200:569-71.

Lotufo A.P. Mortalidade pela doença cerebrovascular no Brasil. Rev Bras Hipertens 2000;4:387-91. 
Lusby RJ, Ferrell LD, Ehrenfeld WK, Stoney RJ, Wylie EJ, Carotid plaque hemorrhage. Its role in production of cerebral ischemia. Arch Surg 1982;117:1479-88.

Martin AJ, Gotlieb Al, Henkelman RM. High-resolution MR imaging of human arteries. J Magn Reson Imaging 1995;5:93-100.

Martin AJ, Ryan LK, Gotlieb AI, Henkelman RM, Foster FS. Arterial imaging: comparison of high-resolution US and MR imaging with histologic correlation. Radiographics 1997;17:189-202.

McCarthy MJ, Loftus IM, Thompson MM, Jones L, London NJ, Bell PR. Angiogenesis and the atherosclerotic carotid plaque: an association between symptomatology and plaque morphology. J Vasc Surg 1999;30:261-8.

Maynor $\mathrm{CH}$, Charles $\mathrm{HC}$, Herfkens RJ. Chemical shift imaging of atherosclerosis at 7.0 tesla. Invest Radiol 1989;24:52-60.

Merickel MB, Carman CS, Brookeman JR, Mugler JPD, Brown MF, Ayers CR. Identification and 3-D quantification of atherosclerosis using magnetic resonance imaging. Comput Biol Med 1988,18:89-102.

Merickel MB, Berr S, Spetz K, Jackson TR, Snell J, Gilles P, Shimshick E, Hainer J, Brookeman JR, Ayers CR. Noninvasive quantitative evaluation of atheroscherosis using MRI and image analisis. Arterioscler Thromb 1993;13:1180-6.

Milei J, Parodi JC, Alonso GF, Barone A, Grana D, Matturri L. Carotid rupture and intraplaque hemorrhage: immunophenotype and role of cells involved. Am Heart J 1998;136:1096-105. 
Moody AR, Murphy RE, Morgan PS, Martel AL, Delay GS, Allder S. Characterization of complicated carotid plaque with magnetic resonance direct thrombus imaging in patients with cerebral ischemia. Circulation 2003;107:3047-52.

Mofidi R., Crotty TB, McCarthy P, Sheehan SJ, Mehigan D, Keaveny TV. Association between plaque instability, angiogenesis and symptomatic carotid occlusive disease. British Journal of Surgery 2001;88:945-50.

Moneta G, Taylor D, Zieler R, Kazmers A, Beach K, Strandness D. Asymptomatic high-grade internal carotid artery stenosis: is stratification according to risk factors or duplex spectral anlysis possible? J Vasc Surg 1989;10:475-83.

Nagai Y, Metter EJ, Earley CJ, Kemper MK, Becker LC, Lakatta EG, Fleg JL. Increased carotid artery intimal-medial thickness in asymptomatic older subjects with exercise-induced myocardial ischemia. Circulation 1998;98:1504-9.

NASCET. Beneficial effect of carotid endarterectomy in symptomatic patients with high-grade stenosis. North American Symptomatic Carotid Endarterectomy Trial Colaborators. N Engl J Med 1991;325:445-53.

O'Brien ER, Garvin RD, Dev R, Stewart DK, Hinohara T, Simpson JB. Angiogenesis in human coronary atherosclerotic plaques. Am J Pathol 1994;145:833-94.

O'Leary DH, Polak JF, Kronmal RA. Distribuition and correlates of sonographically detected carotid artery disease in the Cardiovascular Health Study. Stroke 1992;23:1752-60. 
O'Leary DH, Polak JF, Kronmal RA, Manolio TA, Burke GL, Wolfson SK Jr. Carotid-artery intima and media thickness as a risk factor for myocardial infarction and stroke in older adults. Cardiovascular Health Study Collaborative Research Group. N Engl J Med 1999a;340:14-22.

O'Leary DH, Polak JF, Wolfson SK, Bond MG, Bommer W, Sheth S, Psaty BM, Sharett AR, Manolio TA. Use of sonography to evaluate carotid atherosclerosis in the elderly: the Cardiovascular Health Study. Stroke 1999b;22:1155-63.

Perdigão C. Antagonistas do cálcio e aterosclerose. Rev Fac Med Lisboa 1999;4(Suppl 2):31-42.

Polak JF, O'Leary DH, Kronmal RA, Wolfson SK, Bond MG, Tracy RP, Gardin JM, Kittner SJ, Price TR, Savage PJ. Sonographic evaluation of the carotid artery atherosclerosis in the elderly: relationship of disease severity to stroke and transient ischemic attack. Radiology 1993;188:363-70.

Polak JF, Shemanski L, O'Leary DH. Hipoechoic plaque at US of the carotid artery: an independent risk factor for incident stroke in adults aged 65 years or older. Cardiovascular Health Study. Radiology 1998;209:288-9.

Quick HH, Debatin JF, Ladd ME. MR imaging of the vessel wall. Eur Radiol 2002;12:889-900.

Randoux B, Marro B, Koskas F, Duyme M, Sahel M, Zouaoui A, Marsauiy C. Carotid artery stenosis: prospective comparison of CT, three-dimensional gadolinium-enhanced $\mathrm{MR}$, and conventional angiography. Radiology 2001;220:179-85.

Reilly LM, Lusby RJ, Hughes L, Ferrell LD, Stoney RJ, Ehrenfeld WK. Carotid plaque histology using real-time ultrasonography: clinical and therapeutic implications. Am J Surg 1983;146:188-93. 
Richardson PD, Davies MJ, Born GV. Influence of plaque configuration and stress distribution on fissuring of coronary atherosclerotic plaques. Lancet 1989;2:941-44.

Roederer G, Langlois Y, Jager K. The natural history of carotid arterial disease in asymptomatic patients with cervical bruits. Stroke 1984;15:605-13.

Rosner, B. Fundamentals of biostatistics. $2^{\text {nd }}$ ed. Boston: PWS Publishers, $1986,584 p$.

Salonen JT, Salonen R. Ultrasonographically assessed carotid morphology and the risk of coronary heart disease. Arterioscler Thromb 1991;11:1245-9.

Salonen JT, Salonen R. Ultrasound B-mode imaging in observational studies of atherosclerotic progression. Circulation 1993;87(Suppl 2):56-65.

Serfaty JM, Chaabane L, Tabib A, Chevallier JM, Brighet A. Atherosclerotic plaques: Classification and caracterization with T2-weighted high-spatialresolution MR imaging-An in vitro study. Radiology 2001;219:403-10.

Shinnar M, Fallon JT, Wehrli S. The diagnostic accuracy of ex vivo MRI for human atherosclerotic plaque characterization. Arterioscl Thromb Vasc Biol 1999;19:2756-61.

Skinner MP, Yuan C, Mitsumori L, Hayes CE, Raines EW, Nelson JA, Ross R. Serial magnetic resonance imaging of experimental atherosclerosis detects lesion fine structure, progression and complications in vivo. Nature Med 1995;1:69-73.

Stary HC. The sequence of cell and matrix changes in atherosclerotic lesions of coronary arteries in the first forty years of life. Eur Heart $J$ 1990;11:3-19. 
Stary HC, Blankenhorn DH, Chandler AB, Glagov S, Insull WJr, Richardson M, Rosenfeld ME, Schaffer SA, Schwartz CJ, Wagner WD, Wissler RW. A definition of the intima of human arteries and of this atherosclerosis-prone regions: a report from the Committee on Vascular Lesions of the Concil on Arteriosclerosis, American Heart Association. Special report. Circulation 1992;85:391-405.

Stary HC, Chandler AB, Glagov S, Guyton JR, Insull WJr, Rosenfeld ME, Schaffer SA, Schwartz CJ, Wagner WD, Wissler RW. A definition of initial, fatty streak, and intermediate lesions of atherosclerosis: a report from the Committee on Vascular Lesions of the Concil on Arteriosclerosis, American Heart Association. Special report. Arterioscler Thromb 1994;14:840-56.

Stary HC, Chandler AB, Dinsmore RE, Fuster V, Glagov S, Insull WJr, Rosenfeld ME, Schwartz CJ, Wagner WD, Wissler RW. A definition of advanced types of atherosclerotic lesions and a histological classification of atherosclerosis. Circulation 1995;92:1355-74.

Sumner DS. Use of color-flow imaging technique in carotid artery disease. Surg Clin North Am 1990;70:201-11.

Tenaglia AN, Peters KG, Sketch MH, Annex BH. Neovascularization in atherectomy specimens from patients with unstable angina: implications for pathogenesis of unstable angina. Am Heart J 1998;135:10-4.

Thomas JB, Rutt BK, Ladak HM, Steinman DA. Effect of black blood MR image quality on vessel wall segmentation. J Magn Reson Imaging 2001;46:229-304.

Toussaint J, Southern JF, Fuster V. T-2 weighted contrast for MRI characterization of human atherosclerosis. Arterioscler Thromb Vasc Biol 1995;15:1533-42. 
Toussaint JF, Lamuraglia GM, Southern JF, Fuster V, Kantor HL. Magnetic resonance images lipid, fibrous, calcified, hemorrhagic, and thrombotic components of human atherosclerosis in vivo. Circulation 1996;94:932-8.

Taylor KJW, Hollands S. Doppler ultrasound: Pt I. Basic Principles, instrumentation, and pitfalls. Raddiology 1990;174:297-307.

Troyer A, Saloner D, Pan XM, Velez P, RAP P. Major carotid plaque surface irregularities correlate with neurologic symptoms. J Vasc Surg 2002;35:7417.

Vallabhajosula S, Fuster V. Atherosclerosis: imaging techniques and the evolving role of nuclear medicine. J Nucl Med 1997;38:1788-96.

Van Der Wal AC, Beker AE. Atherosclerotic plaque rupture: pathologic basis of plaque stability and instability. Cardiovas Res 1999;41:334-44.

Veller MG, Fisher CM, Nicolaides AM. Measurement of the ultrasonic intimamedia complex thickness in normal subjects. J Vasc Surg 1993;17:719-25.

Von Ingersleben G, SchmiedI UP, Hatsukami TS, Nelson JA, Subramaniam DS, Ferguson MS, Yuan C. Characterization of atherosclerotic plaques at the carotid bifurcation: correlation of high-resolution MR imaging with histologic analysis - preliminary study. Radiographics 1997;17:1417-23.

Yuan C, Tsuruda JS, Beach KN, Hayes CE, Ferguson MS, Alpers CE, Foo TK, Strandness DE. Techniques for high-resolution MR imaging of atherosclerotic plaque. J Magn Reson Imaging 1994;4:43-9.

Yuan C, Murakami JW, Hayes CE. Phased-array magnetic resonance imaging of the carotid artery bifurcation: preliminary results in healthy volunteers and a patient with atherosclerosis disease. J Magn Reson Imaging 1995;5:561-5. 
Yuan C, Hatsukami TS, Beach KW, Hayes CE, Nelson JA, Fergusson MS, Clowes AW, Stradness DE. In vivo MR evaluation of atherosclerosis in human carotid artery using phased array coils. J Vasc Interv Radiol 1996a;7:46-7.

Yuan C, Skinner MP, Kaneko E, Mitsumori LM, Hayes CE, Raines EW, Nelson JA, Ross R. Magnetic resonance imaging to study lesionons of atherosclerosis in the hyperlipidemic rabbit aorta. J Magn Reson Imaging 1996b;14:93-102.

Yuan C, Petty C, O'Brien KD, Hatsukami TS, Eary JF, Brown BG. In vitro and in situ magnetic resonance imaging signal features of atherosclerotic plaqueassociated lipids. Arterioscler Thromb Vasc Biol 1997;17:1496-1503.

Yuan C, Lin E, Millard J, Hwang JN. Closed contour edge detection of blood vessel lumen and outer wall boundaries in black-blood MR images. Magn Reson Imaging 1999;17(Suppl 2):257-66.

Yuan C, Mitsumori LM, Beach KW, Maravilla KR. Carotid Atherosclerotic Plaque: noninvasive MR characterization and identification of vulnerable lesions. Radiology 2001a;221:285-299.

Yuan C, Mitsumori LM, Ferguson MS, Polissar NL, Echelard D, Ortiz G, Small R, Davies WJ, Kerwin WS, Hatsukami TS. In vivo accuracy of multispectral magnetic resonance imaging for identifying lipid-rich necrotic cores and intraplaque hemorrhage in advanced human carotid plaques. Circulation 2001b;104:2051-56.

Yuan C, Zhang SXZ, Polissar NL, Echelard D, Ortiz G, Davis JW, Ellington E, Ferguson MS, Hatsukami TS. Identification of fibrous cap rupture with magnetic resonance imaging is highly associated with recent transient ischemic attack or stroke. Circulation 2002;105:181-5. 
Wasserman BA, Smith WI, Trout HH, Cannon RO, Balaban RS, Arai AE. Carotid artery atherosclerosis: in vivo morphologic caracterization with gadolinium-enhanced double oblique MR imaging-initial results. Radiology 2002;223:566-73.

Wilson PW, D'Agostino RB, Levy D, Belanger AM, Silbershatz H, Kannel WB. Prediction of coronary heart disease using risk factor categories. Circulation 1998;97:1837-47.

Zwiebel WJ. Spectrum analisis in carotid sonography. Ultrassound Med Biol 1987;13:623-36. 